\title{
LA INTERACCIÓN ENTRE AGENTES DEL SECTOR AUTOPARTES EN BOGOTÁ Y LOS SISTEMAS SECTORIALES DE INNOVACIÓN
}

SEYDYSS GARAY RODRIGUEZ

\author{
UNIVERSIDAD SANTO TOMÁS \\ PROGRAMA DE MAESTRÍA EN ECONOMÍA \\ BOGOTÁ D. C.
}

2012 


\title{
LA INTERACCIÓN ENTRE AGENTES DEL SECTOR AUTOPARTES EN BOGOTÁ Y LOS SISTEMAS SECTORIALES DE INNOVACIÓN
}

\section{SEYDYSS GARAY RODRIGUEZ}

\author{
DIRECTOR: ANSELMO VEGA ARMENTA
}

Trabajo presentado como requisito parcial para obtener el grado de Máster en Economía

UNIVERSIDAD SANTO TOMÁS PROGRAMA DE MAESTRÍA EN ECONOMÍA

BOGOTÁ D. C. 


\section{NOTA DE ACEPTACIÓN}

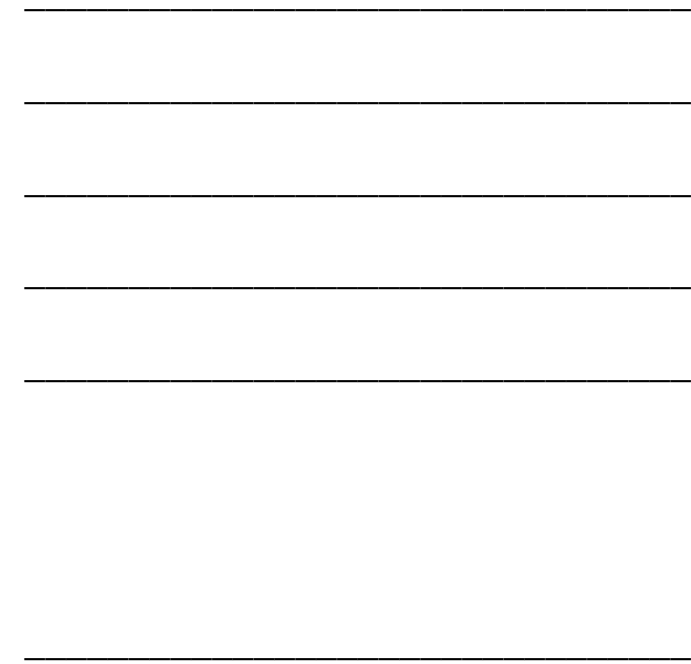

Firma del presidente del jurado

Firma del jurado

Firma del jurado

Bogotá, Febrero de 2013. 


\section{DEDICATORIA}

Deseo dedicar este esfuerzo al "Todo Poderoso" y a quienes se han esforzado, a lo largo de mi vida, de diferentes maneras para brindarme generosamente su apoyo, su comprensión y su conocimiento. 


\section{AGRADECIMIENTOS}

Agradezco de manera especial a las personas que contribuyeron de diferentes maneras para que este objetivo se pudiera alcanzar. Especialmente a mi director de tesis por sus orientaciones y su compromiso, a los empresarios que abrieron las puertas de sus empresas para brindar la información necesaria, así como a los miembros de mi familia que amorosamente fueron comprensivos por los largos días y noches que debí ausentarme de la convivencia familiar. 


\section{TABLA DE CONTENIDO}

Pág.

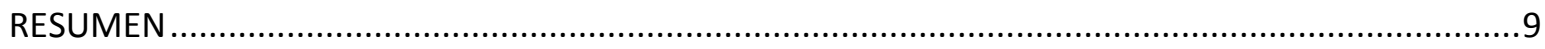

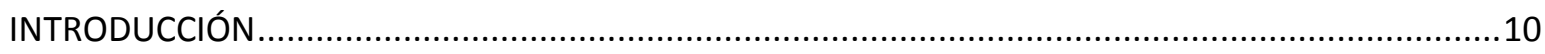

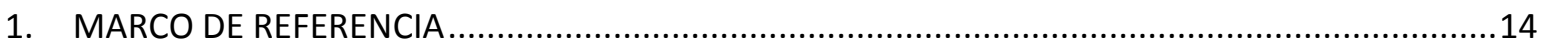

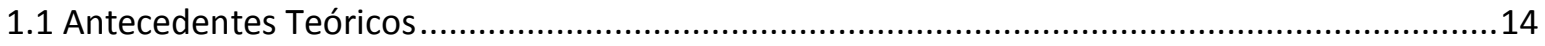

1.1.1 Panorama Colombiano del Sector de Autopartes ...........................................................19

1.2 El concepto de Sistemas Sectoriales de Innovación ............................................................28

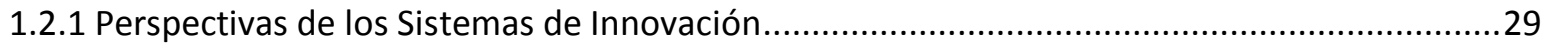

1.2.2 Malerba y los Sistemas Sectoriales de Innovación .........................................................30

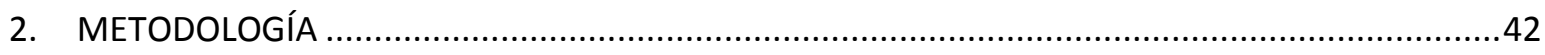

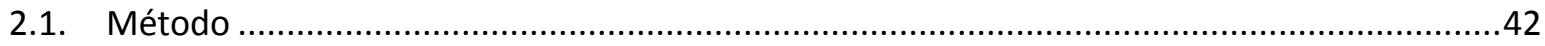

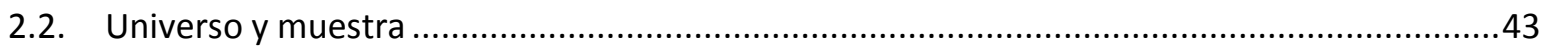

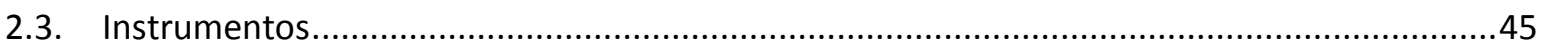

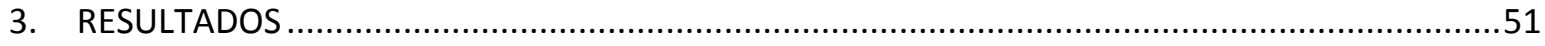

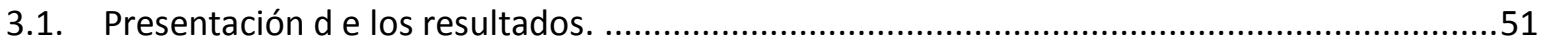

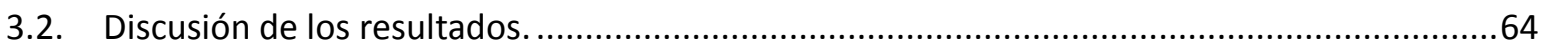

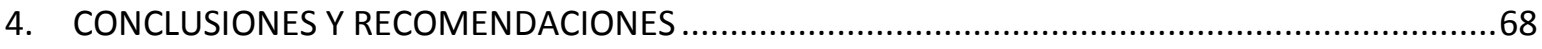

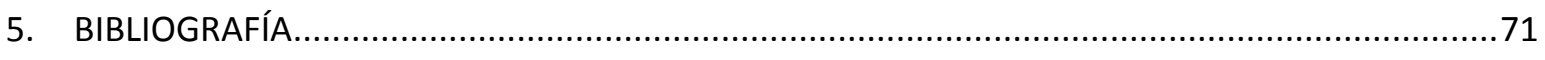

ANEXO 1. ENTREVISTAS CON LOS EMPRESARIOS ............................................................ 74 


\section{LISTA DE TABLAS}

Pág.

Tabla 1. Ranking Mundial de producción de Automóviles -2006-2007en unidades........... 20

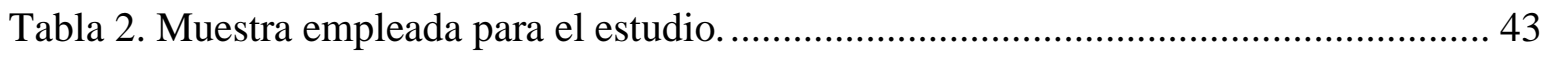




\section{LISTA DE FIGURAS}

Pág.

Figura 1. Exportaciones Colombianas de autopartes -2005-2009, USD millones................ 22

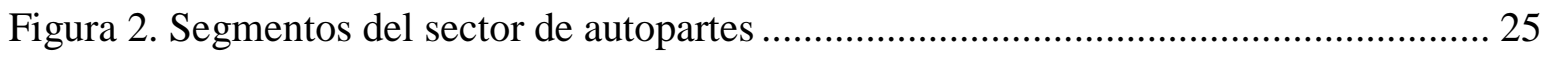

Figura 3. Empresas que emplean estrategias específicas de transferencia de tecnología .... 51

Figura 4. Áreas a las que se orienta la Transferencia de Tecnología .................................... 52

Figura 5. Lugar en donde se ha realizado la transferencia de tecnología ............................ 53

Figura 6.Mecanismos empleados para la transferencia de tecnología ................................... 54

Figura 7.Rubros de inversión para transferencia tecnología ................................................ 55

Figura 8. Fuentes de identificación de necesidades de transferencia de tecnología ............. 56

Figura 9. Logros generados por la transferencia de tecnología …….................................. 57

Figura 10. Mecanismos de protección de la tecnología transferida ...................................... 58

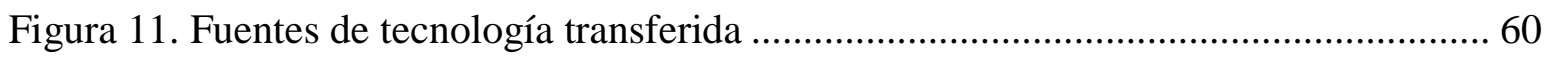

Figura 12. Apoyos recibidos para la transferencia de tecnología ........................................... 61

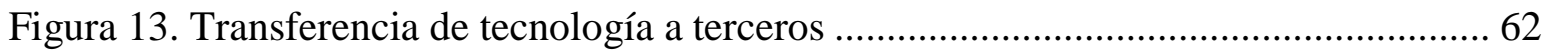

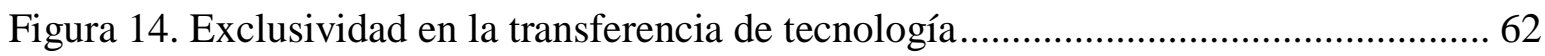

Figura 15. Necesidad de estímulos para la transferencia de tecnología................................ 63 


\section{RESUMEN}

El presente estudio explora la capacidad de innovación del sistema sectorial autopartista, especialmente los productores de partes originales nacionales, respecto a sus formas de interacción para generar conocimiento y aprendizaje esta capacidad de innovación está inspirada por el programa de transformación productiva, entendida como el conjunto de capacidades de la sociedad para innovar, agregar valor y diversificar su economía (McKinsey y Company;, 2009), respondiendo a la política nacional de competitividad y productividad. A partir de una muestra significativa de las empresas/fabricantes de partes originales (Original Equipment Manufacturer, OEM por sus siglas en ingles) nacionales ubicadas en la ciudad de Bogotá.

La realización del trabajo permitió concluir que no existe en Colombia un verdadero sistema de innovación en el sector autopartista. Sin embargo sí existen empresas que realizan esfuerzos orientadas a generar transferencia de tecnología, para responder a las expectativas de las ensambladoras y de la competencia del sector automotriz.

Palabras claves: capacidad de innovación, base tecnológica, cambio técnico, sistema sectorial de innovación. 


\section{INTRODUCCIÓN}

A pesar del gran volumen de ventas de vehículos nuevos en los años recientes, Colombia sigue teniendo comparativamente una muy baja densidad de vehículos por habitante; de acuerdo con cifras reveladas por la Cámara de Comercio de Bogotá, países como Estados Unidos, Francia, México y Chile revelan tasas de posesión vehicular de 806, 595, 154 y 144 vehículos por cada mil habitantes, mientras Colombia revela sólo 79,2. Por su parte, ciudades como Ciudad de México, Guanajuato y Curitiba registran índices de motorización de 406, 156 y 422 vehículos por cada mil habitantes; a septiembre de 2009, Bogotá registraba un total de 578.867 automóviles particulares, cuya edad promedio es de 13.5 años (Cámara de Comercio de Bogotá, 2010). Por lo anterior es de esperarse que la industria automotriz siga manteniendo su dinamismo por varios años más, dado que, comparativamente con otros países existen muchas familias que no tienen vehículo propio, además de que las bajas tasas de interés, los tratados de libre comercio suscritos y la revaluación del peso favorecerán el mantenimiento de la demanda de vehículosy por lo tanto, de autopartes. Todo lo anterior muestra que existen las condiciones de demanda necesarias para que el sector autopartista siga teniendo una importancia notoria en la economía nacional.

Aunque la historia del ensamblaje de vehículos en Colombia se inició hace más de 50 años, los componentes de mayor valor agregado para este mercado se fabrican aún en el exterior, situación que puede cambiar de manera progresiva en la medida en que se 
mantengan los cambios técnicos que se requieren para la modernización de las empresas que fabrican esos componentes. Este propósito implica necesariamente que continúen las acciones que hasta ahora se han hecho en materia de investigación y desarrollo e innovación $^{1}$ y de transferencia de tecnología, las mismas que hasta el momento han contribuido a que se sostenga la incorporación de partes nacionales a los vehículos producidos localmente. Al analizar las decisiones que deben tomarse para que este desarrollo técnico mantenga o mejore su ritmo, merece tenerse en cuenta, que si bien las deficiencias de la infraestructura vial del país pueden verse como un obstáculo para el crecimiento de las exportaciones en la medida en que generan costos de logística altos, esa misma situación constituye una barrera para el ingreso de partes automotrices provenientes de otros países.

El mayor o menor nivel de respuesta que logre dar esta industria a la demanda dependerá en gran medida de la forma como interactúen los diferente agentes que la integran. En el trabajo se presentan los resultados de la investigación adelantada por la autora, dentro del programa de Maestría en Economía de la Universidad Santo Tomás, con relación a la interacción entre agentes del sector de autopartes en Bogotá y la generación de sistemas sectoriales que conduzcan a la innovación, tomando como elemento del sistema, la transferencia de tecnología. En el trabajo se analiza las interacciones de los sectores público, privado e institucional para impulsar el desarrollo del conocimiento y la competitividad de esta industria.

\footnotetext{
${ }^{1}$ En adelante $\mathrm{I}+\mathrm{D}+\mathrm{i}$
} 
Dada la amplitud del concepto de interacción, el trabajo se limitó al análisis de aquellas formas de interacción orientadas específicamente a generar conocimiento y aprendizaje, mediante actividades de transferencia de tecnología. Por otro lado, dado que el sector autopartista también es un sector que incluye a diferentes industrias, el trabajo se restringió a empresas dedicadas a la fabricación de partes originales para las ensambladoras locales.

El referente teórico del trabajo es el denominado Sistema Sectorial de Innovación SSI- planteado por el Doctor en economía Franco Malerba y por otros autores como Chaparro (1998), Fátas y Peris (2003) y Freeman (1997); de acuerdo con este referente, las empresas pueden ser evaluadas según su capacidad de aprendizaje para la adquisición, acumulación y generación de conocimiento, así como también, pueden ser caracterizadas según diferentes niveles y tipos de conocimiento. El trabajo muestra que las empresas del sector autopartista presentan características diferentes a las del resto de la industria colombiana, en cuanto a los avances en su capacidad de innovación, conocimiento e interacción.

En el estudio se tiene en cuenta el marco regulatorio de este sector económico, el cual se muestra disperso frente a las actividades de (I+D), como consecuencia de la ausencia de propuestas concretas y específicas del gobierno para este sector en particular (Ministerio de Comercio, industria y turismo, 2009). Esta falta de propuestas ha contribuido a que persistan falencias relacionadas con la institucionalidad requerida para su desarrollo innovador, a pesar de lo cual no se ha debilitado su crecimiento en términos de productividad y competitividad. 
Dado que se trata de un trabajo de enfoque académico, el mismo constituye un diagnóstico sin intereses o pretensiones económicas, que procura colocar al servicio de la industria colombina de autopartes los conceptos de expertos teóricos internacionales reconocidos en materia de análisis de Sistemas Sectoriales de Innovación enfocado en el proceso de transferencia de tecnología, haciéndolo con la mayor rigurosidad técnica posible y de manera objetiva e independiente.

La metodología planteada en la investigación es de tipo cualitativo y se presenta en tres fases; en la primera se describe a los agentes que intervienen en este sistema sectorial y que constituyen la población de estudio, compuesta por fabricantes de equipos originales, y se obtiene una muestra de tipo no probabilística. En la segunda fase se plantea, organiza y aplica el instrumento empleado para la generación de información primaria; con base en esta información y en los referentes teóricos previamente desarrollados, en la tercera fase se analiza el sistema sectorial objeto de estudio.

El documento se halla organizado en cuatro capítulos; en el primero se construye el marco de referencia, incluyendo los antecedentes teóricos y los fundamentos de los sistemas sectoriales de innovación. El segundo capítulo describe la metodología empleada para la realización del trabajo, la muestra y los instrumentos empleados; en los dos últimos capítulos se presentan los resultados, las conclusiones y las recomendaciones. 


\section{MARCO DE REFERENCIA}

Siendo el objetivo principal de la presente investigación la exploración y análisis de la capacidad de innovación de la industria y el mercado de autopartes en Colombia, tomando como referente de estudio, una muestra en la ciudad de Bogotá y, a la vez, inspirados en el análisis de sistemas sectoriales de innovación desarrollado por Malerba (2002 y 2004), el presente marco de referencia busca describir el estado actual del sector de autopartes. Como se señala en el presente capítulo, el sector de autopartes es una de los más dinámicos de la economía colombiana y sus cifras de crecimiento son aceleradas, sobre todo en los últimos años.

De esta manera, el presente capítulo se compone conceptualmente de dos partes en la primera parte se destaca el panorama del sector autopartista en Colombia, observando cual es la constante en el sentido de la innovación. En segundo lugar, se hace un análisis de los SSI como herramienta que servirá para analizar el sector de autopartes en Colombia durante el proceso investigativo.

\subsection{Antecedentes Teóricos}

La consolidación y complejización de los procesos económicos, sociales y políticos en el presente siglo han hecho del mundo un escenario de racionalización de las actividades 
que proveen a los países de desarrollo, crecimiento e incremento de su capacidad productiva, competitiva y de participación dentro de los mercados mundiales. Por tal razón, según lo señala Aguirre, la comprensión de la estructura de dichas actividades deben llevar a las naciones a un ordenamiento que permita visualizar de qué manera los sectores de la economía y el modelo económico general de un país se relaciona directa e indirectamente con el mercado (2011). Ello por supuesto, lleva necesariamente a la inclusión de una visión de sistemas dentro del proceso de globalización de la innovación y el desarrollo económico.

"Si podemos entender la complejidad podremos también definir políticas, estrategias y caminos a seguir, eso es lo que estamos haciendo con el Sistema de Innovación, dentro del cual están los sistemas sectoriales que explican el comportamiento de un sector de la actividad productiva" (Aguirre, 2011, pág. 1).

Es decir, los sistemas de innovación proveen esquemas complejos y estructurados de organización sistémica en Ciencia, Tecnología e Innovación -CT\&I- para, de esta manera, lograr una gestión del desarrollo de la economía y sus diferentes industrias a nivel nacional así como su capacidad de modelar nuevas estrategias a partir de las oportunidades existentes. Todo ello, por supuesto, requiere de una perspectiva que no sea inducida de forma exclusiva por el macro-entorno, dado que, como sucede en su mayoría con los denominados SSI, estas modalidades terminan siendo indiferentes a las realidades regionales y sectoriales o locales.

Como bien lo señala Aguirre, en el caso de los sistemas sectoriales de innovación:

"El sistema sectorial es muy característico de un sistema de innovación porque cada sector tiene sus propias necesidades, formas de producción, 
aprendizajes; por ejemplo Salud, Educación, Transporte, todos son diferentes entre sí y tienen sus formas de innovación diferentes a otros sectores" (Aguirre, 2011, pág. 2).

Esto quiere decir que, dentro de las economías nacionales en conjunto con sus procesos de innovación, las relaciones de sentido entre la competitividad, la innovación y la tecnología también se producen en aquellos escenarios que sirven de punto de encuentro entre la denominada macroeconomía y microeconomía: los sectores económicos.

Al encontrarse constituidos por un conjunto de instituciones, organizaciones, prácticas productivas y necesidades de innovación, desarrollo y tecnologíasexclusivases posible desarrollar estrategias particulares que fortalezcan la infraestructura natural a su cadena de valor, la gestión del conocimiento y la inclusión de prácticas industriales mediadas por la inversión en tecnologíainnovación de alta calidad y competitividad.

Se afirma que en Colombia, antes de que se produjeran algunos adelantos en los sistemas de innovación sectorial, la inclusión de la innovación desde una perspectiva sistémica dentro de la economía del país ha sido hasta ahora una realidad cuya génesis se ubica a mediados de la década de los noventa. Según lo describe Zartha (2011), La innovación desde la perspectiva sistémica se remonta a la introducción en el año de 1994 de los Sistemas Nacionales de Innovación -SNI-. Para ese año, al producirse la reestructuración de Colciencias surge la subdirección denominada Programas de Innovación y Desarrollo Empresarial, dando inicio a la denominada Política Nacional de Innovación en donde el SNI es el eje estructurador. 
"Un Sistema Nacional de Innovación puede ser concebido como un escenario social de generación, apropiación y transferencia de conocimientos y habilidades necesarios para incrementar la competitividad internacional y mejorar las condiciones de vida de la población, dentro de un criterio general de desarrollo sostenible" (Zartha, 2011, pág. 5).

De esta manera, con la puesta en marcha del Sistema Nacional de Innovación se aceptó la necesidad cada vez más creciente de adquirir mayor capacidad para aprender de manera permanente y bajo principios de interacción con el mercado y las demás políticas nacionales. Dentro de dicho sistema se identifican 5 componentes básicos (Chaparro, 1998):

1. Los actores y los beneficiarios.

2. Las redes de innovación para el aprendizaje y el intercambio.

3. Los Programas estratégicos aplicados en áreas y sectores sociales o productivos prioritarios.

4. La infraestructura institucional de investigación y servicios tecnológicos.

5. El financiamiento de la innovación.

Así mismo, dentro del documento se hacen importantes alusiones al desarrollo de sistemas regionales de innovación que permitan fijar la operación estratégica al escenario de las organizaciones, los esquemas productivos que se adelantan en las regiones, llevando de manera diversificada el desarrollo al ámbito del territorio en el país.

Sin embargo, dentro de dicho modelo formulado desde Colciencias no queda en evidencia la búsqueda del desarrollo de SSI que se acondicionen de manera horizontal a las necesidades de los diferentes sectores característicos de la industria. Refiriéndose 
concretamente al sector automotriz y al de autopartes no existe sobre estos una comprensión su estructura sistémica de innovación, siendo por supuesto dos sectores relevantes para el país y para el desarrollo económico.

Como bien lo señala Aguirre (2011), se hace fundamental que los países comprendan en primer lugar la manera como operan los sistemas sectoriales de innovación esto permitirá formular a una escala mayor las posibilidades, caminos y estrategias de implantación más adecuadas para la nación en cuanto a la Ciencia, la Tecnología y la Innovación.

Centrando el discurso particularmente en el escenario del sector autopartista en Colombia, éste resulta ser uno de los sectores más productivos y prósperos tanto a nivel nacional como lo que se refiere al territorio nacional. Por lo tanto, la reflexión y la planeación que se pueda generar entorno al desarrollo tecnológico de este sector redundarán en el fortalecimiento de su potencial productivo y el nivel de complejización de su aparato de innovación y desarrollo Tecnológico. No se puede olvidar, como bien lo señalan Fatás y Peris (Fátas \& Peris, Sistemas sectoriales de innovación y crecimiento económico, 2003), que la innovación, desde el punto de vista económico, siempre ha mostrado que los ritmos y los patrones de innovación tecnológica difieren de manera muy significativa de un sector a otro, dado las diferencias en las fuentes de crecimiento tecnológico, y los subsistemas de la cadena de valor en donde se hace más sensible la diversidad tecnológica, la transferencia de conocimiento y la investigación para la innovación. 
Por lo tanto, comprender en un primer momento la estructura desde donde el sector autopartista pone en marcha su aparato productivo será un referente fundamental para profundizar, como le es propio a la presente investigación, en la capacidad de innovación del sistema Sectorial Autopartista especialmente lo productores de partes originales, respecto a sus forma de transferencia de tecnología.

\subsubsection{Panorama Colombiano del Sector de Autopartes}

Desde la perspectiva planteada por Proexport (2010), Colombia resulta ser el escenario ideal para la fabricación y el ensamble de vehículos, camiones, buses y autopartes que se destinan para el abastecimiento del mercado nacional y regional.

"La Industria Automotriz representa el 6,2\% del PIB, emplea cerca del 2,5\% de la población ocupada y ubica a Colombia como el quinto productor de automóviles en Latinoamérica. Esta industria en Colombia comprende la actividad de ensamblaje (incluidos camiones, buses y motocicletas) y la fabricación de partes y piezas utilizadas en el ensamblaje para fabricación de equipos originales y como repuestos" (Proexport, 2010, pág. 2).

Es un espectro de producción económica sin duda amplio que, en cifras económicas, demuestra la presencia de importantes beneficios que la hacen sin duda una industria atractiva para la inversión. Un primer beneficio percibido de esta industria es su dinamismo, dado que desde el año 2006 hasta el año 2010, las exportaciones alcanzaron un crecimiento sostenido del 42 por ciento, al pasar de USD\$350 millones a USD\$498 millones (Proexport, 2011). Así mismo, la industria automotriz resulta tener una excelente 
posición geo-económica, al contar con el acceso a un parque automotor de 37 millones de unidades; un crecimiento del mercado doméstico, con compras alrededor de los 600 millones de dólares en autopartes a productores locales; una mano de obra calificada y a precios muy competitivos, con salarios para trabajadores por encima de los 2 dólares por hora y unas importantes ventajas como lo son los incentivos existentes de régimen de Zona Franca y la presencia de un total de 12 reconocidas empresas autopartistas.

De esta manera, como queda señalado en la tabla 1, la producción nacional de vehículos tendió al crecimiento, demostrado en las cifras del año 2006 y 2007, en la que la producción tuvo un incremento significativo, alcanzando un crecimiento del 33 por ciento, pasando de producir 136.640 unidades a 181.941 respectivamente. Ello le permitió ubicarse en el puesto número 36 con respecto al ranking mundial de producción de vehículos.

Sin embargo, como lo señala el mismo organismo (Proexport, 2009), cosa diferente sucedió para el año 2008, periodo en el que tanto la producción como las ventas alcanzadas en el año inmediatamente anterior, en cuanto a producción, se pasó de 181.941 a 116.694 unidades. En cuanto a las ventas, estas pasaron de 229.304 unidades a 152.315, respectivamente, el próximo periodo 2009 la producción descendió a 90.074 unidades, recuperándose notoriamente al 2010 con 126.631 unidades.

Tabla 1. Ranking Mundial de producción de Automóviles -2006-2007en unidades

\begin{tabular}{rlrrr}
\hline Posición & \multicolumn{1}{c}{ País } & \multicolumn{1}{c}{2006} & \multicolumn{1}{c}{2007} & \% Crecimiento \\
\hline 1 Japón & 11.146 .162 & 11.072 .529 & $-1 \%$ \\
\hline 2 & Estados Unidos & 10.813 .135 & 10.500 .317 & $-3 \%$ \\
3 & China & 6.679 .256 & 8.032 .913 & $20 \%$ \\
\hline 4 Alemania & 5.313 .032 & 5.712 .062 & $8 \%$ \\
5 & Corea & 3.776 .673 & 4.012 .642 & $6 \%$ \\
6 & Francia & 3.156 .569 & 2.986 .769 & $-5 \%$ \\
\hline
\end{tabular}


Tabla 1. Continuación.

\begin{tabular}{|clccc|}
\hline 7 & España & 2.717 .805 & 2.901 .486 & $7 \%$ \\
\hline 8 & Brasil & 2.277 .970 & 2.649 .851 & $16 \%$ \\
\hline 9 & Canadá & 2.496 .659 & 2.542 .150 & $2 \%$ \\
\hline 10 & México & 1.934 .560 & 1.981 .150 & $2 \%$ \\
\hline 36 & Colombia & $\mathbf{1 3 6 . 6 4 0}$ & $\mathbf{1 8 1 . 9 4 1}$ & $\mathbf{3 3 \%}$ \\
\hline 37 & Venezuela & 155.239 & 155.799 & $0 \%$ \\
\hline 43 & Ecuador & 50.235 & 58.968 & $17 \%$ \\
\hline
\end{tabular}

Fuente: Estadísticas Libro anual 2008, Ministerio de Transporte Colombia - Ministerio de Transporte de Perú- Acolfa 2008

Centrando la discusión en el sector de las autopartes, según las cifras que refiere (Proexport, 2010), queda también señalado que el crecimiento del sector de autopartes en Colombia, como sucede en general con la industria automotriz, ha experimentado resultados positivos los cuales se reflejan en sus ventas. Entre los años 2003 y 2006 sucedieron importantes picos decrecimiento de las ventas llegando a un porcentaje de 150 por ciento, pasando de vender 448 millones de dólares a 1.150 millones. Por otra parte, las exportaciones de vehículos también se incrementaron de manera significativa en un 130 por ciento durante los últimos 5 años. Del total de exportacionesde autopartes reportadas por la industria el 74 por ciento de dicho total estuvo dirigido a los mercados de Venezuela, Ecuador y Brasil. Sin embargo, a partir del año 2008, como sucede en general con la 
industria automotriz, se producen descensos tanto en la producción como en las ventas de autopartes a nivel nacional y para la modalidad de exportación.

Figura 1.Exportaciones Colombianas de autopartes -2005-2009, USD millones

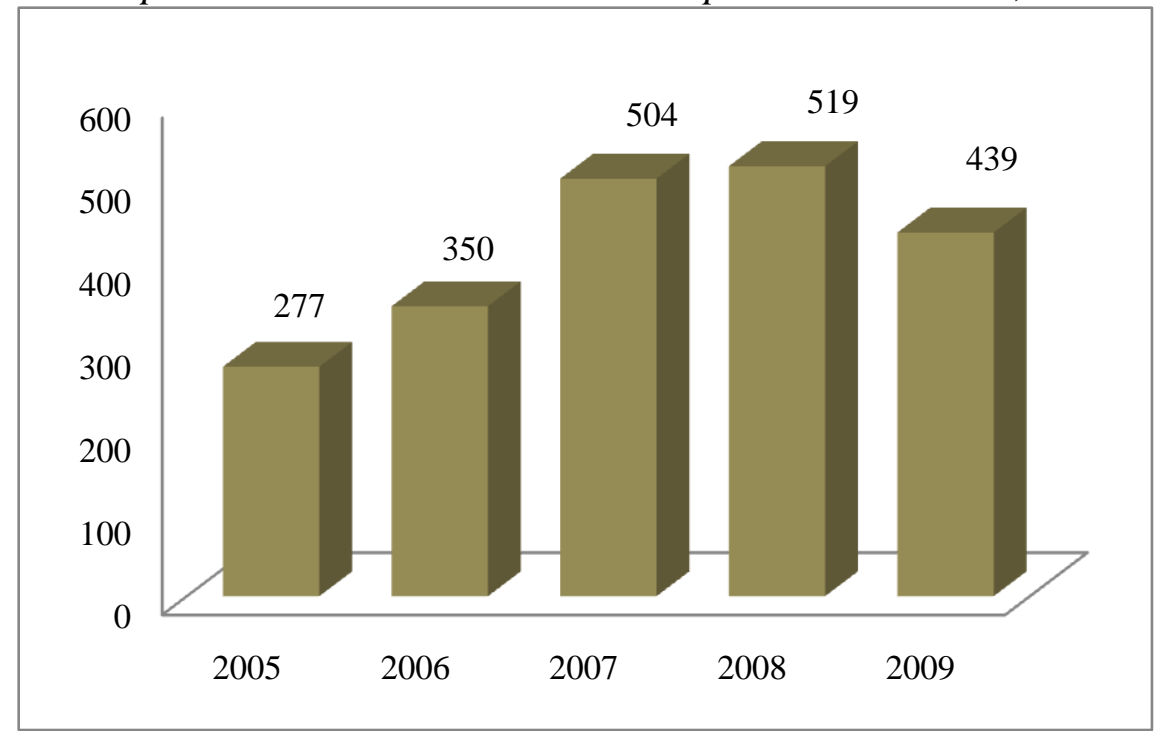

Fuente: (Fiducoldex, 2010)

Pese a las dificultades señaladas con anterioridad dentro del total de la industria automotriz, Colombia ha logrado convertirse en una importante plataforma exportadora que, según lo señala Fiducoldex (2010), le ha permitido convertirse en proveedor de empresas como YAZAKI, Michelin, Saint Gobain, Good Year, Dupont, DANA Corporation, Vitro y AGP American GlassProducts (Vidrio blindado), entre otras empresas. A esto cabe sumarle que la mayoría de las más reconocidas empresas de autopartes internacionales están establecidas en Colombia:

"Michelin y Goodyear tienen producción en Colombia, YazakiCiemel produce instalaciones y cableados eléctricos para el sector automotriz. Su planta está 
ubicada en la Zona Franca de Bogotá.Saint Gobain tiene 2 plantas de producción, una de ellas se encuentra en Barranquilla en donde se producen vidrios panorámicos, laterales, laminados y templados para vehículos. Espumaltex es una empresa que manufactura productos polimerizados para el mercado automotor.IMAL fabrica, ballestas, helicoidales, cinturones de seguridad, copelas anti-ruido y hojas parabólicas, entre otras. Thermoform S.A. produce paneles de puertas, cubiertos de transmisión, interiores y consolas, entre otros" (Ministerio de Comercio, industria y turismo, 2009, pág. 56).

No cabe duda que el desarrollo de la industria se ha intensificado en los últimos años y que la competencia que existe entre países es cada vez más grande. Uno de los sistemas aplicados para este desarrollo es precisamente la innovación en ciencia y tecnología sumando el apoyo a la industria desde las instituciones que han denotado el camino del autopartismo en Latinoamérica.

Por ello,la agenda internacolombiana ha reconocido la necesidad de contar con estrategias de desarrollo económico diferenciadas que atiendan las particularidades de algunos sectores de la economía colombiana, en este caso, el Autopartismo en Colombia. Bajo esta premisa surge en el año de 2007 el objetivo de desarrollar a largo plazo una política nacional de competitividad en donde sector público y privado se colaboren mutuamente en la ejecución de todas las diferentes iniciativas que surjan de las políticas formuladas.

"Se definió una visión para convertir a Colombia en un país de ingresos medios en 2032; se facilitó la creación del Sistema Nacional de Competitividad (SNC); se creó el Consejo Privado de Competitividad (CNC); y se reestructuró el Ministerio de Comercio, Industria y Turismo (MCIT)" (Ministerio de Comercio, industria y turismo, 2009, pág. 2). 
Dicha visión contempla tres importantes estrategias para incrementar la competitividad en Colombia: 1) el desarrollo de sectores de clase mundial; 2) el aumento de la productividad y 3) la formalización de la fuerza laboral. El soporte fundamental para el cumplimento de dichas estrategias consiste entonces en el desarrollo de actividades que procuren el fortalecimiento de la ciencia, la tecnología y la innovación. En consecuencia, al hacer referencia particular a la primera estrategia para el mejoramiento de la competitividad, el Ministerio de Comercio, Industria y Turismo lleva a cabo el Programa de Transformación Productiva con el objeto de mejorar sustancialmente un conjunto de sectores establecidos y acelerar el desarrollo de otros considerados por el organismo gubernamental como emergentes.

El sector autopartes se constituye en uno de dichos sectores que, aunque se encuentra establecido, enfrentaba al momento de incluirse amenazas en su nivel de competitividad.

De tal forma que dicha propuesta sectorial está basadaen cinco grandes líneas: en primer lugar, está la consolidación en el mercado interno, con énfasis en la necesidad de una normatividad clara y en el afianzamiento del Convenio Automotor Andino; en segundo lugar, está el incremento del desarrollo tecnológico asociado a los procesos productivos de la cadena; en tercer lugar las mejoras y desarrollo de la infraestructura vial, fluvial, portuaria, férrea; en cuarto lugar, la normativa logística en relación con las tablas de fletes, la reposición vehicular y el descongelamiento del parque automotor; por último, la promoción e inserción internacional del sector (Ministerio de Comercio, industria y turismo, 2009). 
Como bien lo describe el Ministerio de Comercio, Industria y Turismo, el sector de autopartes es una dimensión productiva fundamental de la denominada industria automotriz. Por tanto, su cadena de valor incluye en principio el suministro de autopartes, para el caso del ensamblado de vehículos, el mercado de reposición de partes; este último, a su vez, dividido en tren motriz, chasis, interiores, exteriores y eléctricas y electrónicas (Ministerio de Comercio, industria y turismo, 2009).

De esta manera, las ventas en fábrica de las diferentes tipologías de autopartes han concentrado el mayor número en el segmento de chasis, y alcanzaron para el año 2006 ventas superiores a los 488 millones de dólares, seguido de las autopartes exteriores, con un total de 321 millones de dólares.

Figura 2. Segmentos del sector de autopartes

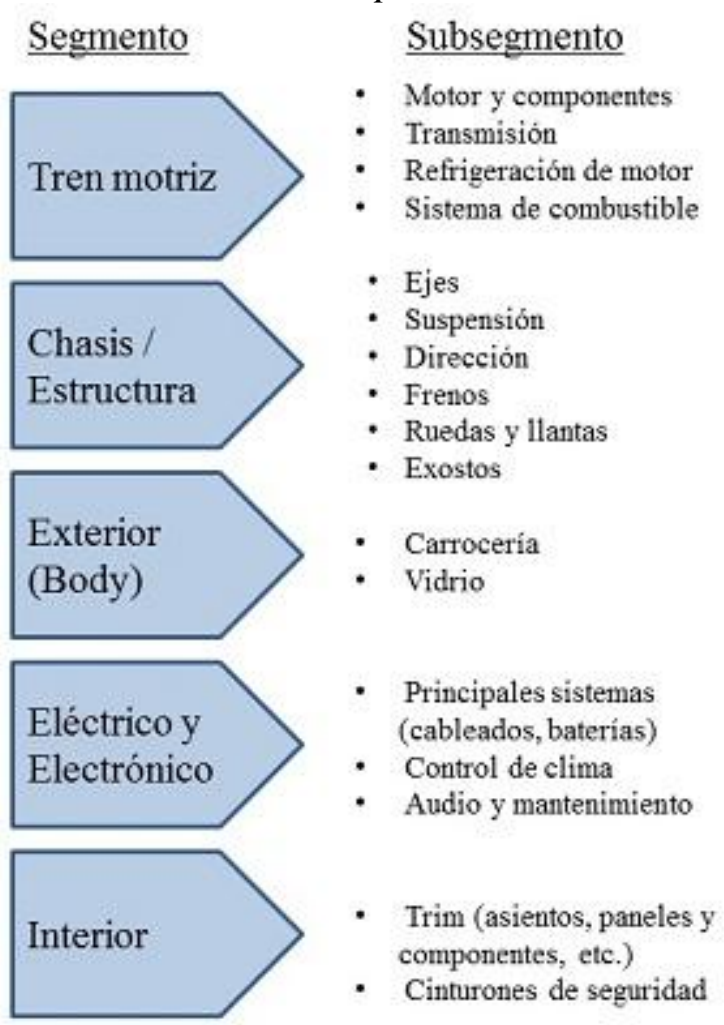

Fuente: (Ministerio de Comercio, industria y turismo, 2009) 
Dentro del sector de autopartes en Colombia, se presenta oportunidades para impulsar el potencial crecimiento en la economía del mercado local, como lo es: la presencia de una base significativa de ensamble de vehículos, fabricación de partes, una privilegiada ubicación geográfica en el continente y afinidad con otros mercados de América Latina y el Caribe (Ministerio de Comercio, industria y turismo, 2009).

Así como presenta oportunidades también, presenta amenazas que afectan dicho crecimiento: la oferta de productos fabricados de menor valor agregado; menores beneficios de economías de escala; mayores costos logísticos y de transporte, igual que en el ingreso de materias primas; poca inversión en investigación y desarrollo e innovación y falta de mayor inyección en transferencia de tecnología.

Por otro lado, en Colombia no se fabrican partes de mayor valor agregado, las partes de alta sofisticación y complejidad tecnológica se importan. Por ejemplo, mientras Estados Unidos fabrica el $100 \%$ de las autopartes, Colombia genera el $25 \%$ de éstas para las ensambladoras locales y mercados de la región. No puede aumentar la escala de producción por que los costos se ven encarecidos, que como resultado da mayor dificultad para la inversión en plantas y tecnología. De igual forma, la falta de inversión en I+D+I es uno de los problemas fundamentales. Casi la totalidad de las autopartes desarrolladas en Colombia se basan en diseños realizados por terceros países, existe además una menor automatización de la producción, incentivada por la idea de un menor costo relativo a la mano de obra. 
Podríadecirse también que el marco regulatorio en el sector se muestra disperso de las actividades de $\mathrm{I}+\mathrm{D}+\mathrm{I}$, porque carecen de propuestas gubernamentales para este sector en particular, y persisten las falencias de institucionalidad para eldesarrollo innovador. A pesar de esta condición, no se ha debilitado el crecimiento de la productividad y competitividad del sector pero la competencia en la región se basa en el desarrollo.

Bajo estas condiciones, la innovación debe convertirse en la clave para llevar a las industrias locales y nacionales a un posicionamiento Mundial. Países como México y Argentina muestran en sus estudios de mercado una clara tendencia a reconocer que los efectos de la inversión I+D+I son fundamentales a la hora de establecer directrices hacia el corto, mediano y largo plazo. La misma percepción se puede visualizar en la propuesta de desarrollo e innovación sectorial para el sector de autopartes puesto que las aspiraciones más relevantes que orientan el sector hacia una concepción sistémica de sus procesos de innovación buscan lograr un mejoramiento en los procesos de ensamble y sub-ensamble, la sofisticación de los productos locales, la generación de economías de escala que lleven al apalancamiento de inversiones de capital, el enfoque hacia un portafolio especializado de partes con ventajas competitivas y la organización de la cadena productiva a partir del desarrollo de una estructura de cluster automotriz. 


\subsection{El concepto de Sistemas Sectoriales de Innovación}

La revisión de literatura que se presenta a continuación toma como base las investigaciones relacionadas con el Sistema Sectorial de Innovación ${ }^{2}$ y la capacidad de innovación empresarial, elemento que resulta determinante para la competitividad de la industria de autopartismo en Colombia.

La innovación se muestra como una dimensión organizacional, que permite el logro de ventajas competitivas de innovación, del proceso innovador, su influencia sobre la cadena de valor, de la organización y la gestión. Resulta ser un proceso de integración de la tecnología existente para crear o mejorar un producto, un proceso o un sistema. En un sentido económico consiste en la consolidación de un nuevo producto, proceso o sistema mejorado (Freeman, 1997).

A partir también de la definición de sistemas como un conjunto de partes o elementos organizados que interactúan entre sí para lograr objetivos, surge el interés por estudiar en el marco de los SSI, las interacciones de las empresas - proveedoras de partes con agentes del entorno tanto dentro como fuera de él, que han permitido desarrollar su capacidad innovadora gracias a la cercanía entre las empresas proveedoras y su relación con la industria automotriz.

Los SSI se diferencian en cuanto a la dinámica de conocimientos estructurados y habilidades desarrolladas, que permiten combinar los recursos de manera eficiente, generar

\footnotetext{
${ }^{2}$ En Adelante, SSI.
} 
vínculos y complementariedades para responder a la demanda de la sociedad, en lo que respecta a diseño, producción y distribución de bienes y servicios.

\subsubsection{Perspectivas de los Sistemas de Innovación}

La aproximación teórica y analítica del sistema sectorial tiene sus raíces en la teoría evolucionista que destaca los aspectos cognitivos de los agentes económicos como las creencias, los objetivos y las expectativa, los cuales se encuentran condicionados al aprendizaje, la experiencia y el contexto en el que los agentes se desenvuelven.

El carácter dinámico de la innovación soportado por la teoría evolutiva económica e influenciada por las teorías darwinistas trae a nuevos autores que, desde diferentes perspectivas formadas en la década de los 80 "s, realizan estudios sobre los procesos de innovación dentro de las empresas. De manera que los estudios de los sistemas nacionales de innovación surgieron de la mano de científicos evolucionistas e institucionalistas como Christoper Freeman, Richard Nelson y BengtEke Ludvall, (Freeman 1987, (Lundvall, 1992) Lundvall 1988 y 1992 y Nelson 1992 y 1993), que pusieron en cuestión los postulados ortodoxos sobre el papel del conocimiento como genérico, codificable, accesible sin costo e independiente del contexto.

La perspectiva de los Sistemas Nacionales de Innovación pone en cuestión el modelo lineal dominante. Para el SNI las innovaciones son nuevas combinaciones de conocimiento que tienen un significado económico, llevada a cabo normalmente por las empresas; es la mezcla de varios procesos y no solo de la inversión en las I+D. El postulado 
central es que las instituciones sociales condicionan o canalizan la acción económica general y los procesos de innovación en particular (González de la Fe y López, 2011; p. 133).

Estos modelos de sistemas de innovación que analizan los componentes desde la macro y microeconomía han sido fundamentales a la hora de postular medidas para mejorar las posiciones de las industrias dentro de los países en busca de la consolidación de un mercado internacional y también inspiraron a los sistemas sectoriales de innovación que planteo Malerba (2002), del cual se hablará a continuación.

\subsubsection{Malerba y los Sistemas Sectoriales de Innovación}

El concepto de Sistemas Sectoriales de Innovación, planteado por Malerba (2002), es particularmente relevante para el análisis de la capacidad de innovación y difusión tecnológica de la industria de Autopartes en Colombia. Permite el análisis de estructuras y procesos industriales específicos, incluyendo aquellos que sobrepasan fronteras tanto regionales como nacionales, lo que facilita el análisis de la industria Colombiana de Autopartes en un contexto global.

Los SSI caracterizan los actores e interacciones que conforman las dinámicas de innovación de una industria. Un SSI consiste en ubicar "los actores involucrados en innovación, los links y relaciones entre actores e instituciones relevantes" (Malerba, 2002). Todas estas dimensiones ayudan en la explicación de diferencias en innovación entre 
sectores. A partir del concepto de SSI, la $\mathrm{OCDE}^{3}$ ha llevado a cabo detallados estudios comparativos de diversos sectores tales como el de energía, biofarmacéutico y muchas industrias de servicios intensivos en conocimiento.

En cuanto a los SSI (Malerba, 2002 y 2006) se puede afirmar que se basa en los otros sistemas de innovación, pero el concepto sistema sectorial de innovación permite comprender el papel de la co-evolución interactiva de diversos factores tecnológicos e institucionales en el crecimiento de la productividad de los distintos sectores que conforman un sistema económico nacional o, en general, multiregional; a su vez, integra algunas de las aportaciones previas más relevantes sobre los sistemas de innovación (Fátas, 2008).

Los SSI ayudan a analizar el sector no solo en su realidad concreta si no que deja vislumbrar y desarrollar planes a largo plazo dentro de los sectores productivos. Los SSI utilizan tres componentes para poder desarrollar un análisis cuantitativo y cualitativo de los sectores:

Cuadro 1. Componentes de los SSI.

\section{COMPONENTES DESCRIPCIÓN}

Las empresas difieren significativamente en su participación en la Flujos de Conocimiento: producción y difusión de conocimiento. Este set de flujos afecta la capacidad de un cluster ${ }^{4}$ regional de empresas para generar y absorber innovación.

Actores, Relaciones y

Flujos de conocimiento entre actores en redes formadas en base a Redes sus relaciones.

\footnotetext{
${ }^{3}$ Organización para la Cooperación y el Desarrollo Económico

${ }^{4}$ Porter define Clúster como concentraciones de empresas e instituciones interconectadas en un campo particular para la competencia,pudiéndose observar en el mundo gran variedad de clústeres en industrias como la automotriz, tecnologías de la información, turismo, servicios de negocios, minería, petróleo y gas, productos agrícolas, transporte, productos manufactureros y logística entre otros.
} 


\begin{tabular}{ll}
\hline & La organización y performance de innovación y difusión son \\
afectadas por el entorno institucional de cada empresa, las \\
instituciones pueden ser específicas del sector, nacional o \\
internacional.
\end{tabular}

Fuente: (Malerba, 2006)

La presente investigación destaca sobremanera el trabajo realizado por Malerba (2002), como fundamento esencial para analizar el estado del sector de Autopartes en Colombia. Malerba permite caracterizar el sector y el conjunto de actividades que están unificadas, precisamente en las circunstancias actuales del mercado en medio de una demanda emergente y en la medida de la base del conocimiento.

Malerba (2006) plantea que el análisis de SSI puede llevar a que se replanteen las políticas sectoriales que determinan, en buena parte, el desempeño de un sector productivo en particular, tanto en el ámbito regional como nacional. Algunas políticas pueden necesitar ser definidas por la industria. Dado que los hacedores de políticas son actores en el SSI, estudios de este tipo posibilitan una clarificación en cuanto a sus necesidades; esto mejora su aporte al sistema de innovación en cuestión.

También los SSI refieren la definición de "sector"; es decir, empresas que por su actividad tienen características comunes y,ala vez, se pueden considerar heterogéneas. Lo que muestra Malerba (2002 y 2004) es una aproximación al análisis de la innovación. Los SSI están compuestos por varios agentes que a partir de la interacción y un conjunto de actividades en común de mercado quieren crear, producir y vender productos del sector. 
El SSI consta de una base de conocimiento, tecnologías inputs ${ }^{5}$ y una demanda potencial o existente que caracteriza el sector, así como una serie de instituciones.Es precisamente la coexistencia e interacción de estos tres bloques lo que permite la situación emergente de los sectores a partir de la innovación y la dinámica del mercado.

En primer lugar, el conocimiento y tecnología corresponden a la base del cambio tecnológico, su función es central en el proceso de innovación, es importante señalar dentro de este componente tres aspectos dominantes en las empresas; a), alta idiosincrasia en el nivel de las empresas, b), no difusión automática y sin límites de las empresas, y c), absorción de conocimiento de las empresas según sus diferentes habilidades acumuladas a lo largo del tiempo. Esta caracterización de la base del conocimiento, tecnologías e inputs, es fundamental en el análisis de la innovación a la hora de examinar el dominio del conocimiento para saber cuáles son las fronteras del sector que irremediablemente no son fijas porque los mercados cambian constantemente.

En este punto también podríamos decir que el conocimiento permite identificar particularidades dentro de los SSI, las complementariedades dinámicas entre las tecnologías y las actividades son el principal nicho de transformación y crecimiento de los SSI, y ponen en movimiento procesos de innovación y cambio.

Desde la postura de Malerba (2002 y 2006) el conocimiento juega un papel central en la innovación. En estas condiciones, se convierte en un bien selecto dentro del nivel empresarial, que no se difunde de forma automática y libremente entre las empresas y tiene

\footnotetext{
${ }^{5}$ En la elaboración de un producto es todo aquello que se le ha ido añadiendo a éste, capital o trabajo, antes de que llegue a ser output.
} 
que ser absorbido por las mismas, en la medida en que sus diversas habilidades acumuladas a lo largo del tiempo permitan su consolidación.

En segundo lugar, aparecen los agentes y redes que son un conjunto de agentes diferentes, que pueden ser individuos como consumidores, empresarios, científicos etc. O también organizaciones como empresas, universidades asociaciones de comercio, asociaciones industriales, agencias gubernamentales, etc. Se caracterizan por su especificidad de aprendizaje, competencias, creencias objetivos, organigramas y comportamiento; éstas interactúan a partir de procesos de comunicación, intercambio, cooperación, competencias y órdenes.

Así mismo,los agentes desde su negocio se comunican a través de las relaciones que impone el mercado y el no-mercado, generando redes. Estas redes emergen y se transforman dinámicamente, la innovación y la producción son consideradas como procesos que implican interacciones sistémicas entre una amplia variedad de actores, orientada a la generación e intercambio de conocimiento relevante para la innovación.

Es importante señalar que los agentesestán compuestos por las empresas, cuyas dinámicas innovadoras se analizan en función de su grado de implicación tecnológica, las universidades y los centros de investigación públicos y privados y las redes formadas para el fomento de la transferencia de tecnologías y capacidades.

Por último, están las instituciones que son las encargadas de modular los procesos de conocimiento, aprendizaje, transferencia de tecnologías y las acciones e interacciones que establecen los agentes (normas, rutinas, hábitos comunes, practicas, reglas, leyes, 
estándares, etc.) varias de estas instituciones pueden ser nacionales (es el caso del sistema de patentes), mientras otras pueden ser especificas (por ejemplo los mercados laborales o las instituciones financieras).

Para los SSI es importante establecer las relaciones que aparecen de la interacción. El papel de las instituciones y su evolución son configuradoras del entorno operativo de los agentes y también del marco político y económico. Las instituciones agrupan todos los elementos que configuran el marco legal y operativo vinculado a la tecnología. Así, todos los aspectos que afectan a los fenómenos de apropiabilidad y acumulación del conocimiento están delimitados por la legislación, los programas financieros, la naturaleza de los acuerdos de colaboración entre empresas e instituciones, la normativa sobre Autopartismo, los programas marco de investigación, las posibilidades de financiación o la patentabilidad de las técnicas innovadoras.

Un sistema sectorial pone en marchaprocesos de cambio y transformación a través de procesos de co-evolución de sus diferentes elementos. Esto es fundamental en un enfoque dinámico. El interés de un SSI no se circunscribe a caracterizar o describir los sectores, sino en explicar su co-evolución (Guinea, 2006).

Otra de las variables importantes dentro de los SSI es la base del conocimiento que se explica a través de los avances acumulados en el área, que pasan a formar parte de las técnicas y capacidades asociadas al sistema de innovación. La forma de delimitar el campo de actividades, agentes, instituciones y técnicas básicas y aplicadas inherentes al sector consiste en definir parámetros en los que a través de las citas de las revistas especializadas 
y, sobre todo, a través de la patentometría ${ }^{6}$, se contabilicen aquellos avances que aparecen de forma recurrente en los agentes que conforman el sistema sectorial.

Estas variables yestructuras de pensamiento en relación con los SSI, parten de la base de que la innovación debe ser analizada desde dos perspectivas:

1. Como un proceso complejo que implica co-evolución de otros procesos subyacentes. A partir del análisis de las dinámicas del sector.

2. Desde el enfoque sistémico para disponer de medios analíticos coherentes con la idea de la complejidad.

Estas dos perspectivas nos dan la posibilidad de identificar los patrones de innovación desde una óptica transversal del proceso y los vínculos (todos los actores giran alrededor del concepto de SSI) que los organiza a ellos y a sus vínculos y complementariedades dinámicas.

Para finalizar,se debe decir que el modelo de los SSI, se aproxima a los problemas a partir de lo sectorial, y permite un análisis transversal que facilita el seguimiento de procesos complejos sin límites puestos, da una perspectiva nacional o local limitada por el espacio geográfico. Por otro lado, hace una aproximación sistémica con el enfoque sectorial en un contexto dinámico, e incide en la explicación de la estructura y la evolución del proceso.

\footnotetext{
${ }^{6}$ La patentometría es una herramienta necesaria para el análisis de la ciencia y la tecnología. Una mayor cantidad de organizaciones debe explotar estos métodos de trabajo. Esta es una manera de comprender las características de la dinámica tecnológica, identificar fortalezas y debilidades en un área técnica, conocer el potencial comercial de los productos relacionados con esa tecnología, identificar la actividad tecnológica, etcétera. Estos resultados no conducen por sí solos a la toma de decisiones, son una parte de la información que deben dominar los expertos o gestores.
} 
Partiendo de la base de conocimiento como elemento clave que condensa los elementos constitutivos de un SSI, entonces, la identificación de algunas de las dimensiones fundamentales del conocimiento tales como dominio, accesibilidad, oportunidad (y apropiabilidad), acumulación(Malerba y Orsenigo, 1999) y el papel de los agentes, las redes y las instituciones en todo ello, podrían permitir identificar el patrón sectorial de innovación; esto es, podría informar sobre las vinculaciones entre innovación y conocimiento en ese sistema sectorial (Guinea, 2006).

En primer lugar el dominio está dadopor el área o campo del conocimiento y las adquisiciones de tecnología necesarias para el desarrollo de innovadorasaplicaciones, usuarios y demanda de productos propios del sector. (Malerba, 2002).

En segundo lugar laaccesibilidad nos refiere a las oportunidades de adquirir conocimientos de agentes externos, pueden ser de los usuarios, proveedores, conocimiento científico y de tecnología, desarrollado por universidades, centros de investigaciones ylaboratorios. Cuanto más fácil sea el acceso al conocimiento interno del sector, menores serán las posibilidades de apropiarse de éste y cuanto más accesibles sean los conocimientos externos al sector mayores serán las oportunidades científicas y tecnológicas. Cuando el conocimiento acerca de los nuevos productos y procesos es fácilmente accesible, disminuye las barreras de entrada para nuevos competidores en el mercado. (Malerba, 2002). 
En tercer lugar los procesos acumulativos del conocimiento y la generación de nuevos conocimientos se basan fundamentalmente en los conocimientos actuales de la empresa. La acumulatividad se puede dar por tres fuentes:

1. Los procesos de aprendizaje; son la dinámica de generación de conocimiento que estructura la empresa tecnológicamente, y aprovechan la noción pasada o existente para generar nuevas preguntas de investigación y nuevas bases de conocimiento.

2. La capacidad de organización; está directamente relacionado con lo que la empresa hace y puede hacer en el futuro.

3. Los "feed backs" del mercado; la reinversión en(I+D), aumentando las posibilidades de innovación. (Malerba, 2002).

En cuarto lugar la apropiabilidad del conocimiento se define como la forma de proteger las innovaciones de la imitación, tanto dentro como fuera de la industria, y se conocen por un lado como apropiabilidad alta;cuando existe una protección adecuada para sus innovaciones; por otro lado apropiabilidad baja quees la fuga de información alentorno. Selimitan las entradas innovadoras y se restringe el crecimiento innovador, afectando los nuevos desarrollos (Malerba, 2002).

Estos ambientes son claves en términos de conocimiento y aprendizaje; éste último, como un proceso gratuito y automático. Según Malerba (1992) las empresas aprenden primero, por una variedad importante de adaptaciones; segundo, por diversos procesos de aprendizaje; tercero, por las mejoras de rendimiento en el conjunto de conocimientos; y cuarto, por las capacidades tecnológicas de las empresas, que por sus actividades innovadoras avanzan en el acceso a nuevos conocimientos. 
Así, aparece la idea de que, las asimetrías o brechas entre las empresas/regiones/naciones tienden a profundizarse dado que el conocimiento tecnológico no es sencillo de transferir y sobre todo no pueden trasladarse los entornos donde actúan las entidades. Las empresas e instituciones no pueden innovar en aislamiento, necesitan de un conjunto de relaciones con otros agentes y de un medio que las acompañe, pero esto no es simple de transmitir. A su vez, se concluye que las asimetrías también se mantienen o acrecientan, debido a que la innovación genera un proceso de retroalimentación positiva; es decir, que cuantas más innovaciones haya en una comunidad, más riqueza se creará y más incentivos y recursos habrá para la generación de nuevas innovaciones.

Lo que se busca a través del análisis de los Sistemas Sectoriales de Innovación es contribuir con información que apoye las apuestas de mejoramiento de la competitividad del sector de autopartes en Colombia a partir delas interacciones que han generado mejora en los valores agregados de la producción y de los procesos de producción de la mano con la innovación. En consecuencia se intenta realizar el análisis del sector de la industria de autopartes en la ciudad de Bogotá, lo que implica un reto bastante interesante ya que la operatividad de los conceptos de Malerba aún no se ha desarrollado con profundidad en Colombia para este sector.

Malaver (2009) realizó un trabajo en el que se aborda el automotor/autopartes en Colombia desde la perspectiva de los sistemas sectoriales de innovación con el propósito de explicar las posibilidades de mejora en la agregación de valor e incremento de la competitividad. De acuerdo con las conclusiones de este trabajo, en el sector se caracteriza, entre otros aspectos, por la falta de cohesión propiciada por la existencia de asociaciones 
gremiales con intereses divergentes, su atomización generada por las relaciones predominantemente competitivas de los jugadores locales y entre productores e importadores/comercializadores de autopartes, la ausencia de instituciones oficiales con suficiente liderazgo, la no existencia de un centro de investigación/innovación del sector y la casi inexistente relación de los actores empresariales con actores del sistema nacional de ciencia y tecnología y del sistema nacional de innovación. Sin embargo, para tener una visión integral de la situación del sector automotor en relación con sus sistemas sectoriales de innovación, el presente trabajo se enfoca específicamente en el análisis de los procesos de transferencia de tecnología del sector.

Teniendo en cuenta las categorías emergentes de este marco teórico, para el desarrollo de los objetivos del trabajo se diseñó una metodología que permitiera establecer si en las empresas del sector autopartista en Bogotá, existen estrategias orientadas a fortalecer la base tecnológica y, en caso afirmativo, en qué áreas de las empresas se enfocan esas estrategias. Igualmente se buscó establecer si la tecnología transferida proviene de otros países o de organizaciones localizadas dentro del país, y si los procesos mediante los cuales se genera esta transferencia se realizan dentro de la empresa o por fuera de ella. También resultó de interés establecer si es una sola persona o una organización (empresa, institución educativa, etc.) la que aporta la tecnología que es transferida a la empresa y si esa tecnología se materializa en procedimientos, capacitación del personal o equipos adquiridos por las empresas.

Con respecto a los agentes que motivan a la transferencia de tecnología en el sector autopartista, se buscó establecer si la competencia es la que mueve a las empresas a generar 
dicha transferencia, si lo que buscan los empresarios es poder satisfacer los requerimientos de sus clientes, o sin son otras razones diferentes las que los llevan a actuar en esa dirección. Igualmente la metodología buscó establecer cuáles son los logros concretos que las empresas han obtenido como consecuencia de los procesos de transferencia de tecnología y las medidas que las empresas han adoptado para proteger dichos logros de terceros. Igualmente se buscó saber qué tipo de apoyo han recibido las empresas para lograr este propósito de transferencia tecnológica, si han a su vez transferido o compartido esa tecnología con otras empresas y si consideran que están o no dadas las condiciones que incentiven esa transferencia.

Finalmente, se explora con cada uno de los agentes las interacciones con otros agentes de mercado y de no mercado, que aportan a la capacidad innovadora a través de las actividades de transferencia de tecnología. 


\section{METODOLOGÍA}

\subsection{Método}

Dados los objetivos del presente trabajo, el método de investigación empleado es cualitativo; no se trata de probar o de medir en qué grado una cierta cualidad se encuentra en un acontecimiento dado, sino de descubrir tantas cualidades como sea posible (Bonilla \& Rodríguez, 1997).

De acuerdo con el marco teórico previamente desarrollado se identificaron las categorías de análisis relacionadas con los procesos y los sistemas sectoriales de innovación; estas categorías se pueden definir como los puntos clave o descripciones a la vez amplias y muy precisas del sentido que se quiere dar dentro de un trabajo investigativo a ciertos términos o conceptos (Chiappe, 2010). Teniendo en cuenta que el objetivo del trabajo fue explorar la capacidad innovadora de los agentes a partir de los procesos de transferencia de tecnología, se identificaron aspectos importantes para asemejar la forma como se llevan a cabo estos procesos en las empresas seleccionadas y de la existencia o no de sistemas sectoriales de innovación; a partir de la identidad de categorías se redactaron las preguntas adecuadas para la realización de las entrevistas. 


\subsection{Universo y muestra}

El universo en el que se realiza el estudio lo componen las empresas colombianas fabricantes de partes originales a las ensambladoras que operan en el país. Este universo se escogió teniendo en cuenta que dentro de la industria de autopartes, estas empresas son las que más cerca se encuentran de la innovación, dado que, movidas por las fuerzas de la competencia, las ensambladoras permanentemente incorporan innovación en los componentes que emplean para la producción de los modelos de vehículos que se están lanzando al mercado. Esta condición hace que las empresas colombianas fabricantes de partes originales para las ensambladoras se vean permanentemente expuestas a los retos generados por la innovación, lo que hace suponer que los procesos de transferencia de tecnología que utilizan deban ser especialmente eficaces.

El universo está compuesto aproximadamente por 112 fabricantes registrados en la Asociación Colombiana de Fabricantes de Autopartes ACOLFA (McKinsey y Company, 2009). En Bogotá se encuentran localizadas 20 de estas empresas y de ellas se seleccionó una muestra de 10 empresas que representan el 50\% de los fabricantes la ciudad de Bogotá, como se muestra en la Tabla 2.

Tabla 2. Muestra empleada para el estudio.

\begin{tabular}{llll}
\hline $\mathrm{N}^{\circ}$ & \multicolumn{1}{c}{ Organización } & \multicolumn{1}{c}{ Productos } & \multicolumn{1}{c}{ Representante } \\
\hline 1 & AGP de Colombia S. A. & Vidrios & Gerente \\
\hline 2 & $\begin{array}{l}\text { IPT Comercializadora Internacional } \\
\text { S. A. }\end{array}$ & Soldadura & Gerente de Proyectos y Negocios \\
\hline 3 & Colombiana de Frenos S. A. & Frenos & Gerente \\
\hline
\end{tabular}




\begin{tabular}{llll}
\hline 4 & Chaid Neme Hermanos & $\begin{array}{l}\text { Puertas, } \\
\text { carrocería }\end{array}$ & Asesor \\
\hline 5 & Expumaltex & Silletería & Gerente General \\
\hline 6 & Fanalca & Chasís & $\begin{array}{l}\text { Vicepresidente de Planeación y } \\
\text { Desarrollo }\end{array}$ \\
\hline 7 & Incolbestos S. A. & $\begin{array}{l}\text { Pastillas de } \\
\text { frenos }\end{array}$ & Gerente \\
\hline 8 & Metalúrgicas Bogotá S. A. & Chasís & Gerente \\
\hline 9 & Servintec Ltda. & Pinturas & Presidente \\
\hline 10 & Trimco Ltda. & $\begin{array}{l}\text { Piezas de } \\
\text { interior }\end{array}$ & Presidente \\
\hline
\end{tabular}

Por recomendación de los directivos del sector en cabeza del Ing. Fernando Meza Director de Innovación de Chaid Neme y Ejecutivo de la asociación del sector se seleccionaron las empresas más representativas del sector en la ciudad. La selección busco incluir diferentes componentes dentro del proceso de fabricación de vehículos, considerando que en cada componente pueden existir diferentes dinámicas de transferencia de tecnología dependiendo del desarrollo de cada uno de ellos a nivel mundial; si se hubieran incluido solamente empresas proveedoras de componentes de frenos, por ejemplo, se hubiera perdido la posibilidad de incluir a proveedores de pinturas y por lo tanto de saber qué situaciones se presentan en este tipo de empresas en cuanto a sistemas de innovación. De cada uno de estos componentes se buscó incluir a las empresas más destacadas y por último la selección final tuvo en cuenta también de la disponibilidad de las empresas para atender las entrevistas en los plazos requeridos. 
Los fabricantes de partes originales en Colombia abastecen a las ensambladoras que están localizadas en el país tales como La Compañía Colombiana Automotriz (marcas Ford, Mazda y Mitsubishi), General Motors Colmotores (marca Chevrolet), Sofasa (marcas Renault y Toyota), Carrocerías Non Plus Ultra (marca propia, CKD Volkswagen), Compañía de Autoensamble Nissan (marca Nissan), Didacol (marca Hino), Monoblock (marca Mercedes Benz), Navitrans (marca Agrale). La muestra empleada produce diferentes tipos de productos, lo cual permite presentar en el estudio la situación de la transferencia de tecnología en los diferentes subsectores que componen el sector de autopartes en Bogotá.

Para aplicación de los instrumentos de investigación se entró en contacto de manera directa en cada empresa con la persona de más alto rango encargada de este proceso de transferencia de tecnología, teniendo en cuenta los objetivos del trabajo y el tipo de información requerida para asegurar su cumplimiento.

\subsection{Instrumentos}

Para la obtención de la información se aplicaron dos técnicas de investigación, la observación estructurada y la entrevista personalsemi-estructurada.En el contexto del presente trabajo la entrevista semi-estructurada se utiliza en los términos en que la definió Stake (1994), es decir una en la que el entrevistador interactúa con un individuo y lo alienta 
a que exprese con libertad sus ideas sobre el tema de estudio, con el propósito de ir más allá de las respuestas superficiales que se obtienen por otros métodos.

En cuanto a la observación directa, ésta se entiende como el examen atento de los diferentes aspectos de un fenómeno a fin de estudiar sus características y comportamiento, dentro del medio en donde se desenvuelve éste; es una técnica de recogida de datos que permite registrar, de una forma metódica y sistemática, el comportamiento deun individuo o grupo de individuos. (Bassedas \& Coll, 2004)

En la entrevista se busca en primer lugar, establecer si las empresas que hacen parte de la muestra cuentan o no con una estrategia de transferencia de tecnología; en el caso de que no la tengan, también se busca establecer las razones por las cuáles sucede de esta forma y los medios a través de los cuales estas empresas acceden a las actualizaciones tecnológicas que requieren para mantener su nivel de competitividad.

En el caso de aquellas empresas que sí cuentan con una estrategia de tecnología, la entrevista busca en primer lugar conocer los mecanismos que las empresas emplean para este propósito. Igualmente se busca saber en qué nivel jerárquico dentro de esas empresas se encuentra asignada la responsabilidad por la estrategia de transferencia de tecnología y los mecanismos a través de los cuales la empresa controla el avance de esta estrategia; por último se busca saber los logros concretos que las empresas han obtenido gracias a su estrategia de transferencia de tecnología. 
Antes de aplicar este instrumento se explicará a cada uno de los entrevistados que se trata de un trabajo con propósitos académicos, teniendo en cuenta que es un tema que debe manejarse de manera confidencial.

Se hizo registro sonoro de las entrevistas y la transcripción de las mismas se presenta en el ANEXO 1. ENTREVISTAS CON LOS EMPRESARIOS 


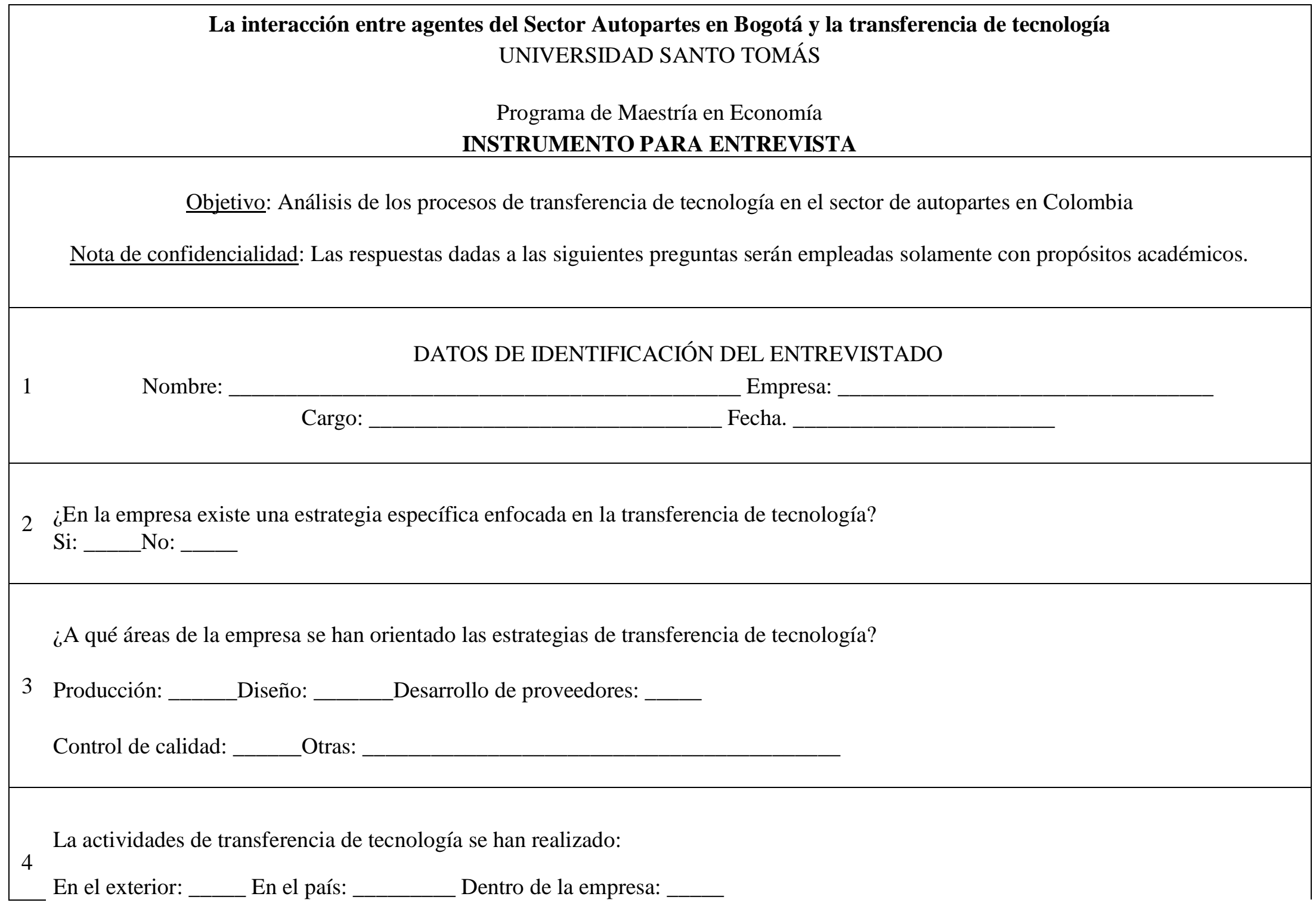


Hasta donde pueda revelarlo, ¿qué mecanismos emplea la empresa para la realización de su estrategia de transferencia de tecnología?

5 Un equipo de personas:____ Un experto:

Las inversiones hechas en transferencia de tecnología estánrepresentas en: Equipos: Instalaciones:

Procedimientos:____Personal capacitado:_____ Otro:

¿Cómo detecta la empresa las necesidades de transferencia de tecnología?

7 Por comparación con la competencia: Asistiendo a ferias especializadas: Por sugerencia deproveedores especializados:

Por sugerencia de los clientes (ensambladoras): Otros mecanismos:

¿Qué logros concretos ha tenido la empresa como consecuencia de su estrategia de transferencia de tecnología?

8 Reducción de costos: Desarrollo nuevos productos: Reducción tiempos de fabricación:

Reducción de inventarios: Otros:

¿De qué manera protege la empresa los logros que alcanza como consecuencia de la transferencia de tecnología?

9 Con patentes: ___ Restringiendo el acceso a ciertas áreas de la empresa: Mediante políticas de contratación de personal: Otros mecanismos:

1 El acceso a la transferencia de tecnología se ha dado mediante:

0 Universidades: ___ Centros de investigación:____ Laboratorios: ___ Otros: 


\begin{tabular}{|c|c|}
\hline 1 & $\begin{array}{l}\text { En los procesos de transferencia de tecnología la empresa ha recibido apoyo de: El Estado: ___ Agremiaciones industriales: } \\
\text { Otros: }\end{array}$ \\
\hline $\begin{array}{l}1 \\
2\end{array}$ & ¿La empresa ha transferido tecnología a otras empresas?Si: ___ No: ___ \\
\hline $\begin{array}{l}1 \\
3\end{array}$ & ¿Ha asistido la empresa a procesos de transferencia de tecnología exclusivos___ Con presencia de colegas: ___ \\
\hline $\begin{array}{l}1 \\
4\end{array}$ & $\begin{array}{l}\text { ¿Considera que hacen falta en el país condiciones específicas que estimulen o faciliten la transferencia de tecnología? Si: ___ No: } \\
\text { Cuáles: ___ }\end{array}$ \\
\hline 1 & La empresa ha interactuado con otros agentes para apoyar la capacidad innovadora. \\
\hline
\end{tabular}




\section{RESULTADOS}

En el capítulo se presentan y se discuten los resultados obtenidos a través de las entrevistas realizadas con los directivos de las empresas seleccionadas.

\subsection{Presentación de los resultados.}

Figura 3. Empresas que emplean estrategias específicas de transferencia de tecnología

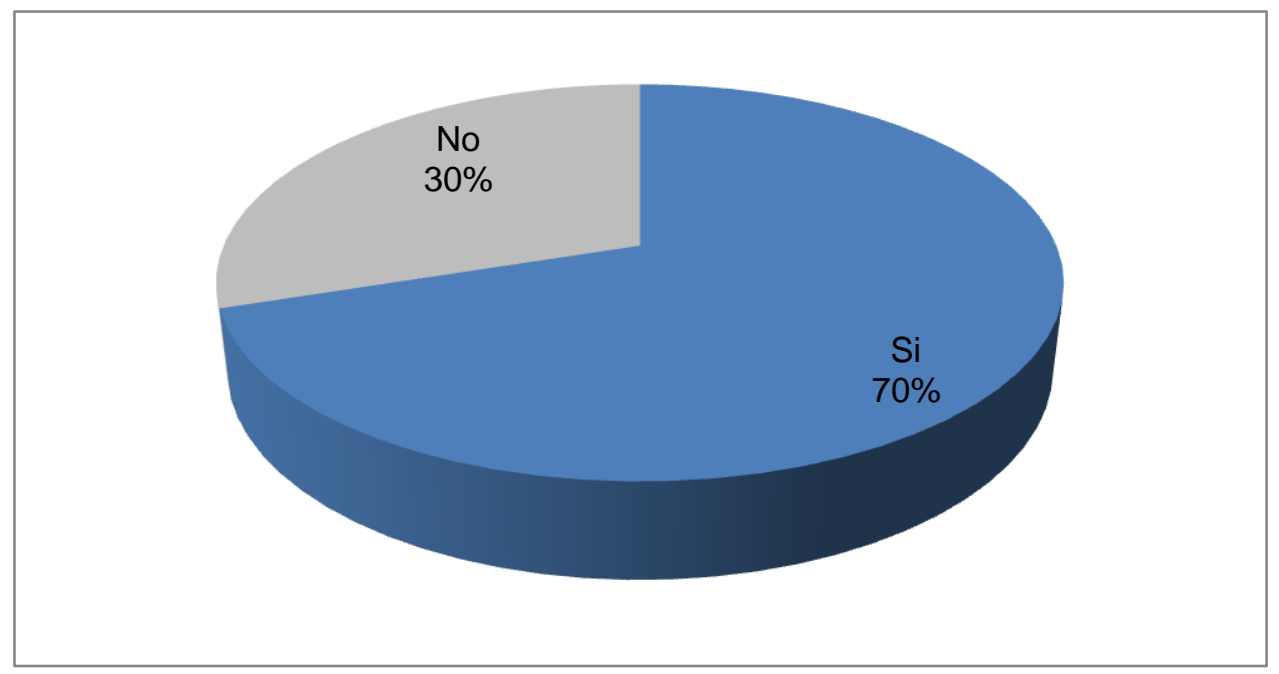

Fuente: Elaboración propia a partir de los datos de las entrevistas

Dentro de las respuestas se hizo mención a la interacción que algunas de las empresas hacen con entidades del sector público, incluyendo convocatorias de Colciencias y el SENA. Uno de los empresarios que manifestó no contar con estrategias específicas 
manifestó que la empresa va avanzando en la medida en que el mercado lo exige, por lo que procuran siempre incrementar su eficiencia para poder participar en nuevos negocios.

Estas estrategias en algunos casos se han aplicado desde hace al menos cinco y hasta ocho 8 años (caso Chaid Neme) y en otros cerca de cuatro años (caso Servimco). Los tipos de estrategias utilizadas se describen más adelante.

Figura 4. Áreas a las que se orienta la Transferencia de Tecnología

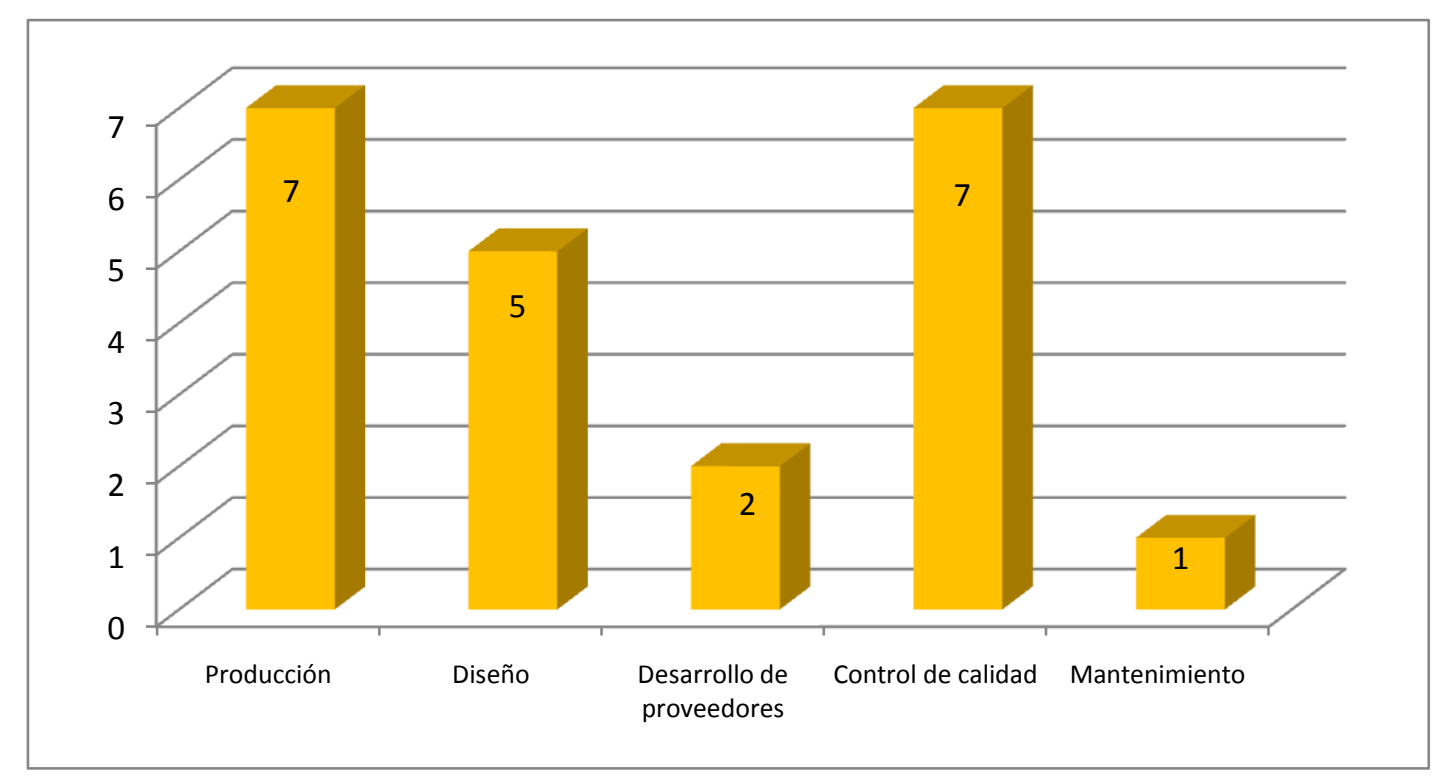

Fuente: Elaboración propia a partir de los datos de las entrevistas

Dentro de los empresarios que contestaron han enfocado sus estrategias de transferencia de tecnología en diseño de productos, uno de ellos destacó que lo hace enfocándose en desarrollo de nuevos productos y el otro lo hace en implementación de software. Se observa que varios de los empresarios que tienen actualmente implementadas estrategias de transferencia de tecnología lo hacen simultáneamente en varias áreas de la 
empresa; cinco de ellos (50\%) involucran simultáneamente las áreas de diseño, producción y control de calidad.

En cuanto a los resultados obtenidos, las respuestas son variadas. Para algunos empresarios realizar transferencia de tecnología es cuestión de subsistencia; en otras palabras, consideran que si no hubieran hecho esos esfuerzos hoy simplemente sus empresas ya no existirían. La reducción de costos y de tiempos de fabricación son otros de los logros señalados por los empresarios y el desarrollo de nuevos productos, aunque este último aspecto es el menos resaltado por los empresarios. Al referirse al control de calidad, se destacó lo relacionado con instrumentos de medición; también se destacaron experiencias específicas como el fortalecimiento de las áreas de ingeniería de diseño.

Figura 5. Lugar en donde se ha realizado la transferencia de tecnología

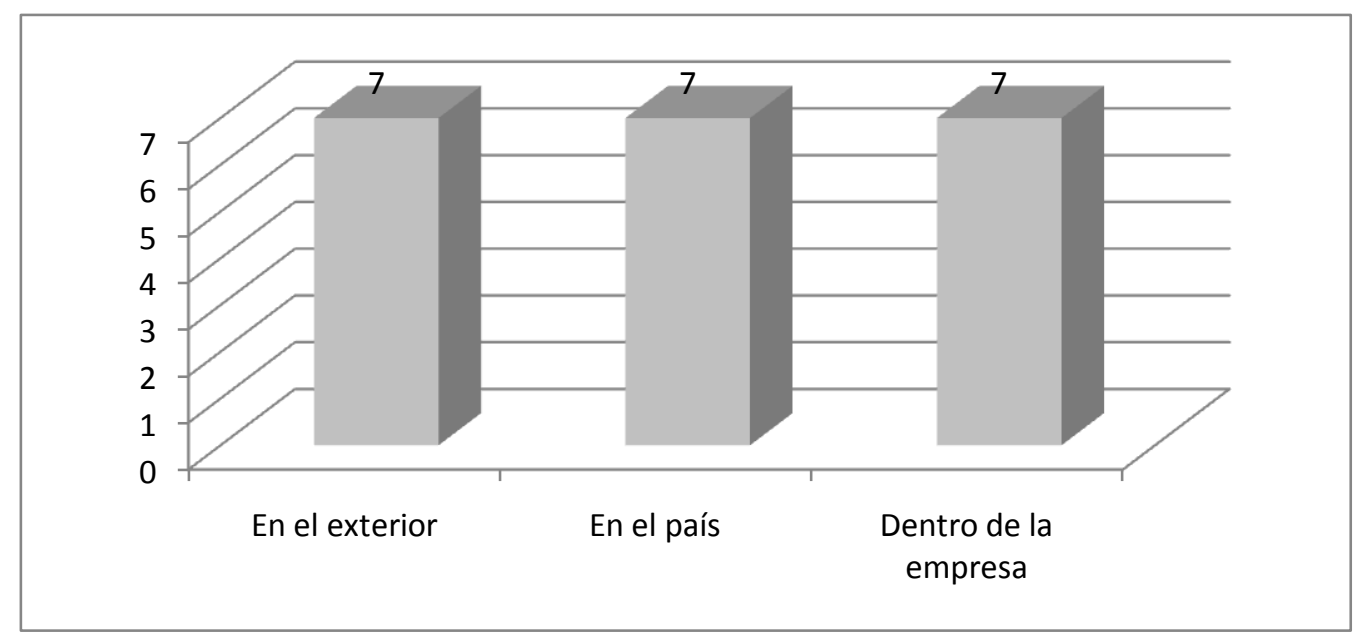

Fuente: Elaboración propia a partir de los datos de las entrevistas

Se observa que los empresarios utilizan diferentes ubicaciones al momento de decidir en dónde realizar actividades que les permitan lograr transferencia de tecnología, 
pues no existe una localización que sea empleada con mayor frecuencia para este propósito. De acuerdo con las respuestas a esta pregunta, es igual el número de empresarios que se desplazan al exterior o dentro del país para entrar en contacto con las organizaciones o personas que les aportan la transferencia de tecnología, o los que hacen que esas organizaciones o personas se desplacen hasta las sedes de sus empresas.

Figura 6.Mecanismos empleados para la transferencia de tecnología

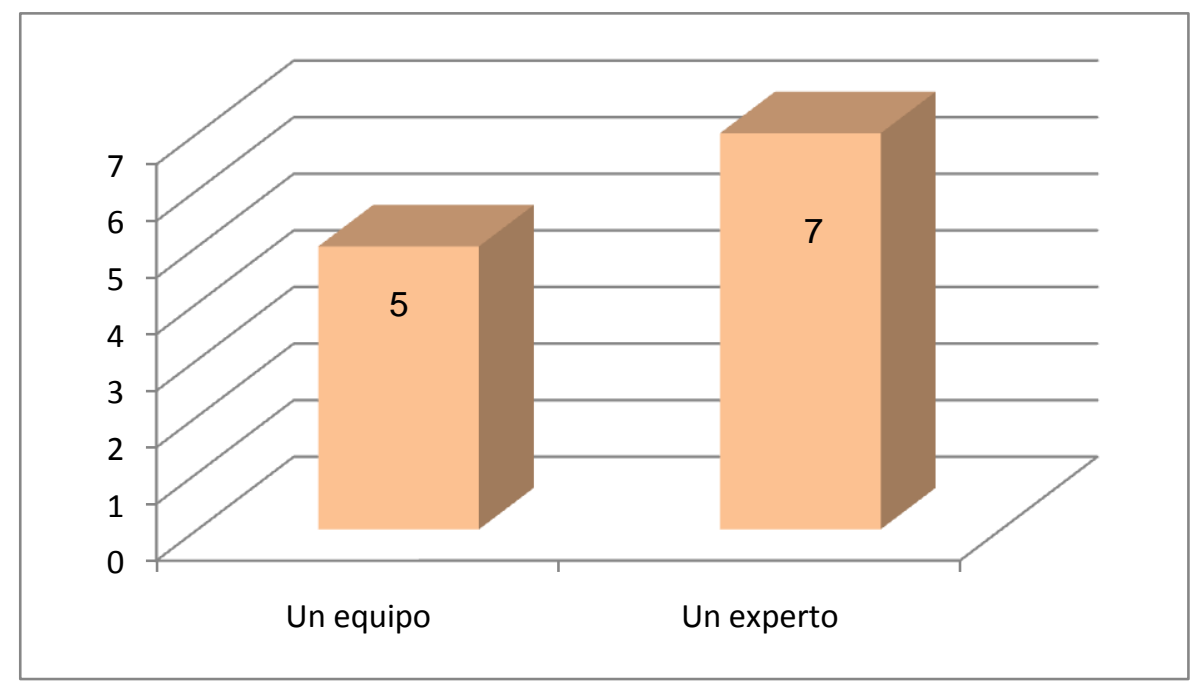

Fuente: Elaboración propia a partir de los datos de las entrevistas

El mecanismo de acudir a un experto fue el que más veces fue señalado durante las entrevistas con los empresarios como el empleado para la generación de transferencia de tecnología; sin embargo hubo empresarios que manifestaron emplear tanto esta opción como la de acudir a un equipo para ese propósito. Uno de los entrevistados manifestó que la forma como genera transferencia de tecnología es mediante actividades de benchmarking con sus pares localizados en diferentes partes del mundo. 
Los expertos que las empresas contratan para estos procesos normalmente tienen como propósito la capacitación de los funcionarios y operarios, por medio de charlas y entrenamientos en la implantación de procesos y puesta en marcha de equipos que las empresas adquieren. De donde vienen incluyen países como Estados Unidos, Corea y Japón; los empresarios se cuidaron de mencionar con mucho detalle concretamente cuáles son los conocimientos o mejoramientos específicos que han obtenido y de manera general se refirieron a los procesos de manufactura; solo se mencionó un caso específico de mejoramiento del proceso de fabricación de rines y otro de fabricación de resortes.En el caso de empresas multinacionales como Yasaki, una parte importante de la tecnología transferida a su sede nacional proviene de la casa matriz y de las sedes de la empresa en otros países del mundo.

Figura 7.Rubros de inversión para transferencia tecnología

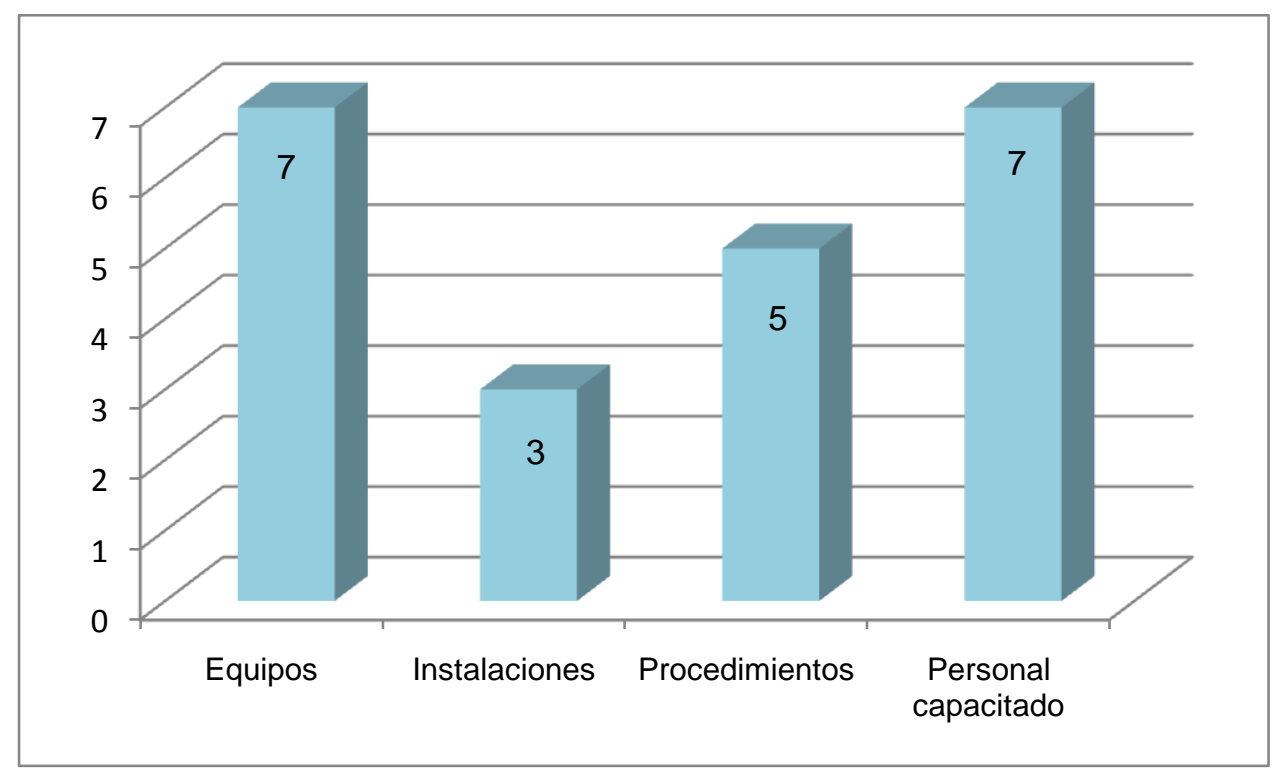

Fuente: Elaboración propia a partir de los datos de las entrevistas 
Las inversiones que los empresarios hacen dentro de los proceso de transferencia de tecnología están representados especialmente en equipos y en capacitación de personal; los procedimientos son el tercer destino al que se dirigen las inversiones relacionadas con transferencia de tecnología.

De acuerdo con las entrevistas, las instalaciones solo se han visto involucradas en los procesos de transferencia de tecnología cuando se ha requerido de modificaciones para montar nuevos equipos de ensamblaje o cuando el crecimiento de la demanda ha requerido ampliaciones.

Figura 8. Fuentes de identificación de necesidades de transferencia de tecnología

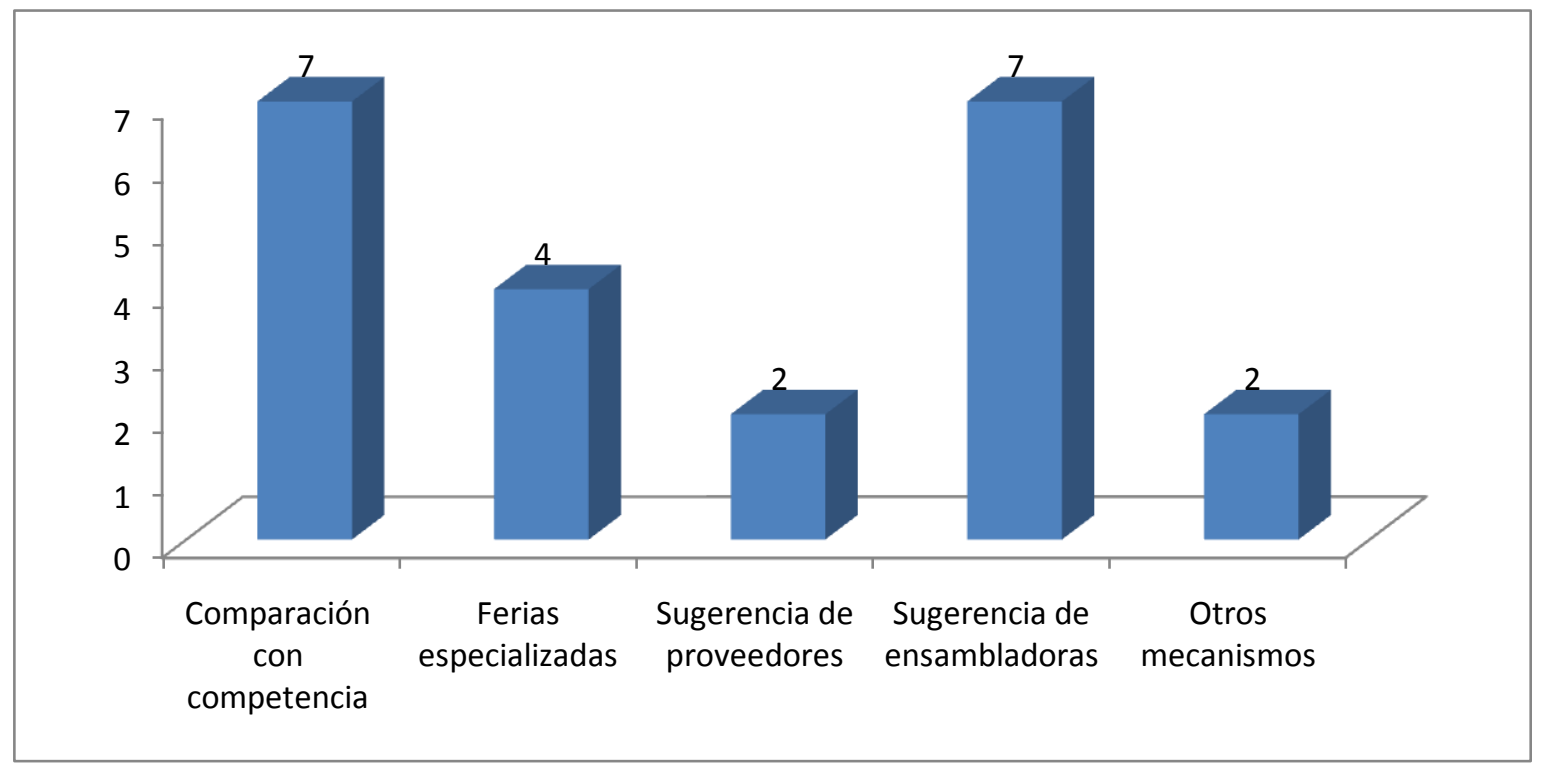

Fuente: Elaboración propia a partir de los datos de las entrevistas

Los empresarios respondieron que la comparación que hacen con su competencia y las sugerencias que reciben de las ensambladoras de automóviles son las principales fuentes que les indican la conveniencia de generar mecanismos de transferencia de tecnología; las 
ferias especializadas son el tercer mecanismo que les permite detectar oportunidades o necesidades de este tipo.

El benchmarking fue destacado por la mayoría de los entrevistados, dado que si no se tiene en cuenta se corre el riesgo de desaparecer del mercado por contar con procedimientos obsoletos e ineficientes que generan mayores costos y que no permiten adaptarse a la evolución propia de la industria automotriz. Igualmente las ensambladoras juegan un papel destacado como promotoras de este proceso porque son las que definen las especificaciones técnicas que deben cumplir los componentes que suministran los productores nacionales, especificaciones que en algunos casos implican modificar la tecnología que se empleaba previamente. En tercer lugar están las ferias, aunque algunos de los entrevistados señalaron que no acuden con mucha frecuencia a estos eventos porque lo que buscan es vender equipos, mientras que otros acostumbran a enviar delegaciones de ingenieros a esos eventos para mantener a sus empresas actualizadas.

Figura 9. Logros generados por la transferencia de tecnología

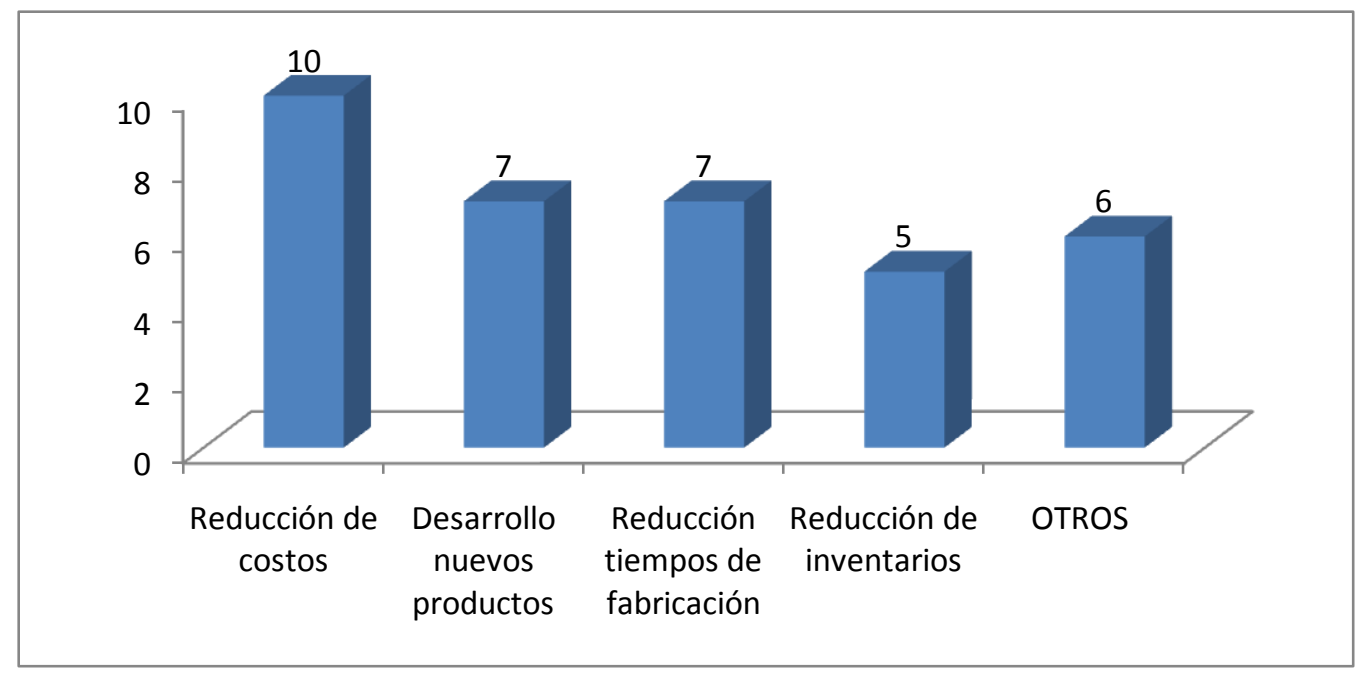

Fuente: Elaboración propia a partir de los datos de las entrevistas 
De acuerdo con los entrevistados, los principales beneficios que han obtenido como producto de sus estrategias de transferencia de tecnología son la reducción de costos y la reducción de tiempos de fabricación de sus productos; el tercer beneficio corresponde a desarrollo de nuevos productos.

La reducción de costos es un propósito constante de acuerdo con los entrevistados y se busca a través de diferentes mecanismos, como la reducción de materia prima y la reducción de tiempos de los procesos de fabricación; esta variables es especialmente crítica cuando se presentan picos de demanda. En el sector automotor se presentan variaciones notorias de un año a otro, dado que el volumen de vehículos vendidos depende de variables macroeconómicas que pueden a su vez cambiar tanto por razones internas como externas. Así, cuando la demanda de vehículos es alta, los tiempos de entrega se vuelven más críticos que los costos de fabricación, mientras que cuando el mercado reduce la demanda, el precio se vuelve el factor determinante.

Figura 10. Mecanismos de protección de la tecnología transferida

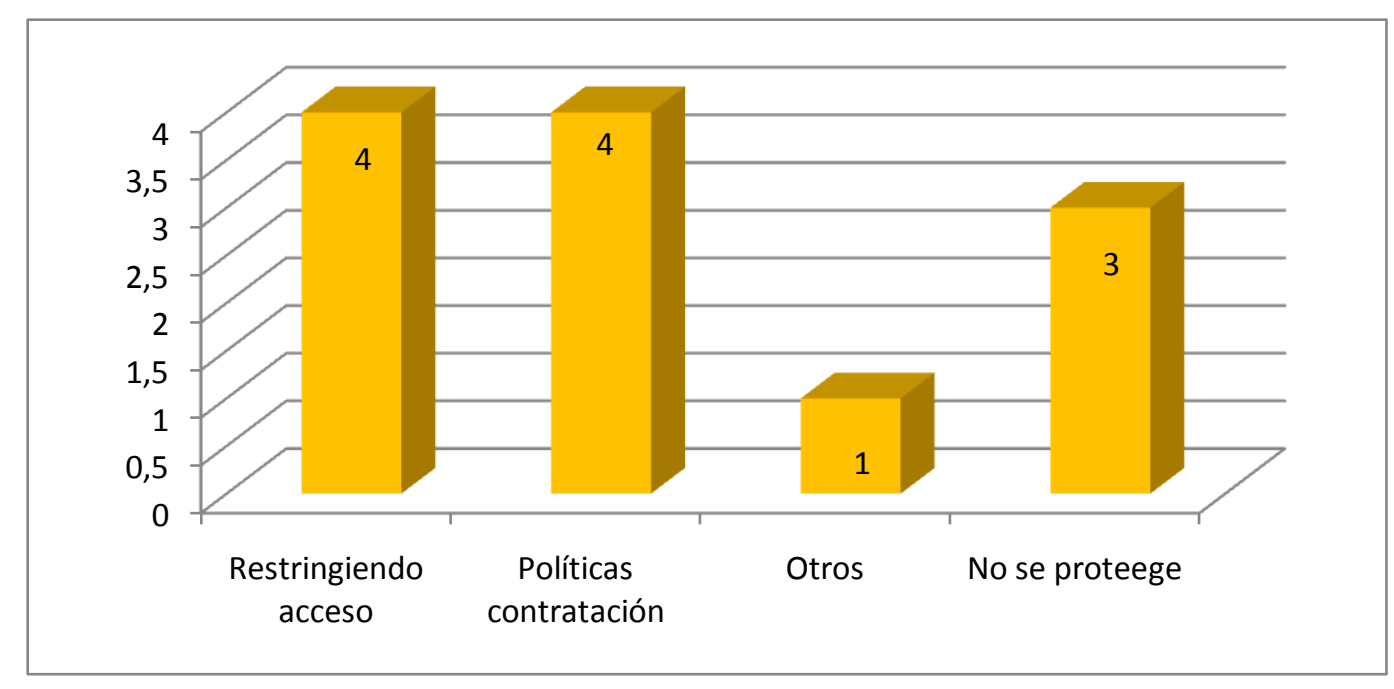

Fuente: Elaboración propia a partir de los datos de las entrevistas 
En cuanto a los mecanismos empleados para proteger los logros que las empresas han obtenido como producto de los procesos de transferencia de tecnología, los más señalados fueron las medidas relacionadas con la restricción de acceso y con políticas de contratación de personal; sin embargo algunos empresarios coincidieron en señalar que no han considerado necesaria la adopción de ningún tipo de medidas de protección, dado que consideran bajos los riesgos de que se presenten pérdidas para la empresa por ese concepto.

Se destaca el hecho de que, de acuerdo con una de las entrevistas, resulta complejo en el país obtener patentes sobre la tecnología que la empresa posee o produce, en comparación con países como Estados Unidos. Las diferentes medidas de protección buscan evitar que el know-how de las empresas llegue a su competencia y desaparezcan ventajas competitivas; sin embargo los entrevistados no mostraron una especial preocupación por este aspecto dado que no existen muchas empresas en el país que desarrollen el mismo tipo de productos; por ejemplo, la empresa que produce bisagras es una sola, la que produce tanques de combustibles o componentes de frenos también es una sola, etc., por lo que no existe un riesgo alto de que existan terceros interesados en saber cómo son los procesos o los equipos que las empresas utilizan.

En el grupo de “otros" están las medidas relacionadas la especialización del personal de las empresas por secciones, lo cual limita la posibilidad de que las personas que trabajan en una sección conozcan las minucias de los procesos que se utilizan en las demás secciones de la empresa, con lo cual se pone en evidencia fácilmente cuando una persona llega a un área que no es la suya a obtener información reservada. El control de acceso se ejerce mediante la suscripción de cláusulas legales por parte de los empleados que tiene 
acceso a información de cierto nivel, como por ejemplo las áreas de investigación, desarrollo y diseño.

Figura 11. Fuentes de tecnología transferida

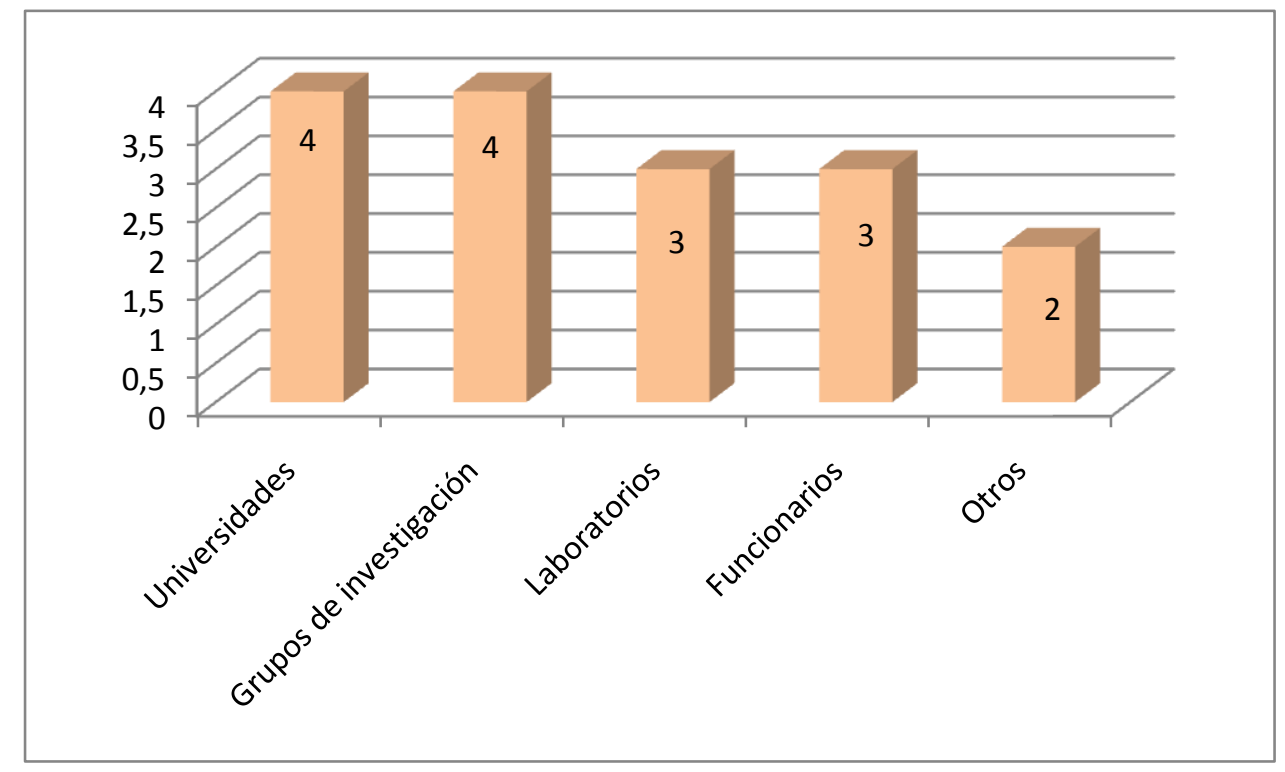

Fuente: Elaboración propia a partir de los datos de las entrevistas

Las universidades y los grupos de investigación fueron las fuentes con mayor frecuencia señaladas por los empresarios durante las entrevistas como las más empleadas para la transferencia de tecnología; los laboratorios y los funcionarios se encuentran en tercer lugar de acuerdo con los empresarios. Otras fuentes empleadas incluyen el uso de regalías y la asistencia técnica brindada en el desarrollo de productos por proveedores y ensambladoras.

El contacto con los grupos de investigación se realiza especialmente a través de Tecnova, organización por medio de la cual se coordinan acciones con universidades, entidades oficiales y otras empresas; los empresarios plantean las necesidades específicas 
que tienen de resolver situaciones concretas que pueden requerir investigación y esta organización coordina las acciones para que se generen los desarrollos necesarios; Tecnova involucra a universidades y organismos oficiales y los empresarios manifestaron su inconformidad por la lentitud de este mecanismo de transferencia de tecnología para lograr resultados.

En cuanto a los laboratorios, algunas de las empresas tienen sus propios laboratorios para investigación y desarrollo, mientras que otras se apoyan en laboratorios externos especializados que son contratados para trabajos específicos, o para tareas de entrenamiento.

Figura 12. Apoyos recibidos para la transferencia de tecnología

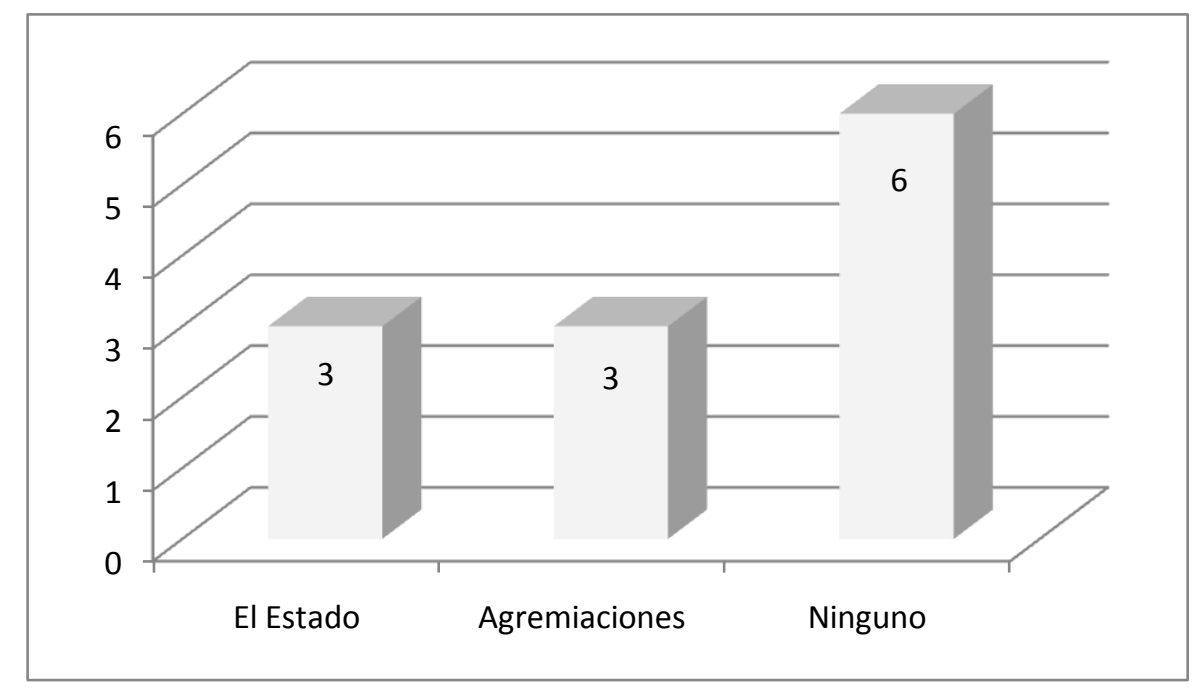

Fuente: Elaboración propia a partir de los datos de las entrevistas

La mayoría de los empresarios manifestó que no reciben ningún tipo de apoyo en sus propósitos de generar mecanismos de transferencia de tecnología; algunos señalaron a agremiaciones como Acolfa y entidades del Estado como Proexport. Acolfa ha servido en 
algunos casos de puente para el desarrollo de proyectos con Bancoldex, mientras que Proexport y Fiducoldex han facilitado el acceso a crédito para adquirir maquinaria. El Sena también ha intervenido mediante procesos de diagnóstico de la situación tecnológica de algunas empresas.

Figura 13. Transferencia de tecnología a terceros

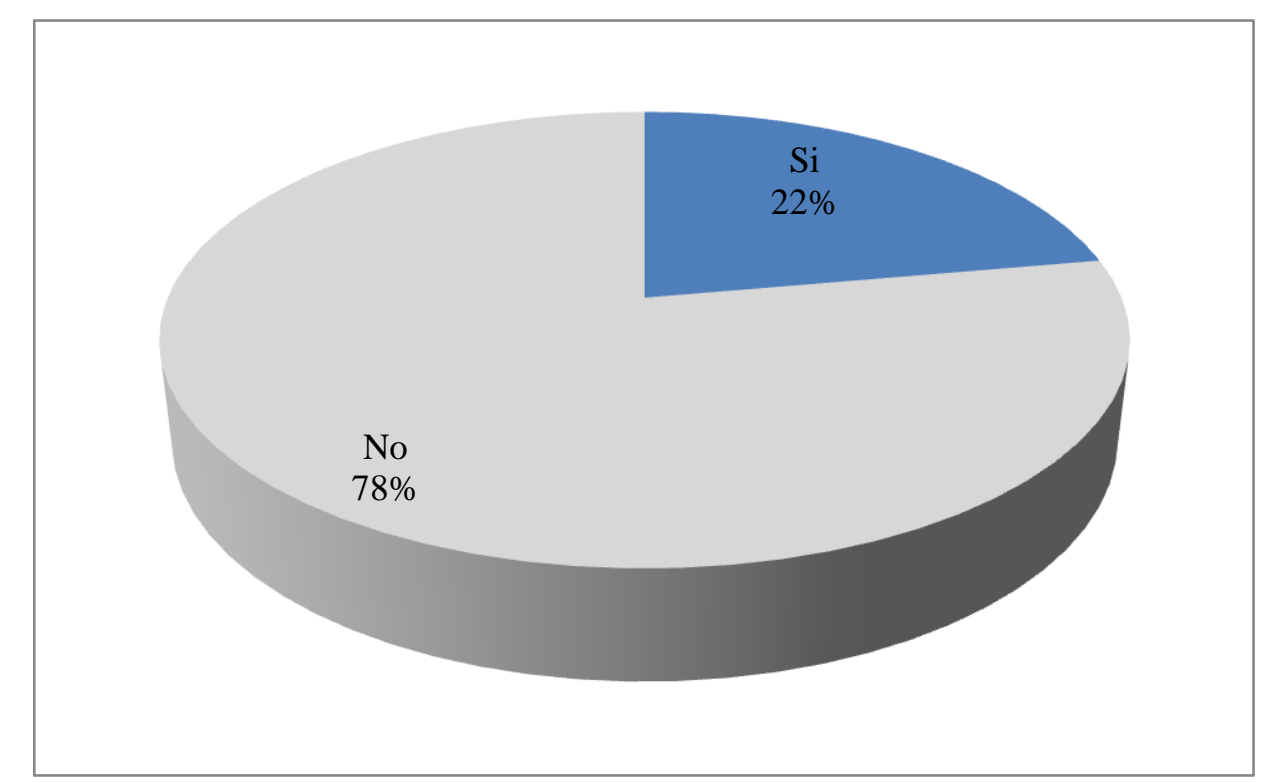

Fuente: Elaboración propia a partir de los datos de las entrevistas

La mayoría (78\%) de los empresarios entrevistados manifestó que no han transferido la tecnología que han adquirido a terceros.

Figura 14. Exclusividad en la transferencia de tecnología 


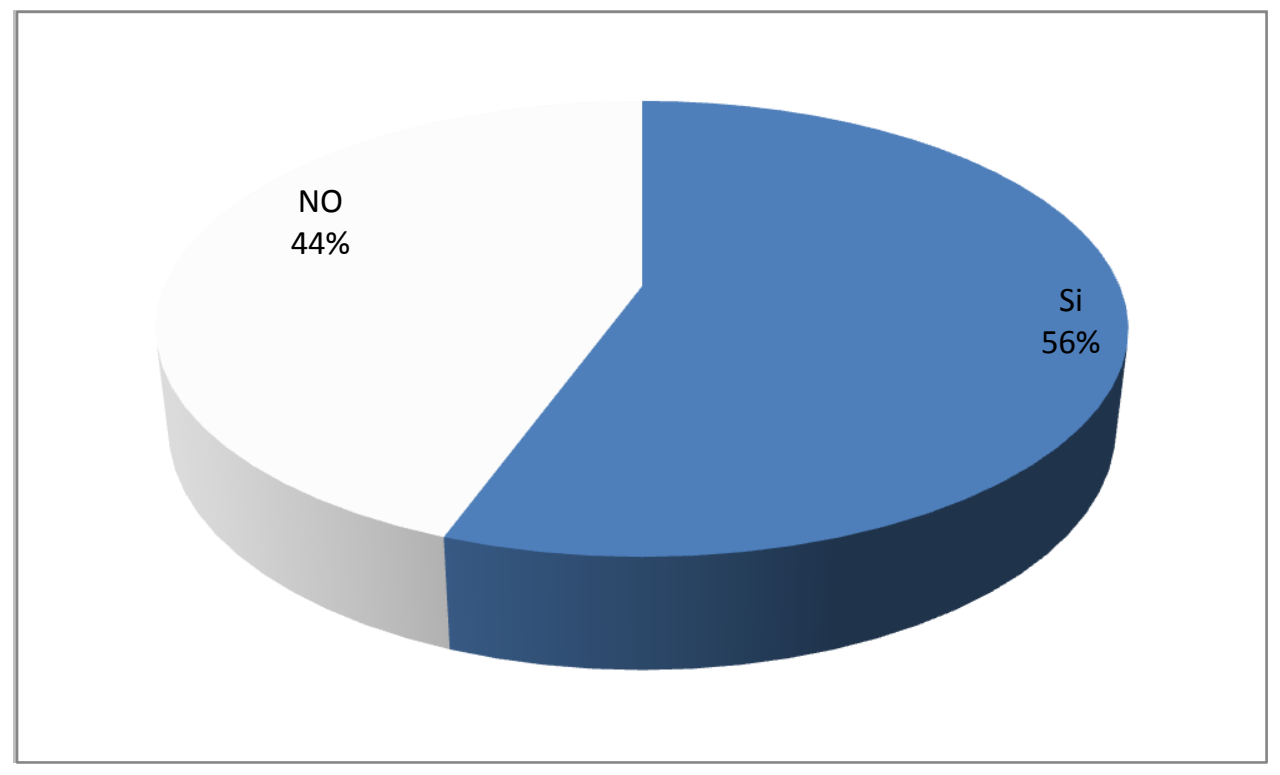

Fuente: Elaboración propia a partir de los datos de las entrevistas

La exclusividad es una característica que se presenta en cerca de la mitad de las experiencias de transferencia de tecnología, de acuerdo con lo señalado por los empresarios.

Figura 15. Necesidad de estímulos para la transferencia de tecnología

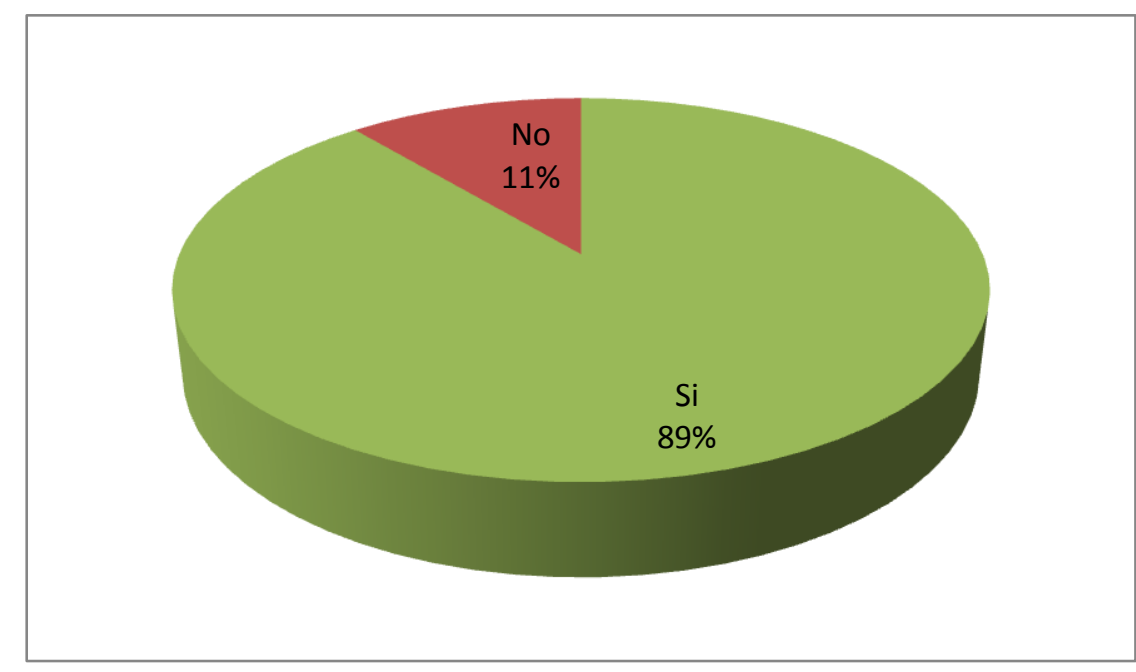

Fuente: Elaboración propia a partir de los datos de las entrevistas 
La gran mayoría de los empresarios entrevistados coincidieron en señalar la necesidad de estímulos de diferente tipo para que se genere mayor transferencia de tecnología; dentro de las medidas sugeridas están el establecimiento de excepciones tributarias,ventajas arancelariasy estímulos crediticios para la importación de tecnología de punta, la simplificación y agilización de los procesos que deben cumplirse en organismos oficiales como Colciencias y la Superintendencia de Industria y Comercio en trámites de patentes, el establecimiento de una política específica del Estados enfocada al desarrollo de la industria automotriz y el apoyo en el tema tecnológico especialmente ante los tratados de libre comercio.

Por último, respecto de las interacciones que adelantan con otras empresas para desarrollar su capacidad innovadora, dos de los empresarios respondieron que lo hacen con productores y distribuidores de equipos y con otras empresas del sector automotor.

\subsection{Discusión de los resultados.}

Tal como se esperaba, la mayoría de las empresas incluidas en la muestra (70\%) adelantan estrategias dirigidas a generar transferencia de tecnología, lo cual indica que fue acertado el criterio con el cual se seleccionó la muestra, pues se trata de empresas que, debido a las fuerzas de la competencia, no pueden quedarse estancadas en esta materia. El hecho de que existan las áreas de diseño, producción y control de calidad sean las que más se interesan por generar transferencia de tecnología es una situación lógica si se tiene en cuenta que se trata de empresas del sector de industria; si se tratara de un sector de servicios 
seguramente la situación hubiera sido diferente, pues el tipo de tecnología que requerirían sería otra; además esta situación también indica que las empresas son conscientes de que el buen resultado en el mejoramiento de sus procesos no lo pueden lograr solo si se enfocan en el área de producción dejando de lado, por ejemplo, el control de calidad, dado que sus clientes, en este caso las ensambladoras, aplican estrictos procesos de recepción de los componentes que ellos suministran.

Este resultado puede implicar que no se están realizando procesos de transferencia sobre aspectos técnicamente muy complejos, si se tiene en cuenta que en el país existen bajos niveles de investigación y desarrollo; sin embargo también puede deberse a que existan sistemas de innovación que funcionen con mayor facilidad localmente que desde otros países, así los saltos tecnológicos que impliquen no sean tan grandes.

La inversión en equipos y en personal capacitado como principales rubros a los que se destinan los esfuerzos en transferencia de tecnología implica que se trata de innovaciones directamente relacionadas con los productos que se fabrican, lo que coincide con el hecho de que son las mismas ensambladoras y la comparación con la competencia las fuentes que les permiten identificar la necesidad de realizar tales inversiones, especialmente para reducir costos, desarrollar nuevos productos y reducir tiempos de fabricación.

Las respuestas dadas con respecto a los mecanismos que las empresas emplean para proteger la tecnología que han adquirido, muestran que ese aspecto no resulta ser una preocupación importante, lo que puede deberse a que esa tecnología está disponible para ser 
adquirida por quien la requiera y que no se trata de grandes secretos cuyo conocimiento genere un real peligro para las empresas; esto coincide con el hecho de que cerca de la mitad de las empresas ha asistido a procesos de transferencia de tecnología que no tiene el carácter de exclusivos. De hecho algunas empresas manifestaron haber transferido parte de esa tecnología a terceros, aunque en la mayoría de los casos esta situación no se ha dado.

La ausencia de mecanismos de estímulo para la transferencia de tecnología coincide con el hecho de que la mayoría de las empresas han adelantado estos procesos sin apoyo del Estado o de las agremiaciones de las que hacen parte.

Analizando los resultados observados en algunos apartes de la entrevista, se evidencia procesos acumulativos del conocimiento. Los procesos de aprendizaje: el $70 \%$ de las empresas entrevistadas utiliza como mecanismos empleados para la transferencia de tecnología la contratación de un experto, el $50 \%$ se inclina por un equipo de expertos. Los feed backs, las fuentes de identificación de necesidades de transferencia de tecnología más significativas son: la sugerencia de las ensambladoras (demanda) y la comparación con la competencia (competividad). Los efectos de la innovación en las mejoras tecnológicas de las empresas seleccionadas para el estudio, se evidencia que el total de las empresas entrevistadas reconocen que los logros generados por la transferencia de tecnología, representan reducción de costos (relación costo beneficio) en sus procesos, productos y servicios, al 70\% les representa desarrollo de nuevos productos (innovación) y al 70\% reducción de tiempos de fabricación (eficiencia). 
Finalmente, los procesos de interacción pública, privada e institucional para el sector no ha habido tales procesos de interacción, en lo que tiene que ver con la innovación, las empresas del sector realizan esfuerzos aislados atendiendo sus propias necesidades, y los retos del sector autopartista y automotriz. 


\section{CONCLUSIONES Y RECOMENDACIONES}

De acuerdo con el referente teórico citado, los sistemas de innovación proveen esquemas complejos y estructurados de organización en ciencia, tecnología e innovación (Aguirre, 2011) y en ellos se identifican cinco componentes: los actores, las redes, los programas estratégicos, la infraestructura y el financiamiento (Chaparro, 1998); teniendo en cuenta esa conceptualización y las respuestas dadas por los directivos empresariales entrevistados, se puede concluir a partir de la muestra seleccionada (50\% de las empresas de Bogotá - Asopartista) que no existe en Colombia un verdadero sistema de innovación en el sector automotriz. Sin embargo sí existen empresas que realizan esfuerzos orientadas a generar transferencia de tecnología, para responder a las expectativas de las ensambladoras y de la competencia.

La innovación en el sector automotor ha generado especialmente inversiones en equipos y en capacitación de personal, y ha provenido tanto de países extranjeros como del interior del país. El destino de esas inversiones se ha centrado en las áreas de diseño, producción y control de calidad, por tratarse de empresas de carácter industrial y sus propósitos han sido la reducción de costos, el desarrollo de nuevos productos y la reducción en los tiempos de fabricación.

La búsqueda realizada hasta el momento, sobre política de posicionamiento competitivo orientada al fomento del desarrollo tecnológico del sector automotor, no arroja datos al respecto. Aunque sí existen organizaciones que apoyan estos esfuerzos, como el 
SENA, Proexport y Colciencias, así como las asociaciones de empresarios del sector de autopartes. Ninguno de los empresarios se refirió a alguna política oficial de posicionamiento estratégico del sector en virtud de la cual se les convoque a participar con el propósito de fomentar la transferencia de tecnología.

Teniendo en cuenta que en el país existe aún un alto porcentaje de población que no tiene vehículo automotor y que el número de vehículos por habitante es inferior al de otros países de Latinoamérica, la conformación de un sistema de innovación en este sector puede propiciar que el tipo de partes que se suministren por parte de proveedores locales incluya cada vez componentes con mayor nivel de complejidad, e inclusive que se logre exportar parte de la producción a otros países, teniendo en cuenta los tratados de libre comercio recientemente suscritos. De no lograrse la evolución tecnológica de los fabricantes de autopartes, esos mismos tratados pueden convertirse en el medio a través del cual los proveedores extranjeros que sí están evolucionando permanentemente en su tecnología, desplacen cada vez más a los proveedores nacionales.

Se recomienda que las empresas del sector automotor, a través de las agremiaciones que los representan, promuevan el impulso de medidas que permitan el diseño y la aplicación de estrategias de investigación y transferencia de tecnología en el marco de la Ley 1286 de 2009, por medio de la cual se e transforma a Colciencias en Departamento Administrativo y se fortalece el Sistema Nacional de Ciencia, Tecnología e Innovación en Colombia, teniendo en cuenta que dicha ley fortalece financieramente a esta institución con recursos del Fondo Nacional de Regalías. Estrategias de este tipo pueden contribuir no solamente a los empresarios, sino aumentar las oportunidades de empleo en este sector. 
Desde el punto de vista académico, se recomienda a las empresas del sector un apoyo decidido en la realización de investigaciones que contribuyan a identificar cuáles podrían ser los componentes que se lograrían fabricar en Colombia si se adelantan estrategias de investigación y desarrollo que permitan la creación o transferencia de tecnología, mediante la conformación de sistemas sectoriales de innovación en los que participen los diferentes interesados, como el Estado, las ensambladoras, Colciencias, el SENA, las agremiaciones de fabricantes de autopartes y las instituciones educativas, entre otros.

Dada la importancia del sector en la generación de empleo, desarrollo y considerando los resultados de las entrevistas realizadas en el desarrollo de los objetivos de la investigación, se sugiere que se conformen mesas de trabajo en las que intervengan el sector privado, el sector público y la academia, para desarrollar una agenda que lleve a objetivos concretos en materia de transferencia de tecnología, buscando en primer lugar la producción de partes originales, cada vez con mayor valor agregado, así como la exportación a mediano plazo a países vecinos.

Se deja abierto un abanico de posibilidades para continuar con el estudio de otros aspectos del sistema sectorial de innovación que aporte elementos para el desarrollo, el crecimiento y reconocimiento del sector automotriz como un sector de talla internacional. 


\section{BIBLIOGRAFÍA}

Aguirre, C. (26 de Agosto de 2011). Colciencias. Recuperado el 13 de Octubre de 2011, de Hay que entender el mundo para innovar: http://www.colciencias.gov.co/noticias/hay-que-entender-el-mundo-para-innovar

Bassedas, E., \& Coll, S. (2004). Evaluación y seguimiento en parvulario y ciclo inicial. Pautas de observación. Madrid: Visor.

Bonilla, E., \& Rodríguez, P. (1997). Más allá del dilema de los métodos. La investigación en ciencias sociales. Bogotá: Norma.

Cámara de Comercio de Bogotá. (2010). Observatorio de movilidad: La oferta de transporte en Bogotá. Bogotá: Cármara de Comercio de Bogotá.

Chaparro, F. (1998). Logros alcanzados y desafíos futuros en el fomento de la innovación y el cambio tecnológico: el caso de Colombia. Bogotá: Colciencias.

Chiappe, C. (2010). Problemas del método y de la enseñanza de la metodología. Recuperado el 10 de Septiembre de 2012, de http://www.pedagogica.edu.co/storage/rce/articulos/6_06pol.pdf

Fátas, F., \& Peris, A. (2003). Sistemas sectoriales de innovación y crecimiento económico. Madrid: Instituto de Investigaciones Económicas y Sociales "Francisco de Vitoria". 
Fátas, F., \& Peris, A. (2003). Sistemas sectoriales de innovación y crecimiento económico. Madrid: Instituto de Investigaciones Económicas y Sociales "Francisco de Vitoria".

Fiducoldex. (2010). Sector automotor colombiano. Invierta en Colombia , 1 (1), 19.

Freeman, C. (. (1997). The 'national system of innovation' in historical perpective. Archibugi, D. y Michie, J. (eds.). Technology, Globalisation and Economic Performance .

Lundvall, B. (1992). National Systems of Innovation. Towards a Theory of Innovation and Interactive. Londres: New York: Pinter.

Malaver, F. (2009). Los núcleos de conocimiento en las apuestas estratégicas de Bogotá y Cundinamarca y los sistemas sectoriales de innovación. Bogotá: Pontificia Universidad Javeriana - Grupo Cinnco.

Malerba, F. (2002). Sectoral Systems of Innovation. Research Policy, 31 (2), 247 264.

Malerba, F. (2006). Sectoral Systems: How and Why Innovation Differs Across Sectors. En R. Nelson, D. Mowery, \& J. Fagerberg, The Oxford Handbook of Innovation (págs. 380 - 406). Oxford: Columbia University.

McKinsey y Company. (2009). Desarrollando sectores de clase mundial en Colombia. Bogotá: Ministerio de Comercio Industria y Turismo de Colombia.

McKinsey y Company;. (2009). Desarrollando sectores de clase mundial en Colombia. Bogotá: Ministerio de Comercio Industria y Turismo. 
Ministerio de Comercio, industria y turismo. (2009). Colombia: la transformación de un país. Sector Automotriz. Bogotá: PROEXPORT.

Proexport. (2009). Colombia: La transformación de un país-Sector Automotriz. Bogotá: Proexport.

Proexport. (2010). Importancia del sector automotor en Colombia y atractivos de inversión. Bogotá: Proexport.

Proexport. (2012). Informe Industria Automotriz en Colombia. Bogotá.

Proexport. (2011). Sector Automotor Colombiano. Bogotá: Proexport.

Stake, R. (1994). Case Studies. En N. Denzin, \& Y. Lincoln, Handbook of Qualitative Research (págs. 236 - 247). New York: Sage Londreas.

Zartha, J. (2011). Sistema de Innovación Agroindustrial. Medellín: Universidad Pontificia Bolivariana. 


\section{ANEXO 1. ENTREVISTAS CON LOS EMPRESARIOS}

\section{BUNDI}

Ingeniero Ronald Martínez de la empresa Bundi, el cargo que tiene el ingeniero es, gerente comercial, la entrevista se realiza el de julio a las 3:20pm tecnología?

¿En la empresa existe una estrategia específica enfocada en la transferencia de

\section{$\mathrm{Si}$}

¿A que área de la empresa se ha orientado estrategias de transferencia de tecnología? A producción, a diseño, a desarrollar de proveedores, a control de calidad, o a otra área?

A producción, diseño y control de calidad.

¿Ustedes tienen diseño acá? Hacen diseño de productos?

Si reglamentares

¿Alguna otra área?

No

¿Las actividades de transferencia de tecnología, se han realizado en el exterior, en el país o dentro de la empresa?

Cuando hablas del exterior como es, ¿del exterior para acá?

Sí, sí señor, o que hayan viajado a capacitarse, de algún proceso especifico? En el país es que aquí mismo lo hayan hecho y dentro de la empresa, ósea que estén haciendo investigaciones, procesos de desarrollo.

La transferencia de tecnología es un conocimiento, entonces ese conocimiento puede ser que aquí y allá a través de procesos de investigación, o procesos de mejoramiento se haya llegado a un ideal que permita un mejoramiento continuo en la generación de productos y que se trabaje sobre el mejoramiento de eso, continuamente. Esa es la transferencia de tecnología interna. Que se contrate personas con ciertas características o cierto perfil para complementar procesos específicos.

$\mathrm{Si}$ 
¿Hasta donde pueda revelar que mecanismos emplea la empresa para la realización de la transferencia de tecnología? Puede ser a través de un equipo, y/o a través de un experto.

A través de maquinas y si, también expertos.

\section{¿Alguna otra?}

No

¿Las inversiones hechas en transferencia de tecnología, están representadas en equipos, maquinas, instalaciones, procedimientos, personal capacitado? ¿algún otro?

Maquinas, adecuación física de la planta, procedimientos y personal capacitado.

¿Esta es una de las plantas?

Esta es la planta en Colombia, hay otras plantas alrededor del mundo.

¿Cómo detecta la empresa la necesidad de transferencia de tecnología?

Por benchmarking, nosotros hacemos benchmarking con nuestras otras filiales, esta compañía tiene más de 100 filiales a nivel mundial, entonces con ellos hacemos algún proceso de comparación, e cuanto a maquinaria, personal, equipos.

¿Hay alguna de esas otras? ¿Asistiendo a ferias especializadas, por comparación con la competencia, por sugerencia de proveedores especializados o por sugerencia de los consumidores?

Por sugerencia de los consumidores y de compañeros.

¿Qué logros ha obtenido la empresa como consecuencia de la transferencia de tecnología? Reducción de costos, desarrollo de nuevos productos, reducción de tiempos de fabricación, reducción de inventarios, o algún otro?

Pues cuando usted habla de reducción de tiempos de fabricación es como decir reducción de costos, yo hablaría de reducción de costos, es eso pues implica, reducción de costos de material, reducción en tiempos de fabricación, nos ha llevado al tema de reducción de inventarios.

¿De qué manera protege la empresa los logros que alcanza como consecuencia de la transferencia de tecnología? por ejemplo patentes o restringiendo algunas aéreas de la empresa, o mediante políticas de contratación de personal?

Lo que pasa es que nuestro producto permite que sea muy difícil copiarlo, nosotros fabricamos sistemas de compulsión de fluidos para tuberías de combustible, otro punto es el acceso de personas externas a la planta, las personas externas son muy pocas. 
¿El acceso a la transferencia de tecnología se ha dado mediante trabajo con universidades o ustedes mismos?

Nosotros mismos, todo hemos sido nosotros mismos.

¿En los procesos de transferencia de tecnología la empresa ha recibido apoyo del estado o agremiaciones industriales?

No

¿La empresa ha transferido tecnología a otras empresas?

No

¿Ha asistido la empresa a procesos de transferencia de tecnología exclusivos?

Pero a filiales, entre filiales, visitamos las plantas y vemos sus procesos y eso lo adaptamos y lo revisamos.

¿Considera que hace falta en el país condiciones que estimulen o faciliten la transferencia de tecnología?

Claro

¿Podría mencionar alguna?

Por ejemplo, excepciones de tipo tributario, que a veces por traer maquinaria cobran bastante, de pronto que haya más, nosotros sabemos que el gobierno tiene mecanismos a través de Proexport, pero se hace muy complejo hacer un proceso, no, eso es una tesis de de una maestría. Es una vaina muy compleja, entonces yo alguna vez hice un proceso y no eso no fue posible.

¿Bundi es colombiana?

No es internacional

¿Más participación internacional que colombiana?

$100 \%$ internacional.

Nosotros tenemos algo en particular, aquí nosotros no recibimos plata de afuera, no hay inversión extranjera.

Si nosotros queremos hacer transferencia de tecnología, si queremos crear un nuevo producto tenemos que con recursos propios, digamos aquí no es que le pedimos a nuestro papa, si usted quiere, produce la plata. Pero aquí, si nosotros queremos crear una nueva planta, o un nuevo producto, y ese nuevo producto requiere contratar nuevo personal, traer nuevas maquinas, tener más instalaciones, toca saber que es con recursos propios, lo que produzcamos nosotros. 
¿Con que empresas, organizaciones e instituciones del sector privado y público tienen interacciones para desarrollar su capacidad innovadora?

Estamos afiliados a Acolfa y con ellos son los que hemos tratado, hemos tratado de estar en proyectos con Bancoldex.

¿Con alguna universidad, hasta ahora no?

No

¿Por ahora no les interesa?

$\mathrm{Si}$, nosotros tenemos muchos proyectos en mente, pero tocario mirarlos.

No sé si le comentaría Fernando, nosotros estamos trabajando en un proyecto de iniciativa de nosotros, donde queremos crear un sistema de mandos medios en mejoramiento continuo de innovación, entonces, este proyecto, con base a una beca que ganamos para irnos a Japón, hicimos un comparativo de Japón-Colombia y encontramos esa gran debilidad, entonces estamos trabajando por medio de Acolfa, y en este momento nos están brindando el apoyo para desarrollar el proyecto.

Muchas gracias ingeniero esa era la entrevista. 


\section{YASAKI}

Buenas tardes, nos encontramos con el señor Hernán Patricio Álvarez, Director de la fábrica de YASAKIS SIMUC S. A, el muy amablemente nos atendió hoy para la entrevista que vamos a realizar como una de las empresas más representativas del sector Autopartista, Don Hernán, el objetivo de la investigación es el análisis de las interacciones, que han fortalecido la capacidad innovadora en los procesos de transferencia de tecnología, en el sector Autopartes en Bogotá.

Como lo dice la entrevista ésta, tiene una nota de confidencialidad, sus respuestas no van a ser divulgadas si no para el uso exclusivo de la investigación y que posteriormente se le socializara los resultados de las entrevistas de las empresas, las cuales hemos trabajado hasta el momento.

Muy bien, la primera parte de la entrevista Don Hernán, son los datos de la identificación del entrevistado, entonces pues el nombre ya lo tenemos, que es, HERNAN PATRICIO ALVAREZ, la empresa es YASAKI SIMUC, el cargo es Director de Fabrica y la fecha pues es 23 de julio del 2012.

¿En la empresa existe una estrategia específica, enfocada a la transferencia de tecnología?

Si nosotros, por ser una compañía manufacturera, dependemos de una corporación, que en este caso es japonesa, lo que transferimos principalmente, son las mejoras en los procesos productivos. Ahí lo manejamos por una herramienta que para YASAKI lo llama NEW YASAKI SISTEM, está enfocada en el sistema de producción de TOYOTA, nosotros, recibimos visitas de funcionarios o viajamos para conocer este tipo de metodologías y buscar la eficiencia, en los procesos productivos.

Nosotros, por ser una compañía de ese estilo, pues si, en Colombia todavía no se desarrollan o se diseña, producto como tal, entonces la innovación viene dada a través del proceso de manufactura como tal.

¿Aquí, como para dar más amplitud de lo que me está comentando, a que áreas de la empresa se ha orientado las estrategias de transferencia de tecnología?

Esta muy enfocada, por ser una compañía de producción, esta muy enfocada al proceso productivo, ¿Tenemos diseño? No, no tenemos diseño, la corporación tiene 5 centros de diseño, ubicados alrededor del mundo, pero no en Colombia. El país más cercano que lo tiene es Brasil, tiene otro en México, como hablando solo de Suramérica.

¿Desarrollo de proveedores?

Ocasionalmente tenemos nuestra principal materia prima, es el cable, que tiene alto contenido de cobre, entonces trabajamos en el desarrollo de trabajadores, muy particularmente con ese proveedor, que es muy grande para nosotros

¿Control de calidad? 
Está muy relacionado con el proceso de producción como tal, ¿Alguna otra área, que usted quiera relacionar, donde hayan hecho, transferencia de tecnología?

La tuvimos en las áreas de desarrollo de producto, entendiendo como lo que llamamos los componentes del arnés, que es listado de componentes, ahí tenemos como asistencia técnica de parte de YASAKI, en lo que tiene que ver con los componentes de los arneses.

¿Las actividades de transferencia de tecnología, se han realizado en el exterior, en el país o dentro de la empresa?

Las 3 opciones son validas, del exterior, porque cuando desarrollamos un vehículo de origen Japonés, donde YASAKI es el diseñador, pues ahí asistimos a las plantas donde se hacen esos arneses.

El último ejemplo seria la, LuvDmax o el Toyota Corea, donde asistimos a formación, en ese tipo de arneses.

En el país porque nos visita personal extranjero, nos hace capacitación en Colombia.

Y dentro de la empresa, porque el visita nuestra empresa, ve nuestros procesos de producción y nos ayuda a mejorarlos e innovarlos.

¿Hasta donde pueda revelarlo, que mecanismos emplean, para la realización de transferencia de tecnología? A través de un equipo de trabajo, a través de un experto?

Más bien de un experto, YASAKI cuenta como con expertos en este caso de procesos de manufactura y esa es la persona que viene y nos jalona como hacia la mejora continua.

¿Las inversiones hechas en transferencia de tecnología, están representadas en: equipos, instalaciones, procedimientos, personal capacitado o cual?

En equipo YASAKI también es un diseñador de equipos de manufactura, entonces un gran porcentaje son equipos YASAKI, donde nos entrena su correcto funcionamiento, procedimientos, porque cuando digamos nuestros procesos también nos incluyen procedimientos y cuando el experto visita la planta, pues nos capacita, en general en la innovación que estamos viendo.

¿Yasaki como detecta las necesidades de transferencia de tecnología? Puede ser por comparación con la competencia, asistiendo a ferias especializadas, donde ustedes se den cuenta de las nuevas tendencias, por sugerencias de proveedores especializados, por sugerencias de los clientes, por otros mecanismos?

Principalmente YASAKI hace una reunión anual, donde invita en Japón a todos sus afiliados, tiene 138 puntos de fabricación alrededor de todo el mundo, entonces invitan a todos los presidentes y vicepresidentes de sus afiliados, YASAKI tiene acuerdos tecnológicos con sus competidores en algunos países, es ahí donde se presentan como las 
necesidades futuras que tienen nuestros clientes, de ahí sale el origen de la innovación en cuanto al producto, luego que el conoce la innovación en cuanto al producto, el diseña el proceso de manufactura para el. De ahí se sale realmente la innovación.

En algunos casos particulares las ensambladoras obviamente piden productos que no son diseñados por YASAKI y traen avances tecnológicos que nosotros debemos atender.

Las ferias no son muy utilizadas por nosotros. Principalmente porque son mas bien para vender equipo.

Competencia, está muy enfocada por YASAKI, cuando analiza sus competidores, nosotros también hacemos arneses de los competidores.

De ahí salen como las primeras necesidades de transferencia tecnológica.

¿Qué logros ha tenido la empresa, como consecuencia de la transferencia de la tecnología? Podríamos hablar de que hay reducción de costos.

Que todavía estamos en la industria, ha habido una reducción importante de costos, porque digamos que en estos países emergentes, casi que todos nuestros costos suben, con relación a IPP pero con los precios de venta deben de mantenerse o reducirse.

¿Desarrollo de nuevos productos?

Sí, estamos atendiendo los nuevos lanzamientos que están haciendo nuestros clientes en Colombia, en Ecuador y Venezuela.

¿Producción de tiempos de fabricación?

$\mathrm{Si}$, nosotros venimos de un tiempo de fabricación bastante largo, donde ahora lo tenemos en una cuarta parte, también hemos reducido los inventarios, tenemos indicadores de gestión para ellos y hemos reducido la plana administrativa de una manera importante.

¿Reducción de inventarios?

Hay reducción que se ve reflejada en los costos, pero, pues hemos hecho los procesos más transversales, lo que nos ha permitido, bajar como la plana administrativa.

¿De que manera protege la empresa los logros que alcanza como consecuencia de la transferencia de tecnología? nosotros podríamos hablar de patentes, por ejemplo de restricción a ciertas áreas de la empresa o mediante políticas de contratación de personal o que otros mecanismos?

Bueno patentes, como no estamos desarrollando producto y lo que hacemos ya es conocido en otros países, pues no somos una compañía que patente lo que cree, entendiendo que lo que crea es más una transferencia de alguien que ya lo tiene. 
Si hay unos sitios de la compañía donde no permitimos tomar fotos y pues cuando hay un visitante, pues nosotros mismos lo llevamos, tenemos unas políticas escritas, que de ciertos niveles de la compañía, son parte de su trabajo, respetarlas y no divulgar lo que tenemos.

Otros mecanismos, básicamente como en la relación de nuestro contrato laboral, queda consignado lo que se hace aquí es propiedad de YASAKI, eso implica que las personas no tengamos el derecho de comunicarlo a otras personas u otras compañías.

¿El acceso a la transferencia de tecnología, se ha dado mediante universidades, digamos han tenido algún trabajo de investigación con universidades que les haya permitido involucrar el tema de transferencia de tecnología?

Hoy en día no lo estamos utilizando, lo utilizamos hace unos años, hicimos un trabajo grande con la universidad, creo que con la tuya, del área del sistema de información, era relacionado hacia sistemas, nuestro sistema de información que manejamos es desarrollado localmente, internamente por nosotros.

Tenemos ingenieros que desarrollan software, no utilizamos algo como el sac, o una herramienta comercial, ahí trabajamos muy de lleno con la universidad para, adecuarlo a nuestras necesidades.

\section{¿Y NO LO VOLVIERON A USAR?}

No, lo desarrollamos ya internamente.

Bueno los grupos de investigación, son también de universidades, aquí de pronto hay funcionarios que pertenezcan a grupos de investigación, que hayan permitido desarrollar algún......?

No hemos llegado hasta ese punto.

\section{¿LABORATORIOS O FUNCIONARIOS U OTROS?}

No realmente, ocasionalmente hemos acudido a universidades y hemos formado como esos grupos de desarrollo, pero ahora de pronto por la misma situación que la confidencialidad, lo estamos desarrollando como internamente.

Hemos con el tema de ACOLFA si participamos con la universidad BUENAVENTURA, desarrollar el pensum de un programa de carreras, pero fue algo que hicimos porque tenemos las personas formadas para ello. Algunos de ellos van a ser profesores de estos temas en la universidad BUENAVENTURA.

¿EN LOS PROCESOS DE TRANSFERENCIA DE TECNOLOGÍA, LA EMPRESA RECIBIÓALGÚN APOYO DEL ESTADO? O DE AGREMIACIONES INDUSTRIALES? 
No ninguno, nosotros lo hemos podido hacer con recursos, lo estamos haciendo con recursos propios, en el caso de ACOLFA hicimos un entrenamiento general que podría darse lo que hicimos el año pasado con el SENA.

¿La empresa ha transferido tecnología a otras empresas?

No, definitivamente no.

¿Ha asistido a procesos de transferencia de tecnología exclusivos?

Si porque tenemos nuestro experto, la misma YASAKI corporación es la que nos transfiere tecnología de manera exclusiva

¿Considera que hace falta en el país condiciones específicas que estimulen o faciliten la transferencia de tecnología?

Bueno nuestro caso, por ser una compañía que pertenece a una corporación, pues no hemos tenido esa limitación, posiblemente para compañías que no sean corporativas sí, porque no tienen quien las desarrolle o les transfiera tecnología,

¿Con que otras empresas organizaciones e instituciones del sector privado y publico, tiene interacciones que le han permitido desarrollar su capacidad innovadora?

Como puedes ver YASAKI es una compañía más bien cerrada, donde es la corporación la que nos transfiere tecnología e innovación entonces no hemos utilizado mucho ni el sector publico ni el sector privado para ello, es realmente la misma corporación la que nos hace este tipo de transferencia y nos lleva hacia la innovación.

¿Conoce su competencia a nivel nacional?

Si hablamos de clientes, los clientes pueden comprar arneses, como a dos fuentes, una es la casa matriz de la que importan sus componentes ECADE, la otra seria nosotros YASAKI, no tenemos competidores en la zona, ósea, hay unos pequeños fabricantes de arneses pero no hay una compañía localmente que nos pueda competir, entonces o somos nosotros o es la casa matriz, dado lo complejo que es este tipo de industria donde tienes que importar más de referencias diferentes y requieres una infraestructura importante no solo en equipo si no en la información que se maneja.

¿Me comentaba que se dedican también al cableado?

$\mathrm{Si}$, pues nos dedicamos al cableado eléctrico, para vehículos, también para las motos y dentro de los vehículos se incluye toda la línea de camiones que se ensamblan en COLOMBIA, ECUADOR Y VENEZUELA.

Bueno Don Hernán, eso era prácticamente la tarea, la entrevista que debíamos realizar, agradecemos mucho su intervención y su colaboración y es muy valiosa la información que nos entrega porque nos permite además de responder a la investigación, y avanzar un poco más en los estudios del sector. 


\section{METALURGICAS JB}

Cargo que tiene la ingeniera es...

-Yo soy la Gerente General de la compañía. - -La gerente general de la compañía, gracias; Y la fecha pues de la entrevista es 25 de julio,

la primera pregunta señora Liliana es ¿En la empresa existe una estrategia enfocada a la transferencia de tecnología? -No.

Entendiendo la transferencia de tecnología como una entrada de conocimiento a la empresa, si como un insumo que puede ser a través de uso de nueva maquinaria, de que se capacite el personal, a través de capacitación de personal específico para ciertas cosas, o el traslado de personal hacia países extranjeros para traer aplicaciones específicas a la producción y mejorar... -Como tal la estrategia que este planteada, así que tú la vayas a buscar digamos dentro del plan de negocios, no está planteada así, pero nosotros dependiendo de la necesidad puntual pues de pronto hemos hecho alguna inversión especifica en tecnología, hemos traído algún equipo que nos supla alguna necesidad y que nos ayude en el tema productivo, pero que este como uno de los ítem dentro de la estrategia como tal planteada, no está así.

Muy bien, ¿En qué área de la empresa se ha orientado la transferencia de tecnología? En producción, en diseño, en desarrollo de proveedores, control de calidad o si tiene alguna otra área.

Están básicamente enfocadas en la parte de diseño y en la parte de producción.

En diseño quiere decir que acá generan productos nuevos. En diseño es que utilizamos software, o de pronto pues software que nos sirva para hacer más fácil el tema de diseño de troquelaría para poder empezar a sacarla en la planta, entonces necesitamos que tengamos como esa herramienta que le permita aquí al ingeniero tener más fácil ese desarrollo de esa troquelaría para que pueda entrar ya a producción. Muy bien, entonces diseño, ¿Y control de calidad? En control de calidad hemos tenido unos equipos que son específicos que nos sirven para el tema de mediciones, puntos específicos en la planta entonces tenemos nuestro laboratorio en metrología pues tiene una buena inversión en el tema, si vamos a entrar ahí si somos fuertes de pronto en el tema de tecnología a nivel de metrología, porque necesitamos garantizar que los procesos que tenemos internos pues cumplen con esos estándares y hay que hacerles un ciclo de medición después de ciertas, de ciertos número de piezas que han pasado dependiendo de la criticidad de la pieza, entonces ahí si tenemos una inversión importante. - ¿Alguna otra área? -No, las tres.

¿La actividad de transferencia de tecnología se ha realizado en el país, dentro de la empresa, o en el exterior? -Nosotros hemos recurrido a todo, o sea hemos tenido en el exterior y en el país, o sea cuando sabemos que aquí hay alguna persona que nos pueda suministrar algún conocimiento especifico en algún tema puntual pues hacemos uso como de las por ejemplo en los equipos de medición entonces esta la Superintendencia de Industria y Comercio, laboratorios de metrología que han estado aquí en Colombia que 
están, han sido acreditados por un laboratorio a nivel externo entonces ellos vienen y de pronto nos dictan el entrenamiento que necesitamos o el tema es enviar un ingeniero fuera del país. -

¿Qué mecanismos emplea la empresa para la realización de transferencia de equipo? Lo que me estaba diciendo, entonces un experto o sino un equipo de personas o equipo maquinaria que, si, total esta como en esas dos, siempre en esas dos ramas se ubican.

Muy bien, las inversiones hechas en transferencia de tecnología están representadas en equipos, instalaciones, procedimientos, personal capacitado todas u otro que podamos agregar. -Están básicamente las que hemos hecho en equipos, y obviamente en el personal Cali capacitado porque pues ya tenemos acá en la compañía las personas como, el experto que ya sabe manejar esa tecnología que nos hicieron en ese momento, esa transferencia de tecnología para el manejo de un equipo especifico entonces ya tenemos aquí ese personal capacitado.

¿Cómo detecta la empresa las necesidades de transferencia de tecnología podríamos hablar de que por comparación con la competencia, asistiendo a ferias especializadas, por sugerencia de proveedores especializados, por sugerencia de los clientes ensambladores o otros mecanismos? -Básicamente nosotros miramos por comparación de no diría yo como competencia, sino de cómo está el mercado en este momento, o sea que me ofrece el mercado que me facilite aquí como las cosas en planta y adicional vamos de la mano hemos mirado el tema de ferias especializadas, donde aquí varios ingenieros se han desplazado hasta alla para mirar y conocer no como participantes, no como expositores pues sino vamos allá es a mirar que es, que nuevo ha salido, que equipo nuevo tenemos en cuanto a que nos acorte aquí el tema de producción, que nos permita ser más versátiles, más flexibles en ese en esos dos puntos es donde centramos la mirada.

¿Señora Liliana exactamente que produce Metálicas JB? -Nosotros hacemos piezas estampadas, entonces son todas las piezas que van debajo por decir algo debajo de la carrocería del vehículo, entonces protector del motor, tenemos todos protector del tanque de combustible, bisagras, pantallas térmicas, pedales, entonces tenemos... -Para todos los vehículos. -Sí, en este momento estamos con las dos ensambladoras.

Muy bien, ¿Qué logros concretos ha tenido la empresa como consecuencia de la transferencia de tecnología? Podríamos decir que reducción de costos, desarrollo de nuevos productos, reducción de tiempos de fabricación, reducción de inventarios... -Todo como enfocado un poquitico a que nos facilite el ese tema del desarrollo de ese nuevo producto, y de la mano con reducción de tiempo de fabricación o sea van como de la mano. -Y afecta también los costos.

¿De qué manera protege la empresa los logros que alcanza como consecuencia de la transferencia de tecnología? Podríamos decir que aquí se restringe el acceso a áreas específicas de la empresa, de pronto patentes o mediante políticas de contratación del personal que ellos firmen alguna clausula de... -La verdad sobre ese tema no, o sea no tenemos así si usted me pregunta tengo un medio como para proteger toda esa estructura 
No, no tenemos, o de pronto también por desconocimiento, de pronto como hace uno esa patente o de cómo hace uno bueno todo eso que uno ha aprendido con esa persona, pues de pronto la que uno dice listo, usted necesita que le devuelva la organización entonces no se puede ir de la organización después de un tiempo pero obviamente todo va basado en rendimiento, pero así como me la preguntas, no, no tenemos una protección como tal del tema tecnológico.

Muy bien, el acceso de transferencia de tecnología se ha hecho mediante universidades, grupos de investigación, laboratorio o funcionarios o algún otro. Básicamente es por el lado de laboratorios y nosotros mismos que entramos como a mirar, los funcionarios mire que tal cosa, hay una perdida, mire que esta maquinaria la van a traer, o hay uno de nuestros proveedores que está importando ahora una maquinaria nueva vamos y la miramos, pero básicamente serian estos dos, funcionarios y laboratorios.

Muy bien, ¿en los procesos de transferencia de tecnología la empresa ha recibido apoyo del estado? -No. -iAgremiaciones industriales? Si, ACOLFA a veces organiza, como ella es la asociación del gremio, nos ayuda a poner en contacto dice oiga mire ACOLFA se dio cuenta que hay una feria que es importante del sector automotriz entonces ellos ayudan como a patrocinar el tema y en ciertas ferias de estas PROEXPORT ha entrado también a ser el apoyo para participar. - ¿Han tenido por ejemplo contacto con Bancoldex, que les haya prestado para algún desarrollo? -No... -iCon ColCiencias? No, no hemos hecho... -No han hecho el intento de pasar algún proyecto. - - Si sabemos que ColCiencias tiene un rubro importante en el tema de innovación y tecnología pero no hemos nunca trabajado con ellos. - ¿Con el SENA? -Tampoco. -No están en el evento que están organizando la DIAN para unos diplomados que si me han nombrado las otras empresas sobre... -No... -No han participado. -No. -Bueno, muy bien,

¿La empresa ha transferido tecnología a otras empresas? -No. Que haya ayudado por ejemplo a proveedores. Pues hemos ayudado en el tema no tecnológico sino el tema de pronto nosotros como somos empresa certificación entonces muchos de los proveedores nos han dicho oiga cuénteme a ver como es y nosotros nos hemos ido como encaminando un poquitico a mostrarles que significa llegar a certificación, que significa tener procedimientos estandarizados, pero en el tema tecnológico como tal que yo le haya hecho una transferencia, no.

- No, okay.

¿La empresa ha asistido a procesos de transferencia de tecnología exclusivos de su producción? -No. -Que ustedes estén reunidos con colegas o con otras empresas que sean... -Que uno diga nos sentamos en una misma mesa y miramos específico ya para el... - ¿O que los hayan invitado a algo así? -No.

¿Considera que falta en el país condiciones específicas que estimulen la transferencia de tecnología? -Sí, a mi me parece que de pronto acá en Colombia nos limitamos un poquitico a solo hacer, fabricar, fabricar, fabricar, cuando el tema de investigación, desarrollo... Todo el tema de investigación me refiero a todo, tanto a 
tecnológica como a dedicarle ese pedacito que en las empresas a veces uno va y mira y dice bueno entonces cual es el departamento de investigación y desarrollo y los presupuestos son muy apretados o muy limitados entonces dicen siempre el área que dicen no, no hay, si tenemos que hacer algún recorte entonces siempre toman como que no, a ese no le damos la importancia que tenemos, pero a mí me parece que sí le falta al país, sobre todo ahora que nos estamos enfrentando a TLC, Corea, Turquía.

¿Hasta ahora les ha afectado, les ha impactado el tema del tratado? -Pues estamos en el tema pues con las ensambladoras pero ya entramos como que ya nos comparamos aquí con el mundo, ya nos dicen bueno usted es competitiva aquí mire lo que está haciendo Corea, mire lo que está haciendo Turquía; Entonces si nosotros también nos quedamos muchas veces en tecnología puede que a nivel mano de obra y todo, nos den los costos, pero cuando nos dicen no es que ellos tienen una maquina que logra que estampe mas piezas por segundo y uno acá dice, no espere porque mi capacidad por más de que yo la ponga a funcionar al full pues la maquina tenga la limitación de que por su característica no me vaya a llegar a dar el rendimiento que me da la otra, entonces a mi si me parece que le hace falta un poquito, yo se que el país está empezando a hacerle ya pero necesitábamos ya andando en eso antes de abrir por decir algo los TLC tan abiertamente con Estados Unidos, con Corea entonces. -Sí, es importante como antes prepararlos. -Prepararlos, aprender de que, porque otros países nos llevan años luz en el tema tecnológico, o sea que uno dice wow como quienes. - $\mathrm{Si}$, y en todos los sectores. -En todos los sectores. -Porque por ejemplo en la educación uno queda perplejo de los avances que hay. -Claro, o sea queda uno como un poquitico Uy dios mío.

Bueno, y para terminar ¿Podría mencionar con que otras empresas, organizaciones e instituciones del sector privado y público tiene interacciones la empresa para desarrollar su capacidad innovadora? -Así como tal, no te digo que los laboratorios, La Superintendencia de Industria y Comercio y de todas maneras lo que encontremos cuando vemos que hay alguna maquinaria que se nos acomoda entonces pero hablamos directamente con el proveedor y empezamos a hacer gestiones, pero que yo tenga entidades ya especificas que yo vea. -Por ejemplo a BanCol me decía que no. -No, de pronto las inversiones que logramos hacer las manejamos a nivel bando pero no utilizando esa línea especial que es exclusivamente para hacer inversiones en innovación y tecnología o proyectos que salgan bajo el tema innovación, pero si sería bueno. -Muy bien Señora Liliana, muchas gracias eso era todo, gracias por atendernos. -Ay no con muchísimo gusto. 


\section{CHAID NEME}

-Buenas tardes Ingeniero Fernando. - ¿Estás grabando? -Sí. -a bueno. -Hoy pues vamos a iniciar la entrevista que nos va a permitir conocer un objetivo principal de mi proyecto de investigación que estoy llevando a cabo como estudiante, candidata a magister en Ciencias Económicas que es el análisis que de las interacciones que han fortalecido la capacidad innovadora en los procesos de transferencia en el sector autopartista en Bogotá, agradecemos que nos atienda y contribuya a esta investigación y al entorno económico, al entorno académico perdón; Para nosotros es muy grato poder tener su entrevista y su participación sobre estos aportes para la investigación, bueno la entrevista está estructurada inicialmente con los datos personales, si usted me lo permite yo los diligencio, el nombre completo del Ingeniero Fernando... -José Fernando Mesa Claros. - De la empresa Chaid Neme. -Del Grupo Chaid Neme. -Del Grupo Chaid Neme. -Mi cargo es Director de innovación y desarrollo tecnológico. -Tecnológico, la entrevista se hace el día 18 a las 3 de la tarde, a las 3:15 exactamente, la primera pregunta que tenemos en la entrevista es, ¿En la empresa existe una estrategia específica enfocada a la transferencia de la tecnología? Sí, si hay una estrategia mirada desde la interacción con entidades del sector publico que hoy promueven la innovación del desarrollo tecnológico particular en las convocatorias con Colciencias y el Sena principalmente, algunas de las empresas también tienen algunas alianzas internacionales en las cuales tienen firmado un contrato de asistencia técnica sobre el cual se pagan unos royalties o unas regalías sobre las ventas anuales con el fin de acceder al conocimiento tecnológico de ciertos productos y ciertos procesos de manufactura o procesos de fabricación de autoparte muy específicos. -Muy bien, ¿Podríamos definir las áreas de la empresa donde se han orientado estas estrategias? -Sí, fundamentalmente producción, yo diría producción manufactura como tal área de gestión o proceso, diseño o desarrollo de productos, nosotros no diseñamos realmente desarrollamos productos, no diseñamos y eso sucede casi en todas las empresas del sector de autopartes. -Las partes que se diseñan son partes... -El diseño es concebido, o sea el concepto de diseño es desarrollar un producto con sus propias capacidades y conocimientos, un producto nuevo, innovador y optimizarlo con sus propias tecnologías de ingeniería pero nosotros proveemos ya a la industria automotriz en Colombia autopartes que han sido desarrolladas en otras partes del mundo, han sido diseñadas por otras empresas a nivel mundial, lo que hacemos en el proceso de desarrollo de productos es que la negociación de la proveeduría de esa autoparte de equipo original a un ensamblador, por ejemplo, para General Motors para el Aveo nosotros conjuntamente con los ingenieros de las ensambladoras iniciamos un proceso que se llama el APQP y un proceso complementario que es el ABEP que es el análisis de detecto de fallas, en todo ese proceso las ensambladoras nos dan muestras físicas de los productos que hemos desarrollado, nos dan planos y nosotros hacemos todo el desarrollo validado y homologado por ellos. -O sea que las áreas que tenemos ahí de producción, diseño, desarrollo de proveedores, control de cantidad entraría... -En algunas empresas puede que si trabajan con el tema de transferencia de tecnología desarrollo del poder, caso que te acabo de comentar las ensambladoras nos dan transferencia, nos hacen transferencia técnica como proveedores, o sea nos desarrollan como proveedores de equipo 
original en calidad también o sea producción, diseños y desarrollo de productos como quiero nombrar con esta aclaración y control de calidad. -iY alguna otra área? -No, no no lo veo tan explicito, por lo menos en nuestra organización hacer una transferencia, contratar o... No, la veo enfocada en esas 3 áreas. -Muy bien Ingeniero, ¿Las actividades de transferencia de tecnología se han realizado en el exterior, en el país o dentro de la empresa? -Las tres, porque desde el exterior, yo diría o sea se han realizado, es una transferencia desde el exterior si, internamente dentro del país también, e internamente dentro de la empresa también, inclusive en este preciso momento en el tema de mejoramiento continuo, internamente dentro de la organización inclusive estamos creando sinergia para mirar las mejores prácticas de mejoramiento continuo entre las empresas del grupo, eso es un proceso de transformación de mejoramiento interno dentro de la organización. - ¿Y hay alguna entidad del exterior que les esté brindando algún apoyo? Sí, hay empresas como te digo, empresas que son aliadas internacionales nuestras o con quien tenemos una relación comercial para poder desarrollar una parte que no necesariamente va para el equipo original pero que puede ir al mercado en reposición y que va con el apoyo de una marca internacional, por ejemplo, en el caso de las pastillas para frenos se tienen licencias de varios fabricantes de pastillas en el mundo, está Bosch, está... Se me olvido, varias Japonesas entonces con ellos se hacen acuerdos en los cuales nosotros podemos desarrollar la parte de venderlo en estos mercados regionales, exportarlo y ese acuerdo implica que ellos no van a penetrar esos mercados y nos dan la licencia, en contra prestación nosotros pagamos regalías un royalties por esa licencia sobre las ventas de esos mercados de ese producto. - -Hasta donde pueda revelarlo Ingeniero ¿Qué mecanismos emplea la empresa para la realización de transferencia de tecnología, en términos de un equipo, en términos de un experto o de algunas otras manifestaciones que se puedan realizar? -En general es con un experto, o sea cuando, cuando vienen en el caso de las alianzas que tenemos con los Coreanos ellos vienen nos hacen una visita técnica y ese experto propicia parte de la transferencia de tecnología. -Muy bien, Las inversiones hechas en transferencia de tecnología están representadas en equipos, en instalaciones, en procedimientos, en personal calificado ¿y qué otros podríamos incluir? -Están fundamentalmente, ahí están todas... Pero fundamentalmente equipos, procedimientos y personal capacitado, procedimientos o técnicas. - ¿Cómo detecta la empresa las necesidades de transferencia de tecnología, por comparación con la competencia se han hecho estudios últimamente donde podríamos afirmar que, que hay evidencia de estas necesidades, asistiendo a ferias especializadas, por sugerencia de proveedores especializados, por sugerencia de los clientes o sea de las ensambladoras, o que otro mecanismo nos podría informar sobre como la empresa detecta esas necesidades? Aunque no se hagan estudios pero esto es como esa voz del mercado del negocio, si se hace una comparación con la competencia, conocemos nuestros competidores internacionales y por supuesto hacemos una comparación pero no tan estructurada como un estudio, es mas como el día a día, voz a voz; Y surge mucho esta actividad asistiendo a las ferias especializadas. -Ustedes asisten. -Sí, totalmente. -A nivel internacional, a nivel nacional... -No, nuestros agentes, sobre todo los agentes comerciales asisten sagradamente cada año a ferias del sector que se realizan en México, una que se realiza en Guadalajara, la que se realiza ahora en Octubre en Las Vegas, otra que se realiza en Alemania, que son ferias comerciales de autopartistas, entonces ahí estas personas del área 
comercial pues empiezan a medir las necesidades de adquirir o de transferir nueva tecnología, si para el desarrollo... -Ahí ustedes se informa para estar al día. -Si claro, y también por supuesto sugerencia de los clientes, de las ensambladores, entonces si asistiendo a ferias y por sugerencia de los clientes. -Muy bien ingeniero, ¿Que logros concretos ha tenido la empresa como consecuencia de la transferencia de tecnología? Podríamos hablar de un periodo de tiempo, los últimos cinco, entre cinco y ocho años que podríamos decir reducción de costos... -Prácticamente las tres primeras, o sea como consecuencia de estos mecanismos de transferencia de tecnología por supuesto del desarrollo de nuevos productos, diría yo, los mismos productos de nuestras unidades de negocio pero con diferentes prestaciones o diferentes versiones y diseños, si, y por supuesto en todo esto le apuntamos a la reducción de costos y reducción del tiempo de fabricación, a ver que otro se me ocurre... Aumento de productividad, fundamental. -De que manera protege la empresa los logros... - Ah y mejoramiento de la calidad. -Calidad, ¿ustedes tienen alguna certificación? -Todas las empresas nuestras tienen certificación. -Nacional y alguna internacional... -Internacional, no, tienen certificación internacional de ISO TS 16049 que es la normal mundial que certifica los proveedores para equipo original de la industria automotriz, entonces todas nuestras empresas ya llevan más de diez años, ciclos de tres años de certificación, seguimiento, recertificación de este sistema. -Muy bien, excelente, ¿De qué manera protege la empresa los logros que alcanza como consecuencia de la tecnología? Podríamos hablar de patentes, aunque como o se genera productos nuevos... -No, además de la propiedad industrial, la protección de las marcas. -La protección de las marcas. -Protección de las marcas, registros. -Hay alguna restricción en accesos, de acceso a las áreas en alguna de las empresas en producción... -No, en general lo único que no se permite en las visitas industriales a las plantas es tomar fotos o videos, no se está permitido en ninguna planta. Pero no hay así restricciones de visitas, las empresas son muy abiertas a visitas de potenciales socios, inversionistas, a visitas de potenciales clientes, de las universidades, colegios, en fin; Pero se protegen con realmente con la parte comercial, las partes. -Muy bien, Podríamos definir que el acceso a la transferencia de la tecnología, de tecnología se ha dado mediante universidades, grupos de investigación, laboratorios, funcionarios o otro tipo de mecanismos. -En algunos casos, en algunos casos, no es pues muy frecuente pero si hemos tenido algunos proyectos con universidades y grupos de investigación, pero fundamentalmente el acceso se da es mediante el pago de las regalías de los royalties a las licencias para asistencia técnica o desarrollo de producto, fundamentalmente es el mecanismo que ha predominado en este grupo y me atrevería a decir que en toda la industria, hay casos puntuales en los que sí, claro se trabajan con universidades, grupos de investigación, si. - ¿En los procesos de transferencia de tecnología la empresa ha recibido apoyo del estado o de algún tipo agremiación industrial? -Del estado si, hemos recibido recientemente del SENA fundamentalmente, del SENA, a través de las convocatorias de... del área de igualación de desarrollo tecnológico de SENA. $\quad-i$ Y en agremiaciones industriales? Por ejemplo ACOLFA -ACOLFA, Del estado yo diría el SENA, el ministerio de industria y comercio y programa de transformación productiva, y ahí entramos con ACOLFA. -ACOLFA, Muy bien, ¿la empresa ha transferido tecnología a otras empresas? - ¿De autopartes en Colombia? -Sí. -No. - ¿Ha asistido la empresa a procesos de transferencia de tecnología exclusivos, con presencias de colegas en donde se muestre, se divulgue algún 
proceso en los que ustedes hayan avanzado un poco más que los otros? -No, no, no. Considera que hacen falta en el país condiciones... -Pero sin embargo acá hago la aclaración. -Sí. -En este momento hay una experiencia interesante un nove... muy nueva en la cual el programa de transformación productiva por iniciativa propia varias empresas, incluyendo varias nuestras del grupo, a través de las personas que han recibido apoyo del estado, en asocio con una corporación de ayuda, se llama JICA, JICA en español, es una corporación de apoyo a la industria Japonesa y la participación de ingenieros de varias empresas en los programas de JICA en Japón en temas de mejoramiento continuo, hoy se están reuniendo y digamos que, que digamos que sería aquí como novedoso en ese sentido para compartir sus mejores experiencias en lo que se llama Kaizen es como una de las herramientas del mejoramiento continuo, entonces digamos que eso pues... -No se hacía antes... -No se hacía antes, y es la primera vez que hay un trabajo muy asociativo, muy colaborativo de mostrar lo que se está haciendo en las empresas. -Muy importante. - Sí. -Muy bien, ¿Considera que hacen falta en el país condiciones especificas que estimulen o faciliten la transferencia de tecnología? - $\mathrm{Si}$, a pesar de que en los últimos años el gobierno ha mostrado el interés de promover y dar apoyo con financiación a iniciativas o proyectos de desarrollo tecnológico que implican transferencia de tecnología, hace falta como, hace falta una política industrial de la industria del sector que en alguno de sus capítulos establezca como política industrial del estado, la participación permanente y el apoyo a la transferencia de tecnología en este industria; Se ha hecho, se ha venido desarrollando el Programa de transformación productiva es una buena muestra de ello, pero digamos que eso no está enmarcado aun dentro de un esquema de una política industrial, y nos hace falta una política industrial para, para la industria automotriz en Colombia. -Muy bien, Ingeniero ¿nos podría mencionar si la empresa se relaciona con otros agentes, con otras empresas autopartistas fuera de lo que usted me acaba de mencionar de los momentos exclusivos para apoyar la capacidad innovadora de las empresas? ¿Para desarrollarse? ¿Para fortalecerla? -No. -A nivel nacional, no. -No, o sea que sea ¿Cómo? Como se había hablado... -Interactivo... -Una buena interacción, no. -Con otro tipo de agentes... - ¿Cómo? -Como por ejemplo, Universidades o centros de investigación de otro país. - ¿De otros países? -Sí. -Universidades de otros países o centros de investigación, no. -No. -No, lo que tenemos como te dije al comienzo internacionalmente es alianzas con, con centros de investigación pero con empresas líderes en la fabricación de las autopartes que nuestras empresas fabrican, las empresas internacionales lideres, por ejemplo en fabricación de resortes, que es el caso específico de una de nuestras empresas, tienen una alianza de muchos años, mas de cómo doce años, con una empresa Coreana que tienen sus grupos de investigación y su centro tecnológico y nuestros ingenieros, y nosotros también han tenido la oportunidad de ir a ese centro tecnológico, a ese centro de investigación y ser partícipe de eso, pero con universidades no; El tema va a cambiar el año entrante porque nosotros alrededor de un programa con el SENA tenemos en este momento tres y van a ser cuatro Ingenieros que están haciendo una maestría en la Universidad Nacional, y ellos el año entrante tienen que ir, someterse a una pasantía internacional e ir a alguna universidad de renombre para que continúen o fortalezcan su proyecto de investigación; Entonces ahí si se va a dar se va a comenzar a dar como una alianza como un contacto o una transferencia de tecnología. -Para poder hacer, traer más conocimiento. -Con una universidad internacional, pues en este momento no, 
pero el año entrante ya vamos a tener este esquema. - Ok ingeniero, bueno esas eran las preguntas que nos interesaban para el desarrollo de la investigación, agradecemos ingeniero de su tiempo, de su constante apoyo que a tenido y además porque es mi asesor temático de mi, de mi proyecto. 


\section{COLOMBIANA DE FRENOS}

Bueno estamos con el señor, Miguel Acosta jefe de ingeniería y calidad de Cofre, Colombiana de Frenos, quien fue referenciado por el Doctor Luis Guillermo Viveros Gerente General y nos va atender hoy en la entrevista con el fin de darle respuesta al objetivo que es análisis de las interacciones que han fortalecido la capacidad innovadora en los procesos de transferencia de tecnología en el sector Autopartes en Bogotá, la fecha en la que se realiza es el 25 de julio a las 7.10 de la mañana, Entonces : tecnología?

¿En la empresa existe una estrategia específica enfocada en la transferencia de

Miguel Acosta: Emm Sí, si existe un estrategia se dicta digamos desde el plan de negocios, el balance score card que maneja la empresa entonces hay definidos unos proyectos de inversión enfocados en ese sentido

Muy bien ¿a qué áreas de la empresa se ha orientado las estrategias de transferencia de tecnología, al área de producción, al área de diseño, de desarrollo de proveedores, de control de calidad o a otras?

Miguel Acosta: En principio pues se desarrollan para producción, si digamos porque el fuerte de la empresa pues es la parte productiva entonces todo está enfocado tal vez en un $80 \%$ o $90 \%$ a producción, ya lo que tiene que ver con la parte de diseño se le asigna un ........(no entendí que dijo)

¿Hay diseño acá?

Miguel Acosta: Hay hacemos diseño de los rines, digamos en mercado aquí por general se mueve de dos formas, primero es haciendo la copia de un rin que nos manda un cliente; digamos una ensambladora y el otro es haciendo alguna propuesta rente al requerimiento de las mismas ensambladoras depende, se puede hacer de esas dos formas

Ya muy bien ¿Algún otra área?

Miguel Acosta: No son principalmente esas dos

Muy bien ¿la actividad de transferencia de tecnología se ha realizado en el país, dentro de la empresa, en el exterior o en todas?

Miguel Acosta: En todas, en el exterior pues hemos digamos enviado personal digamos no recientemente pero si se a enviados personas fuera del país para que conozcan los procesos, de pronto miren alguna maquinaria que estén en desuso pero en buenas condiciones de otras plantas que fabrican rines y se traiga para cofre, es sucedió más o menos la última vez en el año dos mil...No mentiras el año pasado sucedió una parte y hacia atrás como en el dos mil cuatro o dos mil cinco se hizo esa parte

¿Aquí producen además de rines todo lo que tiene que ver con...? 
Miguel Acosta: Digamos producimos rines es esa la función principal de la empresa y se envasa líquido para frenos esa es digamos la empresa nació como un fabricante para líquido de frenos

Bien ¿En el país y dentro de la empresa?

Miguel Acosta: ¿A qué se refiere con dentro de la empresa?

En la empresa, por ejemplo que ustedes se autoalimenten con temas de conocimiento, por ejemplo que trabajen en temas de investigación y que ustedes mismos se cuenten desarrollos y se, digamos hayan reuniones mensuales, continuas sobre algún tema en especial para el mejoramiento de ese tema

Miguel Acosta: pues digamos se definen algunos temas críticos como problemas digamos dentro de la panta y se hacen equipos de trabajo para darle solución a esos temas pues utilizando diferentes herramientas.

¿Bueno de pronto que tenga que capacitarse con alguna entidad y venir aquí?

Miguel Acosta: se está trabajando también con COLFA y con la EAN en unas capacitaciones y unos diplomados para unas personas

Aaa ustedes también están en aliados, ¿y no van a participar en el DIANIS?

Miguel Acosta: No sé ese no lo he escuchado, hemos participado con la EANE y con la COLFA que ha sido como el convenio que se ha logrado, también hay pues algunas personas capacitan en algunas universidades pues en convenios entre la empresa y el SENA o por la empresa ¿si?

Muy bien ¿Qué mecanismos emplea la empresa para la realización de transferencia de tecnología, normalmente con un experto o con un equipo de personas?

Miguel Acosta: Por lo general se trae un experto

¿Algún otro mecanismo?

Miguel Acosta: No, Digamos el experto es el que nos ha ayudado en el tema de la fabricación de los rines se contrata a una persona que ha trabajado en otra empresa digamos en Estados Unidos, es por lo general lo que hemos usado

Muy bien ¿Las inversiones hechas en transferencia de tecnología están representadas en equipos, instalaciones, procedimientos, personal capacitado u otros?

Miguel Acosta: En equipos si y en personal capacitado

Muy bien ¿Cómo detecta la empresa las necesidades de transferencia de tecnología por comparación con la competencia, asistiendo a ferias especializadas o sugerencia de proveedores especializados, sugerencia de los clientes o sea las ensambladoras u otros mecanismos podría decir cuáles? 
Miguel Acosta: Bueno hemos, en principio digamos por sugerencia de los clientes porque ellos digamos el mercado automotriz es muy dinámico y va revolucionando muy rápido entonces todos los materiales y las maquinas asociadas para transformar esos materiales nos hacen ver la necesidad cambiar la tecnología y de mejorarla, en la parte de comparación con la competencia y lo que tiene que ver con sugerencia de los proveedores especializados entonces tenemos contactos con los fabricantes de maquinaria para producir rines y ellos nos envían pues su portafolio buscando que nosotros mejoremos la capacidad de la empresa, ahí hay una limitante en cuanto a los volúmenes pues esa maquinarias producen digamos 4 o 5 veces más de lo que nosotros producimos entonces quedaría una capacidad ociosa pues el volumen en Colombia no es tan grande

Ya ¿y están exportando?

Miguel Acosta: Estamos exportando pero de unos productos específicos.

A muy bien ¿Qué logros concretos ha tenido la empresa como consecuencia de transferencia de tecnología? .Podríamos decir que reducción de costos, desarrollo de nuevos productos, que reducción de tiempo de fabricación, reducción de inventarios u otros.

Miguel Acosta: Hemos reducido lo que tiene que ver con tiempos de fabricación o sea somos más productivos, la parte de reducción de costos porque las maquinas generan menos errores con las maquinas más recientes mejor dicho, y desarrollo de nuevos productos porque ya con una nueva maquinaria podemos acceder a un tipo de mercado más especifico

¿Y lo han vivido?

Miguel Acosta: Si, eso se ha notado

Muy bien ¿De qué manera la empresa protege los logros que alcanza como consecuencia de la transferencia de tecnología, con patentes, restringiendo el acceso a ciertas áreas de la empresa, mediante políticas de contratación de personal o que otro tipo de mecanismo utilizan?

Miguel Acosta: Digamos que no tenemos ningún mecanismo que proteja

Lo que ustedes está abierto

Miguel Acosta: Exacto

Muy bien ¿El acceso a la transferencia de tecnología se ha dado mediante universidades que de pronto hayan tenido algún contacto con los grupos de investigación con laboratorios específicos o con funcionarios u otros?

Miguel Acosta: Bueno hemos tenido la parte con las universidades con bueno los grupos de investigación de las universidades o personas que van a estudiar a las universidades donde se plantea que investigación se tiene 


\section{¿Han desarrollado proyectos?}

Miguel Acosta: hemos desarrollado un.... Bueno algo que se llamaba, algo que tenía que ver con tecno algo del Sena una convocatoria que tenía varias fases, la primera era un análisis de cómo estábamos nosotros en cuanto a tecnología, en qué estado estábamos si erramos maduros u obsoletos.

¿Y cómo les fue?

Miguel Acosta: Digamos que muchas están obsoletas, mucha maquinaria ya es obsoleta, pero hay procesos que están maduros, digamos la parte de pintura en Colombia hasta donde yo sé solo hay 3 plantas que tienen el sistema de pintura que nosotros tenemos, las dos son ensambladoras que son Renault, GM y nosotros somos la otra que tenemos ese sistema de pintura

\section{Incorporaron ese nuevo conocimiento}

Miguel Acosta: Exacto, si eso sería lo que principalmente manejamos y con las universidades pues la persona que está tomando una maestría en resultado de tecnólogo que es la fase dos, que es formar personas en maestría o en doctorado para que el proyecto de investigación sea en función de un problema o de mejorar algo de la empresa entonces estamos por ese lado también estado?

¿En los procesos de transferencia de tecnología la empresa ha recibido apoyo del

Miguel Acosta: Si con lo del Sena

\section{¿Y COLCIENCIAS?}

Miguel Acosta: Con COLCIENCIAS no hemos podido todavía hacer ningún acuerdo porque es muy difícil cumplir todos los requisitos, a veces son muy complicado cumplir todos esos pliegos y nosotros somos técnicos en fabricar rines o en fabricar las piezas que nosotros hagamos en las diferentes empresas del grupo, pero ya a veces los requisitos técnicos para llenar un formulario, uy eso es una cosa muy complicada

\section{¿Y aparte agremiaciones industriales? .Por ejemplo la COLFA}

Miguel Acosta: pues lo de la COLFA y la EAN que digamos ahí hay una asociación donde todos los diplomados las empresas afiliadas no están pagando nada.

Muy bien esa es una ayuda, ¿podríamos decir que han recibido un apoyo financiero?

Miguel Acosta: No, no la empresa hasta donde yo sé no ha recibido, digamos lo de COLCIENCIAS seria el apoyo financiero o financiado o sea una parte de COLCIENCIAS pero no, esta lo del Sena por ahora. 
Muy bien ¿La empresa ha transferido tecnología a otras empresas del sector Autopartista?

Miguel Acosta: Pues digamos que cofre antes hacia muchas cosas aparte de hacer los rines y envasar el líquido, hacíamos partes de caucho de los sistemas de frenos, había una zona de cauchos, había otra parte donde se hacían las mangueras de los sistemas de frenos entonces todo eso digamos se salió de cofre, se vendió y se entrego a otras empresas del grupo para que fabricaran, una fabrica los cauchos y la otra lo que son las mangueras, eso pues viéndolo desde ese punto de vista seria transferir la tecnología

¿Han asistido a procesos de transferencia de tecnología exclusivos por ejemplo de rines que sean solamente con empresas, con colegas que sean productores de ese mismo bien

Miguel Acosta: Si digamos eso se hacía cuando había como... en Estados Unidos hay una empresa que se llama MarshallWheels y nosotros tenemos un acuerdo tecnológico entonces hay como una licencia entonces de cofre iban personas allá, se reunían con las personas de allá entonces aprendían muchas cosas, si fuera una reunión exclusiva con colegas

¿Considera que falta en el país condiciones específicas que estimulen la transferencia de tecnología?

Miguel Acosta: Bueno es que no sabría decirle o sea si hay alguna ley o algo que facilite eso pero, bueno tal vez lo de COLCIENCIAS si es muy difícil acceder a una cosa de COLCIENCIAS entonces si habría necesidad de que estimule porque pues uno empieza a llenar eso y le ponen muchas trabas entonces uno como gasta o invierte mucho tiempo y al final no se ve ningún resultado

"y de pronto la empresa ha tenido procesos frustrados de transferencia de tecnología precisamente porque se desaniman, no hay ayuda, no hay apoyo nosotros solos"

Miguel Acosta: Pues digamos lo de COLCIENCIAS, pues digamos lo otro con Tecnova bueno que ha pasado también otro caso que tratamos de hacer, no es que sea difícil solo que es demasiado lento y se demora mucho que fue con Tecnovaentonces definimos "oiga tenemos estas cosas que nos gustaría investigar" hay una lista como de proyectos que nos gustaría mejorar y tener transferencia de tecnología mediante conocimientos de su grupo de investigación y universidades a través de Tecnovanuestro contacto hay una feria de Tecnova allá en Medellín se hizo como una rueda de negocios con diferentes grupos de investigación, se les propuso cual era la situación que teníamos, se hicieron los contactos luego empezamos "Oiga, correo Va" mire esto es lo que yo realmente necesito, necesito que me llene esto, las universidades, se enviaban entonces ese proceso es muy lento y digamos que Tecnovanos ayudo a hacer los contactos y digamos que a hacer la parte con COLCIENCIAS pero pues Tecnovacobra un porcentaje de lo que cuesta el proyecto, pues porque esa es su parte facilitar ese tipo de recursos del estado 
¿Podría mencionar con que otras empresas, organizaciones e instituciones del sector privado o público tienen interacción en la empresa para desarrollar su capacidad innovadora?

Miguel Acosta: Digamos con otras empresas, las empresas del grupo entonces compartimos experiencias o sea que están haciendo bien allá, vamos allá y aprendemos o ellos vienen acá y aprenden eso, es así; con el sector público o privado las universidades y el publico el Sena o sea como otros entes como tal no solo ese.

¿Bancoldex, Proexport, Fiducoldex?

Miguel Acosta: Bancoldex pues un crédito laboral para hacer inversión en una maquina

A bueno eso es importante

Miguel Acosta: Si, Exacto se consiguió así, pues yo no sé si sea así que pueda mencionar, cofre en el dos mil nueve se gano un premio de seguridad industrial con Sura y pues ellos aportaron un dinero que se invirtió en una maquinaria para evitar que, mejorar las condiciones de salud y seguridad, eso se podría nombrar ahí de pronto en ese sentido como un aporte

Eso esa todo Ingeniero muchas gracias, esa era la entrevista le agradezco su apoyo y su tiempo. 


\section{ESPUMLATEX}

\section{LOS SALUDO Y LE DOY GRACIAS DON CARLOS ACERO POR RECIBIRNOS HOY EN SU EMPRESA, EMPRESAS ESPUMLATEX}

\section{LA EMPRESA ES DE QUE?}

Se fabrican las espumas moldeadas para la cogineria de los carros, los insinerizantes para los carros, tanto interiores como exteriores y fabricamos accesorios también para los carros. reposición.

Todo lo que fabricamos nosotros va para equipo original no tenemos para ¿ESTA ES LA PLANTA PRINCIPAL?

$\mathrm{Si}$

¿TIENEN OTRAS EN COLOMBIA?

Tenemos otra en Funza, otra en Medellín, y tenemos otra en armenia.

Bueno, el objetivo de la investigación es el analisis de las interacciones que han fortalecido la capacidad innovadora en los procesos de transferencia de tecnología.

Vista la transferencia de tecnología como una accion que les permite el mejoramiento, por ejemplo, de los trabajadores o la inyeccion de nueva maquinaria, o la inyeccion de nuevos procesos, o la capacitacion para generar nuevos productos.

Es hacia ese horizonte, en el sector autopartes en bogota.

Esta entrevista tiene una nota de confidencialidad, o sea estas respuestas que nos va a entregar, no van a ser divulgadas, si no solamente el tema de la investigación y solamente las empresas que estuvieron participando, conoceran los resultados.

¿en la empresa existen estrategias especificamente enfocadas en la transferencia de tecnología?

$\mathrm{Si}$

¿enqueareas de la empresa se ha orientado las estrategias de transferencia de tecnología? ¿produccion, diseño, control de calidad u otro?

Lo que esta enfocado al tema de producción, desarrollo de proveedores, en el tema de control de calidad, también hay transferencia de sistemas de tecnología, de calidad, de sistemas de control de calidad, de tecnología sobre el mejoramiento continuo.

Para nosotros el tema de transferencia de tecnología está enfocada, en el desarrollo de las materias primas, desarrollo de materiales, sustituciones de materiales, digamos 
materiales alternativos y lo que hacemos nosotros en apropiación de tecnologías o en adaptación de tecnologías a las condiciones del mercado local.

¿las actividades de transferencia de tecnología se han realizado en el exterior, en el pais o dentro de la empresa?

Yo creo que hay dentro de las tres, dependiendo del marco en el que uno trabaje, hay cuestiones que nosotros hacemos, pero la gran mayoría de los temas, sobre todo en el tema de innovación en materiales, en procesos, en todo eso, viene del exterior. Y viene transferido, digamos de, ya de la experiencia y conocimiento en procesos similares en el exterior.

Y dentro de la empresa y en el país pues va mucho más a metodología o a proyectos que se han hecho acá, digamos como el mgc para el desarrollo de la competitividad, de la calidad.

A los procesos de mejoramiento de calidad, está dentro del país.

¿Dentro de la empresa se hacen actividades para el tema de transferencia de tecnología? ¿capacitaiones especiales sobre mejoramiento en procesos?

$\mathrm{Si}$, continuamente, y a diferentes niveles, dependiendo de lo que se .....

¿hastadonde pueda indicarnos, que mecanismos emplea la empresa para la transferencia de tecnología? ¿atraves de un experto, equipo o a traves de otros mecanismos?

Hay diferentes mecanismos el principal tema nuestro, es un tema de vigilancia tecnología y con base a esos temas miramos a través de quien o contactamos las fuentes.

otro tema que trabajamos nosotros, es con el tema de proveedores en el exterior, otro tema que nos ayuda a nosotros mucho, es sobre las tendencias, digamos en lo que concierne a los desarrollos de nuevos productos.

Acá se trabaja con un equipo de gente que está en el tema de los desarrollos, en el tema de la innovación, en el tema de la ingeniería, y digamos lo que vengamos a buscar de afuera seria con una asistencia externa.

¿las inversiones hechas en transferencia de tecnologíaestan representadas en equipos, instalaciones, personal capacitado, otros?

Lleva todo eso, todo eso está involucrado y no solo el tema de capacitación interna sino también capacitación afuera a los proveedores y digamos el desarrollo como en equipo, de las cuestiones y la adaptación de los materiales dentro de los procesos y las necesidades que nosotros tengamos acá.

¿como detecta la empresa, las necesidades de transferencia de tecnología? 
Digamos, uno de los temas que jalona principalmente, el proceso, o sea son dos, los que más jalonan el proceso, tema de competitividad y un tema en las tendencias en los desarrollos de los productos en el cliente.

¿asisten a ferias especializadas, por sugerencia de proveedores especializados?

Si, también.

¿por sugerencia de los clientes u otros mecanismos?

Si también hay de todo eso, no puedo decir que es una sola, porque obviamente esta el tema de la vigilancia tecnológica, donde uno mira la competencia, ¿qué está haciendo?, ¿como lo está haciendo?, ¿hacia dónde va?

Eso va muy ligado, con la sugerencia de los clientes o las tendencias que uno vea en los mismos clientes. Entonces ahí uno viene y busca, en donde está la tecnología, quien es el dueño de la tecnología, quien es el dueño de la información, para buscar donde se hace.

¿qué logros ha obtenido la empresa como consecuencia de la transferencia de tecnología? ¿reduccion de costos, de desarrollo de nuevos productos de reduccion de tiempos en la fabricacion, reduccion de inventarios?

Si todo, nuevos procesos, nuevas tecnologías, implementación de nuevas tecnologías, sustituciones de materiales.

¿deque manera protege la empresa los logros que alcanza como consecuencia de la transferencia de tecnología? Patentes, restriccion al acceso a ciertas areas de la empresa, mediante politicas de contratacion de personal, o cual otro mecanismo?

Yo creo que puede ser más o menos hacia el tema de las dos últimas, hay cosas de información que nosotros manejamos con restricción, tenemos políticas de confidencialidad que deben firmar los empleados, que tienen acceso a cierto nivel.

¿por ejemplo los que trabajan en el area de investigación?

$\mathrm{Si}$, los que tienen acceso a cierta información que para nosotros es, digamos como nuestro diferenciador.

¿tienenareas restringidas?

No, realmente no porque los equipos son universales.

¿el acceso a la transferencia de tecnología se ha dado mediante, universidades, grupos de investigación, laboratorios, funcionarios u otros?

Yo creo que hemos venido trabajando....

¿en los laboratorios hacen pruebas o...? 
Si, nosotros tenemos laboratorios acá en esta planta, tenemos laboratorios en itaguií que esta certificado por la entidad dimat.

¿hasta ahora no han trabajado con ninguna universidad, ningun grupo de investigación, algún proyecto?

Si claro, hemos trabajado con colciencias, con la universidad de los andes, hemos hecho grupos de investigación, estamos haciendo unos proyectos con el parque la creatividad.

¿en los procesos de transferencia de tecnología la empresa ha recibido apoyo del estado o apoyo de agremiaciones industriales o cualquier otra entidad?

Podemos decir que apoyo del estado, lo que hemos trabajado con colciencias. Y ps lo que se está haciendo para el mgc si se puede decir que sí.

¿doncarlos no fue al seminario de investigación, al encuentro que hubo?

No estaba acá.

¿la empresa ha transferido tecnología a otras empresas?

Yo creo que sí, lo que le transferimos a nuestra cadena de proveedores, en todos los temas de calidad, en los temas de mejoramiento, les transferimos al igual que a nuestros clientes, nosotros lo hacemos en cascadas a nuestros proveedores, desarrollando nuestros proveedores, sus sistemas de calidad, su gente.

¿ha asistido la empresa a procesos de transferencia detecnología exclusivos?

No, eso realmente no se da.

¿considera que falta en el pais condiciones específicas que estimules o faciliten la transferencia de tecnología? ¿cuales?

Total, todo, el estado no da ningún apoyo a eso, digamos colciencias, es un tema que es muy cerrado, digamos entidades como el sena que tiene muchísimos recursos, pero están enfocados solo en el tema de capacitación técnica, o sea, hay mucho recurso desperdiciado, o mucho recurso sin utilizar en esas cosas y no hay digamos lo que esta hacia el tema de la industria automotriz, no hay ninguna política.

¿podria mencionar con que otras empresas, organizaciones del sector privado o publico, tiene interaccion la empresa para desarrollar su capacidad innovadora?

\section{$\mathrm{Si}$}

Por ejemplo usted me comentaba que con sus proveedores del exterior

Los proveedores con lo que nosotros trabajamos en lo temas de materias primas insumos, y todo ese tipo de cosas, que digamos ellos van adelante y obtienen el 
conocimiento de lo que está pasando y a través de ellos pues se recibe una información sobre nuevas materias primas, sobre nuevos desarrollos, otros son digamos lo que le da uno a los clientes, los clientes hacen sus bases de datos, estos están haciendo esto, puede mejorar en esto cambiar esto, y a través de esto uno puede tener acceso a proveedores globales afuera que le puedan transferir tecnología.

Listo don carlos eso era todo, la entrevista, agradecemos mucho sus respuestas, su confianza y su tiempo. 


\section{FANALCA}

Nuevamente los saludo y le doy gracias don carlos acero por recibirnos hoy en su empresa, empresas espumlatex

La empresa es de que?

Se fabrican las espumas moldeadas para la cojinería de los carros, los insinerizantes para los carros, tanto interiores como exteriores y fabricamos accesorios también para los carros. reposición.

Todo lo que fabricamos nosotros va para equipo original no tenemos para ¿esta es la planta principal?

$\mathrm{Si}$

¿tienen otras en colombia?

Tenemos otra en funza, otra en medellín, y tenemos otra en armenia.

Bueno, el objetivo de la investigación es el análisis de las interacciones que han fortalecido la capacidad innovadora en los procesos de transferencia de tecnología.

Vista la transferencia de tecnología como una acción que les permite el mejoramiento, por ejemplo, de los trabajadores o la inyección de nueva maquinaria, o la inyección de nuevos procesos, o la capacitación para generar nuevos productos.

Es hacia ese horizonte, en el sector autopartes en bogotá.

Esta entrevista tiene una nota de confidencialidad, o sea estas respuestas que nos va a entregar, no van a ser divulgadas, si no solamente el tema de la investigación y solamente las empresas que estuvieron participando, conocerán los resultados.

¿en la empresa existen estrategias especificamente enfocadas en la transferencia detecnología?

\section{$\mathrm{Si}$}

¿enqueareas de la empresa se ha orientado las estrategias de transferencia de tecnología? ¿produccion, diseño, control de calidad u otro?

Lo que está enfocado al tema de producción, desarrollo de proveedores, en el tema de control de calidad, también hay transferencia de sistemas de tecnología, de calidad, de sistemas de control de calidad, de tecnología sobre el mejoramiento continuo.

Para nosotros el tema de transferencia de tecnología está enfocada, en el desarrollo de las materias primas, desarrollo de materiales, sustituciones de materiales, digamos 
materiales alternativos y lo que hacemos nosotros en apropiación de tecnologías o en adaptación de tecnologías a las condiciones del mercado local.

¿las actividades de transferencia de tecnología se han realizado en el exterior, en el pais o dentro de la empresa?

Yo creo que hay dentro de las tres, dependiendo del marco en el que uno trabaje, hay cuestiones que nosotros hacemos, pero la gran mayoría de los temas, sobre todo en el tema de innovación en materiales, en procesos, en todo eso, viene del exterior. Y viene transferido, digamos de, ya de la experiencia y conocimiento en procesos similares en el exterior.

Y dentro de la empresa y en el país pues va mucho más a metodología o a proyectos que se han hecho acá, digamos como el mgc para el desarrollo de la competitividad, de la calidad.

A los procesos de mejoramiento de calidad, está dentro del país.

¿dentro de la empresa se hacen actividades para el tema de transferencia de tecnología? ¿capacitaiones especiales sobre mejoramiento en procesos?

$\mathrm{Si}$, continuamente, y a diferentes niveles, dependiendo de lo que se .....

¿hastadonde pueda indicarnos, que mecanismos emplea la empresa para la transferencia de tecnología? ¿atraves de un experto, equipo o a traves de otros mecanismos?

Hay diferentes mecanismos el principal tema nuestro, es un tema de vigilancia tecnología y con base a esos temas miramos a través de quien o contactamos las fuentes.

otro tema que trabajamos nosotros, es con el tema de proveedores en el exterior, otro tema que nos ayuda a nosotros mucho, es sobre las tendencias, digamos en lo que concierne a los desarrollos de nuevos productos.

Acá se trabaja con un equipo de gente que está en el tema de los desarrollos, en el tema de la innovación, en el tema de la ingeniería, y digamos lo que vengamos a buscar de afuera seria con una asistencia externa.

¿las inversiones hechas en transferencia de tecnologíaestan representadas en equipos, instalaciones, personal capacitado, otros?

Lleva todo eso, todo eso está involucrado y no solo el tema de capacitación interna sino también capacitación afuera a los proveedores y digamos el desarrollo como en equipo, de las cuestiones y la adaptación de los materiales dentro de los procesos y las necesidades que nosotros tengamos acá.

¿como detecta la empresa, las necesidades de transferencia de tecnología? 
Digamos, uno de los temas que jalona principalmente, el proceso, o sea son dos, los que más jalonan el proceso, tema de competitividad y un tema en las tendencias en los desarrollos de los productos en el cliente.

¿asisten a ferias especializadas, por sugerencia de proveedores especializados?

Si, también.

¿por sugerencia de los clientes u otros mecanismos?

Si también hay de todo eso, no puedo decir que es una sola, porque obviamente esta el tema de la vigilancia tecnológica, donde uno mira la competencia, ¿qué está haciendo?, ¿como lo está haciendo?, ¿hacia dónde va?

Eso va muy ligado, con la sugerencia de los clientes o las tendencias que uno vea en los mismos clientes. Entonces ahí uno viene y busca, en donde está la tecnología, quien es el dueño de la tecnología, quien es el dueño de la información, para buscar donde se hace.

¿qué logros ha obtenido la empresa como consecuencia de la transferencia de tecnología? ¿reduccion de costos, de desarrollo de nuevos productos de reduccion de tiempos en la fabricacion, reduccion de inventarios?

Si todo, nuevos procesos, nuevas tecnologías, implementación de nuevas tecnologías, sustituciones de materiales.

¿deque manera protege la empresa los logros que alcanza como consecuencia de la transferencia de tecnología? Patentes, restriccion al acceso a ciertas areas de la empresa, mediante politicas de contratacion de personal, o cual otro mecanismo?

Yo creo que puede ser más o menos hacia el tema de las dos últimas, hay cosas de información que nosotros manejamos con restricción, tenemos políticas de confidencialidad que deben firmar los empleados, que tienen acceso a cierto nivel.

¿por ejemplo los que trabajan en el area de investigación?

$\mathrm{Si}$, los que tienen acceso a cierta información que para nosotros es, digamos como nuestro diferenciador.

¿tienenareas restringidas?

No, realmente no porque los equipos son universales.

¿el acceso a la transferencia de tecnología se ha dado mediante, universidades, grupos de investigación, laboratorios, funcionarios $\mathrm{u}$ otros?

Yo creo que hemos venido trabajando....

¿en los laboratorios hacen pruebas o...? 
Si, nosotros tenemos laboratorios acá en esta planta, tenemos laboratorios en itaguií que esta certificado por la entidad dimat.

¿hasta ahora no han trabajado con ninguna universidad, ningun grupo de investigación, algún proyecto?

Si claro, hemos trabajado con colciencias, con la universidad de los andes, hemos hecho grupos de investigación, estamos haciendo unos proyectos con el parque la creatividad.

¿en los procesos de transferencia de tecnología la empresa ha recibido apoyo del estado o apoyo de agremiaciones industriales o cualquier otra entidad?

Podemos decir que apoyo del estado, lo que hemos trabajado con colciencias. Y ps lo que se está haciendo para el mgc si se puede decir que sí.

¿doncarlos no fue al seminario de investigación, al encuentro que hubo?

No, no estaba acá.

¿la empresa ha transferido tecnología a otras empresas?

Yo creo que sí, lo que le transferimos a nuestra cadena de proveedores, en todos los temas de calidad, en los temas de mejoramiento, les transferimos al igual que a nuestros clientes, nosotros lo hacemos en cascadas a nuestros proveedores, desarrollando nuestros proveedores, sus sistemas de calidad, su gente.

¿ha asistido la empresa a procesos de transferencia de tecnología exclusivos?

No, eso realmente no se da.

¿considera que falta en el pais condiciones específicas que estimules o faciliten la transferencia de tecnología? ¿cuales?

Total, todo, el estado no da ningún apoyo a eso, digamos colciencias, es un tema que es muy cerrado, digamos entidades como el sena que tiene muchísimos recursos, pero están enfocados solo en el tema de capacitación técnica, o sea, hay mucho recurso desperdiciado, o mucho recurso sin utilizar en esas cosas y no hay digamos lo que esta hacia el tema de la industria automotriz, no hay ninguna política.

¿podria mencionar con que otras empresas, organizaciones del sector privado o publico, tiene interaccion en la empresa para desarrollar su capacidad innovadora?

\section{$\mathrm{Si}$}

Por ejemplo usted me comentaba que con sus proveedores del exterior

Los proveedores con lo que nosotros trabajamos lo temas de materias primas insumos, y todo ese tipo de cosas, que digamos ellos van adelante y obtienen el 
conocimiento de lo que está pasando y a través de ellos pues se recibe una información sobre nuevas materias primas, sobre nuevos desarrollos, otros son digamos lo que le da uno a los clientes, los clientes hacen sus bases de datos, estos están haciendo esto, puede mejorar en esto cambiar esto, y a través de esto uno puede tener acceso a proveedores globales afuera que le puedan transferir tecnología.

Listo don carlos eso era todo, la entrevista, agradecemos mucho sus respuestas, su confianza y su tiempo. 


\section{TERMOCONFORT}

La pregunta es en los procesos de transferencia de tecnología la empresa ha recibido apoyo del estado o de agremiaciones industriales e internacional? No eso nos ha tocado de recursos propios, bueno la empresa a transferido tecnologías a otras empresas? No , proveedores? No , los capacitamos en calidad pero no en tecnología, ok $i$ ha asistido la empresa a procesos de transferencia de tecnología exclusivos, en su negocio? Con presencia por ejemplo de colegas? Me repite bien la pregunta, por ejemplo ustedes son me dice que producen la parte interna de vehículos, han participado en la parte interna donde hallan colegas que también hagan lo mismo? En eventos como que? Como ferias para el mejoramiento de ese tipo de la producción o ver mas lo de productos innovadores o necesidades especificas para los nuevos vehículos o los nuevos diseños? No, en lo hemos participado de ferias( solamente de esa línea) es de automóviles, a ok pero en general oseatu te refieres como si hubiéramos hecho un kiosfer si exacto, y los competidores acá en Colombia son pocos? Son más pequeños? Si no, realmente no que te digo yo no en cierto productos que hacemos no tenemos competencia y en algunos otros puede que haya una competencia pero no de nuestro nivel, no de nuestro nivel si. Ok considera que hace falta en el país condiciones especificas que estimulen o faciliten la transferencia de tecnología? Consideramos que hace falta, claro! Cuáles? Total pues que halla realmente un apoyo económico a un proyecto que uno pase para buscar transferencia de tecnología , y que hayan incentivos por ejemplo Alejandro te comento que vamos a pasar de corte manual a corte automatizado que hubiese por ejemplo en esos casos donde realmente la empresa progresa en su tecnología, da un paso adelante en tecnología que digamos, por ejemplo beneficios arancelarios por parte del gobierno o un subsidio para un crédito o cosas de se estilo nosotros no hemos tenido, ok ósea falta mas política más presencia del estado apoyando el ejercicio no? $\mathrm{Si}$ porque todos los logros son propios. y para terminar podrían mencionar con que otras empresas, organizaciones e instituciones de sector privado y público. Tienen interacciones para desarrollar su capacidad innovadora? Ósea con otras empresas del mismo sector? Cada cual trabaja solo puede que se trabaje en grupo pero empresas relacionadas, por ejemplo el grupo neme que tiene veinticinco empresas seguramente ellas si se unen, de pronto las empresas de, nosotros trabajamos con socios comunes de pronto así uno se une aunque sean empresas totalmente distintas, pero si ha nivel del sector, que estamos pues ACOLFA que si es quien reúne la empresas del sector pero creo que , bueno COLCIENCIAS también escuche, si pero no ACOLFA por ejemplo si es el único que trabaja con los autopartistas para buscar hacer algo, los demás vamos a buscar si hay algún apoyo pero digamos en una relación en doble vía quizá con la compra, PROESPORT, BANCOLDEX , FIDUCOLDEX, MINISTERIO DE COMERCIO INDUSTRIAL, pues si puede que si hallan ciertos apoyos pero realmente no hemos tenido algo concreto. Muy bien gracias Doctora esa era la entrevista les agradezco mucho su tiempo su compromiso con nosotros para poder darle fin al ejercicio. 


\section{SERVIMCO}

P: Iniciamos nuevamente la entrevista con Servimco, por error en, servicom perdón, por error en la registró de la grabación se repite nuevamente; iniciamos el nombre de la persona que nos atiende es el director de planta Juan Carlos Neira, el cargo es director, la fecha es 23 de julio y la fecha es 23 de julio.

¿Ingeniero en la empresa existe una estrategia específica enfocada en la transferencia de tecnología?

R: Pues como tal yo diría que una estrategia no existe en qué sentido, nosotros somos un caso especial, somos una empresa dedicada exclusivamente a suministrar la parte de ensamble de suspensión en la planta de Genosmotors Colombia, en ese esquema no existe una estrategia como tal, pero si estamos expuestos a un tema de trasferencia de tecnología en cuanto a que a casa matriz en Japón pues muchas veces nos entregué información relevante a los procesos para poderlos realizar acá en Colombia.

P: Muy bien; a que áreas de la empresa se ha orientado la transferencia de tecnología? al área de producción, al área de diseño, al área de desarrollo de proveedores, control de calidad, u otra?

R: Pues directamente con nosotros, e nosotros no tenemos diseño en eso estamos liados al departamento de ingeniería de Genosmotors, pero más que todo acá en la empresa está la parte de producción, control de calidad hay algunos procesos donde, donde se nos ha dado pautas informativas en cuanto a los procesos y en la parte de pronto de mantenimiento también, sea, sea recibido información de transferencia

P: Muy bien; las actividades de transferencia de tecnología se han realizado en el exterior, dentro del país o dentro de la empresa?

R: Pues se han realizado dentro de la empresa, pero pues obviamente a través de un, de la casa matriz de fronteras de fronteras que pues es en Japón, desde donde nos envía información referente a lanzamientos de modelos nuevos o en cuanto a el soporte que requerimos acá para llevar a cabo los procesos que no conocemos.

P: Hasta donde pueda revelar lo; ¿qué mecanismos la emplea la empresa para la realización de transferencia de tecnología?; esto nos podría ampliar un poco la, la anterior pregunta, a través de un equipo o a través de un expreso esta, este anejo de Japón lo hace en cuanto ellos vienen acá, envían información o envían a algún experto a dictar capacitaciones.

R: Ambas cosas llega mucha información, con detalle de los procesos, adicionalmente en ciertos casos envían una persona con conocimientos específicos, de la materia que nosotros manejamos, que en este caso sería el ensamble de suspensión, también en otros casos pues hay un departamento que se dedica exclusivamente digamos a soportar la producción en el extranjero de parte de Genosmotors Japón, quienes son un equipo que nos viene a brindar soporte 
P: Muy bien; ¿las inversiones hechas en trasferencia de tecnología están representadas en equipos, instalaciones, procedimientos, personal capacitado u otro?

R: Mas que todo en nuestro caso ha sido la parte equipos, dispositivos de ensamble, algunos procedimientos también; en cuanto a instalaciones en un principio nosotros también fuimos, en eso, en eso también fuimos un caso especial y en que nosotros éramos inicialmente propiedad Tracoidacol; al ser un proveedor digamos externo mucha información no, no la suministraban; después de dos años del inicio de las operaciones Genosmotors decidió comprar a sevicom y hacer la parte de su grupo empresarial, entonces desde ese momento había un poco más de, de facilidad en la transferencia de tecnología en cuanto a información, ya en temas más detallados en cuanto a equipos, en cuanto a instalaciones, mas, en más que todo ha sido en cuanto a dispositivos de ensamble

P: Muy bien, ¿ingeniero como la empresa detecta necesidades de transferencia de tecnología, por comparación con la competencia, asistencias especializadas, por sugerencia de los proveedores especializados, por sugerencias de sus clientes ensambladoras o por otros mecanismos y cuáles serían?

R: Pues hay serian otros mecanismos en el sentido en el que tenemos un cliente interno llamémoslo así tanto la planta de Genosmotors Colombia como la planta de Genosmotors Japón quienes son los que, los que pues seguramente tendrán necesidades en todos estos campos y ellos determinan que información es necesaria para ciertos procesos; pues obviamente nosotros sin embargo solicitamos información que no tenemos, o que tenemos duda o inquietudes, pero básicamente pues estamos ligados mucho a las necesidades de la casa matriz

P: ¿Que logros concretos ha tenido la empresa como consecuencia de la trasferencia de tecnología, podríamos decir que hay reducción de costos, desarrollo de nuevos productos, reducción de tiempos de fabricación, reducción de inventarios u otros?

R: Básicamente es la parte de desarrollar nuevos productos, también un poco la parte pues de reducción de tiempos de fabricación, y también en mejora de ergonomía, muchas veces hay dispositivos para la manipulación de los componentes, pues somos ensambladora de camiones, entonces los componentes son bastante pesados, requieren de dispositivos que permitan una, un fácil manejo, manipulación del operario de pronto son esas áreas en las que nos hemos beneficiado

P: De qué manera protege la empresa estos glóbulos, como consecuencia de la transferencia de tecnología, con patentes, restringiendo las .... De la empresa o con políticas de contratación de personal u otro tipo de mecanismo.

$\mathrm{R}$ : Simplemente pienso que hay como un control interno de quien tiene acceso a otra información, hay redes donde no todos los funcionarios tienen accesos, ya es un control más interno, adicional a esto pues realmente no, no hay una protección de esa información, esa información que solamente es confidencial de parte de Japón hacia la ensambladora 
P: Muy bien, en la empresa ¿la transferencia de tecnologías se ha dado mediante universidades, grupos de investigación, laboratorios, funcionarios u otros? Has desarrollando algún proyecto con universidades?

R: Hemos tenido un par de caso de universitarios buscando su proyecto de grado, hacer una investigación en proceso productivo, pero en cuanto a trasferencia de tecnología no, no diría que no, no hemos tenido ese caso

P: Ni con grupos de investigación, laboratorios, funcionarios...

R: No

P: Ok

$\mathrm{R}$ : En los procesos de transferencia de tecnología la empresa ha recibido apoyo del estado o de agremiaciones industriales o otros?

P: No, hasta donde tengo conocimiento, por lo menos en Servicom no, no, no se ha presentado ese caso

R: La empresa ha transferido tecnología a otras empresas?

P: No, ha asistido la empresa a procesos de transferencias de tecnología exclusiva, que sean de este, de su propio digamos de su propio proceso, de su propio negocio? o presencia de colegas ?

$\mathrm{R}$ : $\mathrm{Si}$, ha habido, no éramos sido muy participes pero en algunos cosos a habido conferencias o reuniones, digamos en el extranjero en estados unidos, donde pues grupos de trabajo de estados unidos y de Japón se reúnen para mirar temas específicos en cuanto a, a algún proceso o algún procedimiento que necesitemos capacitarnos.

P: Muy bien, considera que hace falta en el país condiciones específicas que estimulen o faciliten la transferencia de tecnología?

R: Pues, de pronto en Colombia incluso tengo algo de experiencia en el tema, la parte de, de patentes es bastante restringida, es bastante complicado conseguir una patente en Colombia. ahorita no Servicom no lo está, no lo estoy aplicando pero, pero en mi experiencia conseguí una patente que en estados unidos es muy fácil, es otorgada fácilmente, en Colombia es mucho más complicado, la súper intendencia de industria y comercio es bastante, bastante celosa con eso.

P: Tiene muchos procedimientos, podría, mucho protocolos con eso

R: Muchas trabas, si, en cuanto a que es novedoso y que tiene altura investida, todo ese tema es bastante complicado acá en Colombia.

P: Bueno, podría mencionar con que otras empresas, organizaciones e instituciones del sector privado o público tienen interacciones para desarrollar su capacidad innovadora? 
$\mathrm{R}$ : Con que otras empresas? Tenemos varios proveedores del sector privado, que nos suministran equipos de trabajo; con quienes hemos desarrollado procesos productivos; necesito mencionar los proveedores como tal?

P: Bueno si sería interesante

R: Trabajamos bastante con una empresa que se llama equintecltda de acá de Bogotá, tecno ingenieria la parte de suministros de fluidos, de la parte neumática, tracoidacol en su momento cuando fuimos propiedad de tracoidacol pues obviamente estuvimos muy liados con ellos, ellos representan varias marcas en la parte de neumática, de maquinaria pesada y pues con ellos trabajado de la mano sobretodo pues que la planta es reciente y llevamos 4 años trabajando, pero nos tocó toda la parte del montaje de la operación

P: Bien

P: Servicom siempre ha estado acá, ósea además que esto es nuevo, aquí nace?

R: Acá nació servicom, si claro

P: Y nace con hermanos?

R: Si, nacimos de la mano de HMMC, se creó como la necesidad de tener una, pues en Colombia las ensambladoras; se requiere un porcentaje de integración de partes locales y esa es la función de sevicom suministrarle partes locales a la camfein un motors tours, medir el nivel de integración, nosotros como empresa colombiana importamos los componentes dkd hacemos el ensamble y la vendemos a Genosmotors, pues obviamente en ciertas condiciones que ellos requieran.

P: Muy bien, ingeniero, muchas gracias, muy amable, de verdad que su respuesta nos va a servir muchísimo

R: No tranquila, siga o usted, o usted me la notifica por correo. O qué?

P: Si pues la idea es que una vez salan los resultados de la investigación nosotros podamos hacerlos participes a los que participaron en el proyecto y publicar. Ustedes ya tienen página de internet.

R: No, nosotros no tenemos página porque nosotros no buscamos clientes.

P: No buscan clientes, sí.

$\mathrm{R}$ : Entonces realmente nosotros

P: Y no les interesan alianzas con otros clientes, por ahora?

R: Es que nosotros somos como un hermanito chiquito acá, y estamos dispuestos prácticamente a lo que requiera Genos, digamos nosotros ni buscamos clientes, ni 
evendemos a nadie más, exclusivamente estamos para, somos como una alianza de la planta de allá prácticamente eso es lo que somos.

P: Pero son dueños diferentes?

$\mathrm{R}$ : He ya, en su momento fueron dueños distintos, ahora también son los mismos dueños, ya somos parte de HMMC; somos empresas independientes, pero hermanitas

P: Aahh¡ya yaya...listo ¡eso es todo. Entonces ellos allá no fabrican nada, solamente empacan en HMMC?

R: Si prácticamente, pues hay algunos procesos que requieren de cierta fabricación, porque pues hay. 


\section{Grupo IPT}

La finalidad es primero académica las peguntas no serán empleadas sino para fines académicos y el otro tema es que va a servir de insumo para un proyecto más grande que se tiene planteado hacer, que es sobre sistemas sectoriales de innovación.

Este contempla la transferencia de tecnología entonces respondería esta investigación para esa partec y luego vendrán otras que tienen que ver, con los sistemas sectoriales de innovación.

Yo soy el gerente de manufactura y comercial, yo atiendo es la parte comercial del sector automotriz. Yo atiendo a Ford Venezuela, Mades Ecuador. Allí se está montando una, en la planta de maderas se está montando una planta de fierro, más que planta, una plataforma para ensamblar fierro.

Don Efraín la empresa tiene una estrategia específica enfocada en la transferencia de tecnología. La transferencia de tecnología la definimos como un insumo como una entrada de conocimiento a la empresa que le ha permitido desarrollarse, digamos que generar capacidad innovadora, de ampliar su gama de productos, entre otros.

- $\quad$ En nuestro proceso comercial, hace 10 diez años hemos definido que como una de las formas de diversificar en vía de investigación y desarrollo ... para todos muy es claro que el hacer las cosas como hoy las hacemos no vamos a lograr....nada diferente de las ventajas actuales

- $\quad$ Entonces hemos planteado que una división de ingeniería y desarrollo hemos intentado diversificar pues por lo menos nuestro enfoque siempre ha sido totalmente autopartista. Hemos querido hacer cosas por el sector metalmecánico, hicimos torres de comunicación, unas estructuras para Ecopetrol pero finalmente eso ha hecho es perder el foco, entonces va uno aprendiendo que para de alguna forma ser, cerrar la brecha para ser exitosos, será mejor focalizar y especializarse. Entonces la compañía finalizando el año pasado, pensando en nuestra planeación acordamos, nuevamente solo centrarnos en el sector automotriz o ponernos muy de frente con el tema de especializarnos. La transferencia que tenemos de 38 años de estar en el mercado. Lo que más tenemos es lo que hemos aprendido a capitalizarnos y ser más fuertes en eso.

Entiendo.

- $\quad$ Y en colmotores nació un equipo que se llama, un equipo de innovación al cual hemos sido invitados, al cual se le invito ha sido por la General Motor a participar por un comité de innovación

Excelente.

- $\quad$ Eso inicio el año pasado el día doce de diciembre y se inicio este trabajo y hemos venido participando en unos comités donde se generan ideas y donde hemos hecho 
nosotros propuestas de cosas. De hecho entre las cosas que hemos propuesto esta muy ligado a ligado a

- Ligado a generalmente para mi... mas que para innovación de este es tan amplio a veces hay personas que presentan ideas de mejora eso no es innovación, finalmente queremos aquí un grupo de personas trabajando En hacer propuestas innovadoras

Que chévere me parce muy bien

- $\quad$ En el tema de por lo menos a veces uno puede acortar esta brecha sabemos que en corea, en Brasil en los estados unidos de ahí muchos procesos, muchas cosas de las que hoy se retienen aquí en el país ya nos llevan una distancia muy importante y a veces se hace mucho más fácil comprar esa tecnología comprar esas... esa brecha que usualmente es muy grande en tiempo en dinero, a veces es mas barato pues pagar lo que le cobren a uno para eso, estamos en eso hoy no hay así digamos en unos ocho siete, cinco años pensando en innovación pero no hemos hecho nada diferente pero estamos igual

Muy bien, Don Efraín a que áreas de la empresa se ha orientado esta área de transferencia de tecnología, tengo acá producción, diseño desarrollo de proveedores, control de calidad o que otra arrea, estas o alguna adicional o alguna de estas

- $\quad$ Donde más le puede a uno dar valor a una idea innovadora es por el lado de diseño y ahí es donde hemos enfocado nuestro esfuerzo, de hecho la compañía no ha tenido un equipo de ingeniera fuerte $\mathrm{y}$ hoy es un equipo robusto $\mathrm{y}$ en realidad hay personas pensando en eso

Muy bien. Las actividades de transferencia de tecnología se han realizado en el país, dentro de la empresa o en el exterior don Efraín?

- De hecho en el país y dentro de la empresa.

Muy bien. Que mecanismos emplea la empresa para la realización de transferencia de tecnología, normalmente lo hace con un experto, con un equipo de expertos o con alguna maquinaria especificó o con que otro tipo de mecanismo.

- Hoy estamos en la fase de análisis y se está haciendo con un experto, es una persona que nos está direccionando.

Muy bien. Las inversiones hechas en transferencia de tecnología están representadas en equipos, instalaciones, procedimientos, personal capacitado?

- Hoy estamos capacitando más personas y estamos asignando recursos para eso, de nuestras ventas hemos definido un porcentaje para temas de innovación y desarrollo. 
Bien. Y la transferencia de tecnología que hasta ahora se ha hecho en la empresa se ha hecho además de personal en maquinarias y en equipos y en instalaciones, fuera de esta planta tienen otra.

- Ya se compro, había apenas un bloque, pues hay un lote de un área importante para sí aparece algún proyecto a siiii de grandes ligas, podernos. Como

Ampliar i ahh ya. Muy bien. Como detecta la empresa la necesidad de transferencia de tecnología, por ejemplo comparándose con la competencia, asistiendo a ferias especializadas, por sugerencia de proveedores especializados, por sugerencia de sus clientes las ensambladoras o que otros mecanismos, como hace par detectar la necesidad de transferencia de tecnología?

- $\quad$ Finalmente lo hacen por varias vías en su orden hoy en el benchmarking que uno usualmente hace, encuentra que la competencia va avanzando en temas tecnológicos en temas de diseño, entonces uno por vía benchmarking identifica que nos estamos rezagando y cómo segundo elemento que lo jale a uno los suplentes usualmente ellos en el tema de costos, finalmente uno logra llegar a menores costos en la medida en que uno logre pues meterle en su orden tecnología y mejores procesos. Se mora con tecnología. A veces uno no es muy poco, uno no hace inversiones en tecnología por que los volúmenes no son importantes para nosotros, pero obviamente se hace vía tecnología.

Muy bien. Digamos que los logros que se han tenido hasta el momento como consecuencia de la transferencia de tecnología da una reducción de costos, ha desarrollado nuevos productos, ha generado reducción de tiempo de fabricación, reducción de inventarios u otros.

- En su orden el haber pensado en tecnología e innovar cosas nos ha permitido con los suplentes hoy tener un mayor reconocimiento y nos ha dado oportunidades en los negocios

Reconocimiento de marca, de oportunidades. Muy bien. Y se han desarrollado nuevos productos

- $\quad$ Claro ya por lo menos en el pasado tenemos acceso a productos de un nivel de ingeniería bajo, hoy en día hemos dado un salto a productos de mayor nivel de ingeniería y de mayor complejidad, por el medio del proceso cuando uno le invierte ingeniería a su producto logra tener un mayor margen a la hora de hablar de costos.

A bueno Muy bien. De que manera protege la empresa esos logros que alcanza como consecuencia de la transferencia de tecnología?. Por ejemplo acá en la empresa tiene áreas de restricción donde no hay acceso, no,

- $\quad$ No Patentes,No señora

Mediante políticas de contratación de personal,

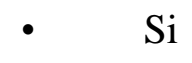


Hay alguna clausula

- Si claro

o algún requerimiento, que se comprometan a tener confidencialidad con los datos que se hablan del tema. Algún otro mecanismo

- $\quad$ No

El acceso a la transferencia de tecnología se ha dado mediante universidades, proyectos de investigación, funcionarios u otros?

- Se han dado pues en su orden hemos participado pues, estamos de acuerdo en alguna forma viendo por este programa de transformación productiva y ahí es donde hemos venido pues de una manera creciendo con nuestro interés de avanzar en...

Pero hasta ahora no han tenido ningún proyecto con alguna universidad que les haya ayudado a desarrollarse

- No.

con laboratorios específicos

- $\quad$ No

Es el propio grupo de investigación que ustedes dicen o sea seria con funcionarios

- Nosotros hacemos cosas con laboratorios.

En los procesos de transferencia de tecnología la empresa ha recibido apoyo del estado.

- $\quad$ No señora

De agremiaciones industriales

- $\quad$ No señora

Podríamos mencionar otros como por ejemplo, se ha presentado proyectos a Colciencias

- $\quad$ No señora.

Porque?

- $\quad$ Porque en su orden no conocemos dentro del equipo de personas que estamos, hasta hace unos dos años no conocemos los beneficios o los programas de Colciencias y finalmente uno tiene en su base de datos que aplicar esos proyectos, esta muy ligado, digamos esta ligado a para donde llegara con un producto a Colciencias, sabemos que hay una fase finalmente en donde las empresas tienen que pagarle a un 
experto que está ligado a colciencia y hay que darle una propina hay que sobornar para quedarnos los proyecto y si uno se va con ellos hay alguna oportunidad. Es lo que no ha pasado, es lo que uno oye.

Es lo que percibe. Y en el tema de agremiaciones por ejemplo con La Colbank.

- $\quad$ Es un gremio que reúne a los autopartistas y antes a uno le toca pagar allá para pretender venderlos. Ellos no dan ... ellos no dan uno hace lovin con las ensambladoras y hace lobicon organismos del estado para tener cosas, pero los beneficios que obtiene son relativamente pocos.

O sea que ha sido la propia empresa con su propio esfuerzo que ha logrado transferencia de tecnología.

Muy bien. La empresa le ha transferido a otras empresas transferencia de tecnología?

- $\quad$ No señora

Ha asistido la empresa a procesos de transferencia de tecnología exclusivos, esto quiere decir como de lo mismo que ustedes producen, filosofía de negocio, ha generado momentos que con otros que también produzcan lo mismo.

- $\quad$ Estuvimos... Hacemos dos partes que tenían pues más en Brasil y en Alemania una parte que nos enseñaron que llama pedalear al corsa, habían hecho ya con alguna,.. ya tenían definidos los procesos y ya lo habían utilizado, estuvimos revisando de que manera nos vendían mas que con los audios y usualmente cuando uno desarrolla una parte tiene una curva de desarrollo. Fase uno es de diseño, fase dos es de sacar muestras, fase tres optimizar procesos y obviamente uno se gasta hasta seis meses y un año de una parte nueva en ponerla totalmente a punto. yo me comprometo con mi cliente a entregarle 500 piezas o 200 se las entrego pero a un costo de diez pesos, pero con el tiempo la tareas nuestra son de ir mejorando los procesos para que ya no muestre los diez pesos sino muestre ocho. Finalmente la plata o la utilidad que uno obtiene sobre sus productos la ubicamos vía mejora de procesos. Entonces a veces uno sabe que es bien complejo que me voy a gastar dos años en optimizar mi proceso a sabiendas que hay empresas que ya la hicieron y ya llegaron a un estado optimo. Entonces es mejor decidirme a pagar cien millones por que me vendan el trabajo y lo aplico acá. Hicimos en alguna oportunidad un intento pero fue muy costoso. A veces uno no alcanza a cuantificar cuento seria el ahorro vía procesos, si hubiese pagado cien millones de pesos que me pedían contra los dos años que me gaste en llegar a lo que ya tenía. En ese entonces me pedían una fortuna, hace doce años, quince años se desbarata mucho la plata. Pero si hemos estado inquietos de eso, en recibir tecnología, pero tiene un costo que si uno hace sus cuentas bien de seguro que lo ideal seria comprar tecnología. Entonces uno ve que los costos iníciales son..son muy altos

Considera que al país le falta condiciones específicas que estimulen y faciliten la transferencia de tecnología? 


\section{- Claro}

\section{Si Cuales podrían ser}

- $\quad$ Por lo menos son que ya la política de estado que finalmente estimule a las empresas a traer tecnología de punta y obviamente se va redundando en clientes que pueda dar oportunidades del exportador al cliente los objetivos de todas estas empresas es haber si lográramos exportar a otra parte. Si seguimos como estamos...nos va coger el día. entonces si hemos hecho la tarea.

Para finalizar don Efraín podría mencionar con que otras empresas, organizaciones e instituciones del sector privado o público tienen interacciones para desarrollar su capacidad innovadora?

- Me la repites

Si la empresa, tiene interacciones con que otras empresas, puede ser del mismo sector $\mathrm{u}$ organizaciones ya instituciones educativas o instituciones de fomento de ayuda o fundaciones del sector privado o público que les haya permitido a ustedes desarrollar su capacidad innovadora?

- Hoy la única vía es en el programa que nos hemos metido como motor Ruta innovadora se llama el programa, solo estamos ahí.

Eso consideran ustedes que los ha fortalecido un poco

- $\quad$ Esta apenas iniciando. Nosotros hemos hecho también intentos muy propios y aislados de eso de innovar pero han sido totalmente un fracaso. Entonces realmente para eso hay que tener un método hay que en alguna forma arrancar uno así a la verraca a hacer cosas sin ningún plan de trabajo no hoy pues hemos cada uno revisado el porqué no ha sido exitoso nuestro propósito, como te decía hemos asignado un presupuesto y lo estamos capacitando. Eso es lo importante el tema de gerenciamiento de proyectos. Cuando se estudian esos proyectos ve que le va uno trasmitiendo las personas asumen y fracasan porque hay un método muy claro y hay metodologías y fases que le permitan a uno empezar a armar proyectos que tengan más éxito que los demás.

Claro. Muy bien don Efraín. Para terminar, en la planta ustedes tienen maquinaria nueva maquinaria, maquinaria que haya tenido que capacitar a sus empleados para poder optimizar algún proceso con esa maquinaria.

- $\quad$ Si hemos comprado maquinaria de tecnología de punta. y cuando uno los compra a los vendedores Nemocono otras empresas ellos nos dan una capacitación para la operación. Asa y por otro lado en el software hemos tenido que enviar a capacitación a otras personas para su manejo.

Muy bien eso ya es significativo. Pero ahí van. 
- $\quad$ Faltaba más allá ya algo se ha hecho. Finalmente este tipo de empresas. Somos 140 vinculados de la planta, cuarenta y cinco en administración una empresa de doscientas personas. Somos todavía pequeñas de tendencia mediana infortunadamente el nivel de negocios no es de buena utilidad donde finalmente no es posible dedicar un buen presupuesto para estimular la investigación de la innovación. Entonces, pero hay vamos.

Muy bien 